\title{
Estudo genético da síndrome de Silver-Russell
}

\begin{abstract}
Dissertação apresentada ao Departamento de Genética e Biologia Evolutiva do Instituto de Biociências da Universidade de São Paulo, para a obtenção de Título de Mestre em Ciências, na Área de Biologia/Genética.
\end{abstract}




\title{
Estudo genético da síndrome de Silver-Russell
}

\begin{abstract}
Dissertação apresentada ao Departamento de Genética e Biologia Evolutiva do Instituto de Biociências da Universidade de São Paulo, para a obtenção de Título de Mestre em Ciências, na Área de Biologia/Genética.
\end{abstract}


Orientadora: Dra. Angela M. Vianna Morgante 


\section{BONALDI, ADRIANO}

Estudo genético da síndrome de Silver-Russell

Dissertação (Mestrado) - Instituto de Biociências da Universidade de São

Paulo, Departamento de Genética e Biologia Evolutiva

1. Síndrome de Silver-Russell 2. Imprinting genômico

3. Microrrearranjos Cromossômicos

Universidade de São Paulo. Instituto de Biociências. Departamento de Genética de Biologia Evolutiva

Comissão Julgadora 
Este trabalho foi realizado com os auxílios financeiros da CAPES (Coordenação de Aperfeiçoamento de Pessoal de Nível Superior) e da FAPESP (Fundação de Amparo à Pesquisa do Estado de São Paulo) concedidos à orientadora (FAPESP-CEPID 98/14254-2) e ao aluno (CAPES-DS e FAPESP 2009/03341-8). 
Aos meus pais, Pedro e Lourdes

À minha irmã, Fernanda

Aos meus amigos e colegas 


\section{Agradecimentos}

Agradeço:

Ao Departamento de Genética e Biologia Evolutiva do Instituto de Biociências da Universidade de São Paulo, pela possibilidade de realização deste trabalho.

À Dra. Angela M. Vianna Morgante, pela orientação neste projeto, por todos os ensinamentos, pela amizade e confiança depositada em mim.

À Dra. Juliana F. Mazzeu, pelos primeiros ensinamentos, pela contribuição nestes estudos, pela amizade e por toda ajuda que me ofereceu durante esses anos.

Às Dras. Ana Cristina Krepischi e Carla Rosenberg, pelos ensinamentos sobre a-CGH, pelos auxílios e colaboração neste estudo e pela amizade.

Às Dras. Chong Kim e Débora Bertola, pelos pacientes enviados e colaboração nos estudos.

À Dra. Regina Célia Mingroni Netto, pelos auxílios e ajuda ao longo desses anos.

Ao Prof. Paulo Otto, pelos auxílios e ensinamentos clínicos.

À Silvinha, por todos os ensinamentos, pela colaboração neste estudo, pela ajuda e amizade.

À Maraísa, por todo apoio, amizade e ajuda durante esses anos.

Aos técnicos Fátima, Mara, Teresa, Paulo e Lígia, pela ajuda e amizade.

Aos amigos Rafaella, Daniela, Ana Carolina, José, Larissa, Jacaré, Renata, Lilian e Ana Carla pela ajuda, amizade e momentos de descontração.

Aos amigos do Laboratório de Genética Humana e laboratórios vizinhos, Rezinha, Karina, Vitor, Daniel, Daiane, Érica, Gustavo, Érika, Débora, Fernando, Laís, Juliana, Cris, Marcelo, Alegria, pela amizade.

À família dos pacientes, pela colaboração.

À minha família: meus pais, Pedro e Lourdes, e minha irmã, Fernanda, pelo amor, apoio constante e por terem me dado confiança para seguir em frente e chegar até aqui.

Agradeço também a todos os meus grandes amigos, principalmente o Thales, e a todas as pessoas que contribuíram, de alguma forma, para que eu chegasse onde estou. 


\section{Índice}

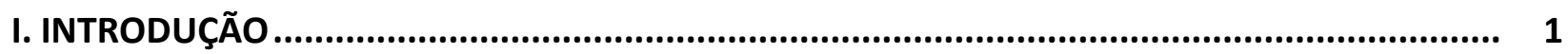

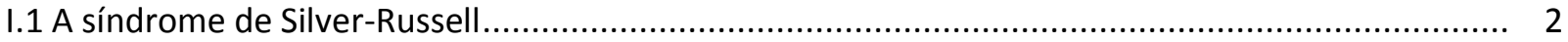

I.2 A epigenética e o Imprinting genômico......................................................................................... 5

I.2.1 Genes sujeitos a imprinting e a metilação do DNA ............................................................. 7

I.2.2 Estabelecimento e manutenção do imprinting genômico................................................ 9

I.2.3 Mutações (epi)genéticas e a perda do imprinting genômico .............................................. 11

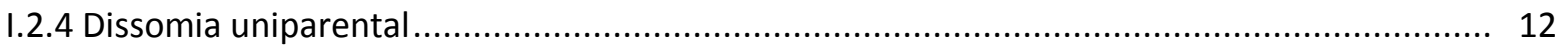

I.3 Alterações (epi)genéticas na síndrome de Silver-Russell ...................................................... 14

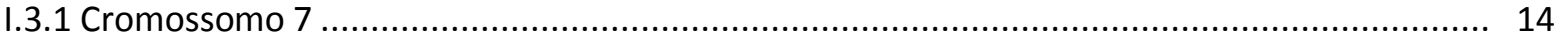

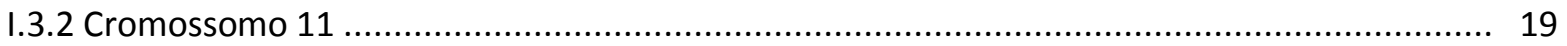

I.3.2.1 Mutações (epi)genéticas em 11p15 na síndrome de Beckwith-Wiedemann (BWS)..... 23

I.3.2.2 Mutações (epi)genéticas em 11p15 na SRS ......................................................... 28

I.3.3 Hipometilação em múltiplos lócus sujeitos a imprinting na SRS ........................................ 35

I.3.4 Outras alterações cromossômicas em pacientes com SRS................................................ 36

I.3.5 Microrrearranjos cromossômicas em pacientes com SRS ............................................. 37

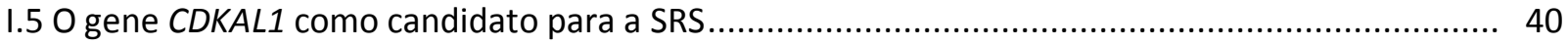

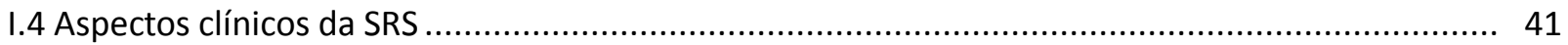

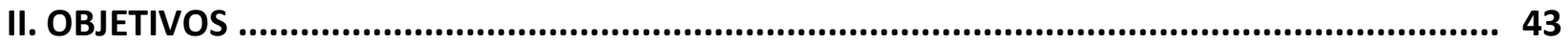

III. PACIENTES E MÉTODOS ................................................................................ 45

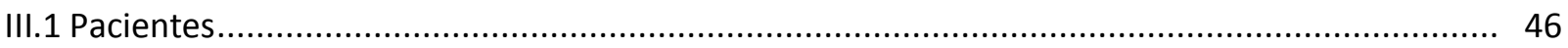

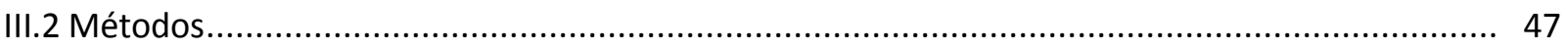

III.2.1 Investigação de alterações (epi)genéticas em 11p15................................................... 47

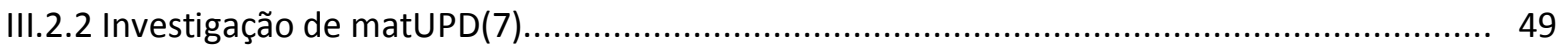

III.2.3 Investigação de alterações cromossômicas submicroscópicas por array-CGH ................... 50

III.2.4 Investigação de mutações no gene CDKAL1 .............................................................. 52 


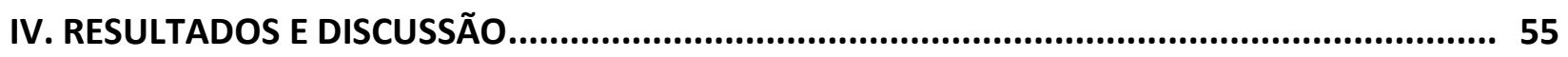

IV.1 Investigação de alterações (epi)genéticas em 11p15 ....................................................... 56

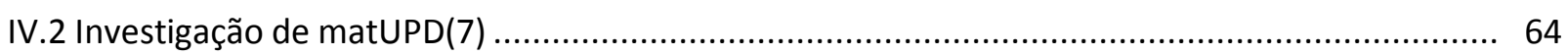

IV.3 Investigação de microdeleções e microduplicações por array-CGH.......................................... 69

IV.4 Busca de mutações no gene CDKAL1 ........................................................................ 86

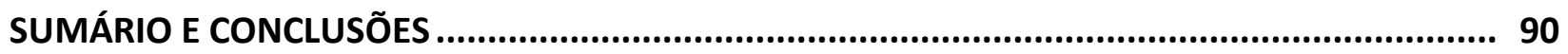

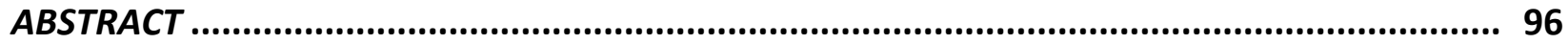

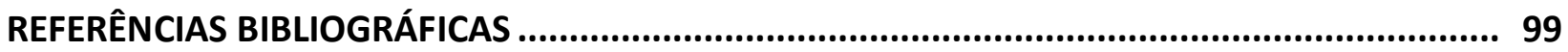




\section{INTRODUÇÃO}




\section{INTRODUÇÃO}

\section{I.1 A síndrome de Silver-Russell}

A síndrome de Silver-Russell (SRS, MIM 180860) foi descrita pela primeira vez por Silver e col. em 1953 e Russell em 1954. Caracteriza-se principalmente por grave retardo de crescimento intrauterino e pós-natal. Os sinais craniofaciais incluem uma face típica, pequena e triangular, com frontal amplo e micrognatia, podendo os cantos da boca estar voltados para baixo e ocorrer anomalias de orelhas (Figura I.1). A macrocrania relativa ao tamanho do corpo é comum e pelo menos metade dos pacientes apresenta assimetria corporal e clinodactilia de quintos dedos. Muitas crianças com SRS têm dificuldades para alimentar-se, nos primeiros meses de vida. Características menos frequentes incluem manchas café com leite, atraso na maturação óssea e sudorese excessiva. O desenvolvimento neuromotor é normal na grande maioria dos casos, mas pode ocorrer atraso na aquisição da fala. A manifestação dessas características é muito variável entre os indivíduos afetados, havendo heterogeneidade clínica considerável. Além disso, o quadro clínico da SRS em adultos é menos marcante do que na infância. A altura média dos pacientes adultos com SRS é de 151,2 \pm 7,8 cm para os homens e 139,9 \pm 9,0 cm para as mulheres (revisão em Eggermann, 2010a).

A SRS é geneticamente heterogênea e ocorre, em geral, de forma esporádica. Os casos familiais evidenciaram a existência de componente genético em sua etiologia e diferentes modos de herança foram propostos, autossômico dominante ou recessivo e dominante ligado ao cromossomo X (revisão em Hitchins e col., 2001a).

A genética da SRS revelou-se complexa. Trata-se da primeira síndrome que afeta dois cromossomos diferentes. Regiões dos cromossomos humanos 7 e 11 sujeitas a imprinting genômico foram associadas com a etiologia da SRS: a dissomia uniparental materna do cromossomo 7 [matUPD(7) - maternal UniParental Dissomy 7] foi o primeiro mecanismo identificado como causa da síndrome, ocorrendo em 5-10\% dos casos (Kotzot e col., 1995; Preece e col., 1997; Eggermann e col., 1997; Price e col., 1999; Bernard e col., 1999; Kotzot e col., 2000; Russo e col., 2000; Nakabayashi e col., 2002; Binder e col., 2006; Netchine e col., 
2007; Binder e col., 2008; Eggermann e col., 2008b; Bartholdi e col., 2009; Peñaherrera e col., 2010).

O braço curto do cromossomo 11 humano apresenta um cluster de genes sujeitos ao imprinting genômico que têm papel crucial no controle do desenvolvimento da placenta e do embrião e no crescimento fetal. Alterações (epi)genéticas no segmento 11p15 como duplicações no cromossomo materno ou perda de metilação (hipometilação) do centro de imprinting telomérico (ICR1) foram descritas em pacientes com SRS. A hipometilação de ICR1 é a causa mais frequente da síndrome, presente em pelo menos 40\% dos casos (Gicquel e col., 2005; Schönherr e col., 2006; Eggermann e col., 2006; Binder e col., 2006; Netchine e col., 2007; Binder e col., 2008; Yamazawa e col., 2008a; Bartholdi e col., 2009; Bruce e col., 2009; Eggermann e col., 2009a; Abu-Amero e col., 2010; Turner e col., 2010; Lin e col., 2010; Peñaherrera e col., 2010).

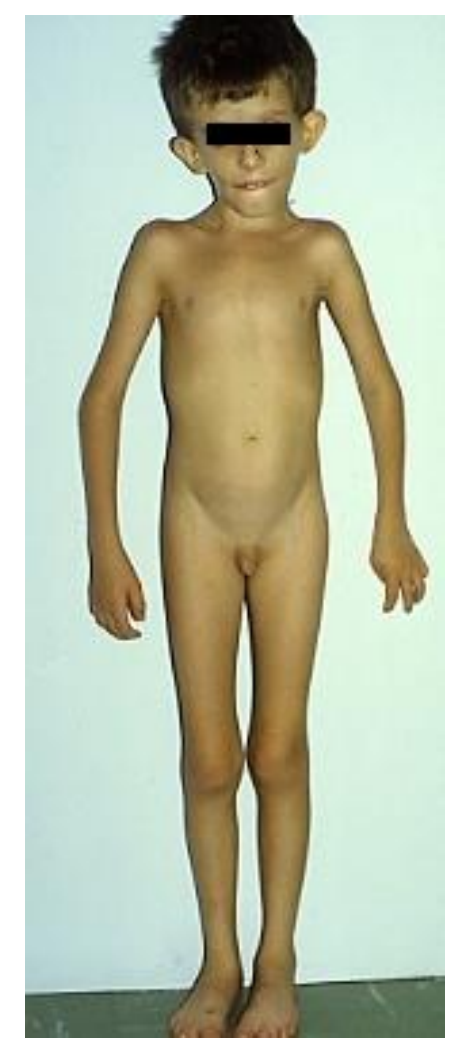

Figura I.1 - Menino com diagnóstico clínico da SRS: baixa estatura, macrocrania relativa, face triangular, frontal amplo e assimetria corporal (http://AtlasGeneticsOncology.org/Kprones/SilverRussellID10149.html). 
Adicionando à heterogeneidade genética da síndrome, alterações cromossômicas estruturais diversas já foram detectadas em pacientes com SRS (Figura I.2). Entretanto, além de alterações dos cromossomos 7 e 11, apenas alterações dos cromossomos 15 e 17 foram detectadas em mais de um paciente que preenchia critérios diagnósticos restritos de SRS. (revisão em Hitchins e col., 2001a; Eggermann, 2010a). Recentemente, microrrearranjos cromossômicos diversos, principalmente microdeleções, foram descritos em indivíduos afetados pela SRS, indicando que também podem ser relevantes para a etiologia da síndrome (Bruce e col., 2010; Spengler e col., 2010; Lin e col., 2010).

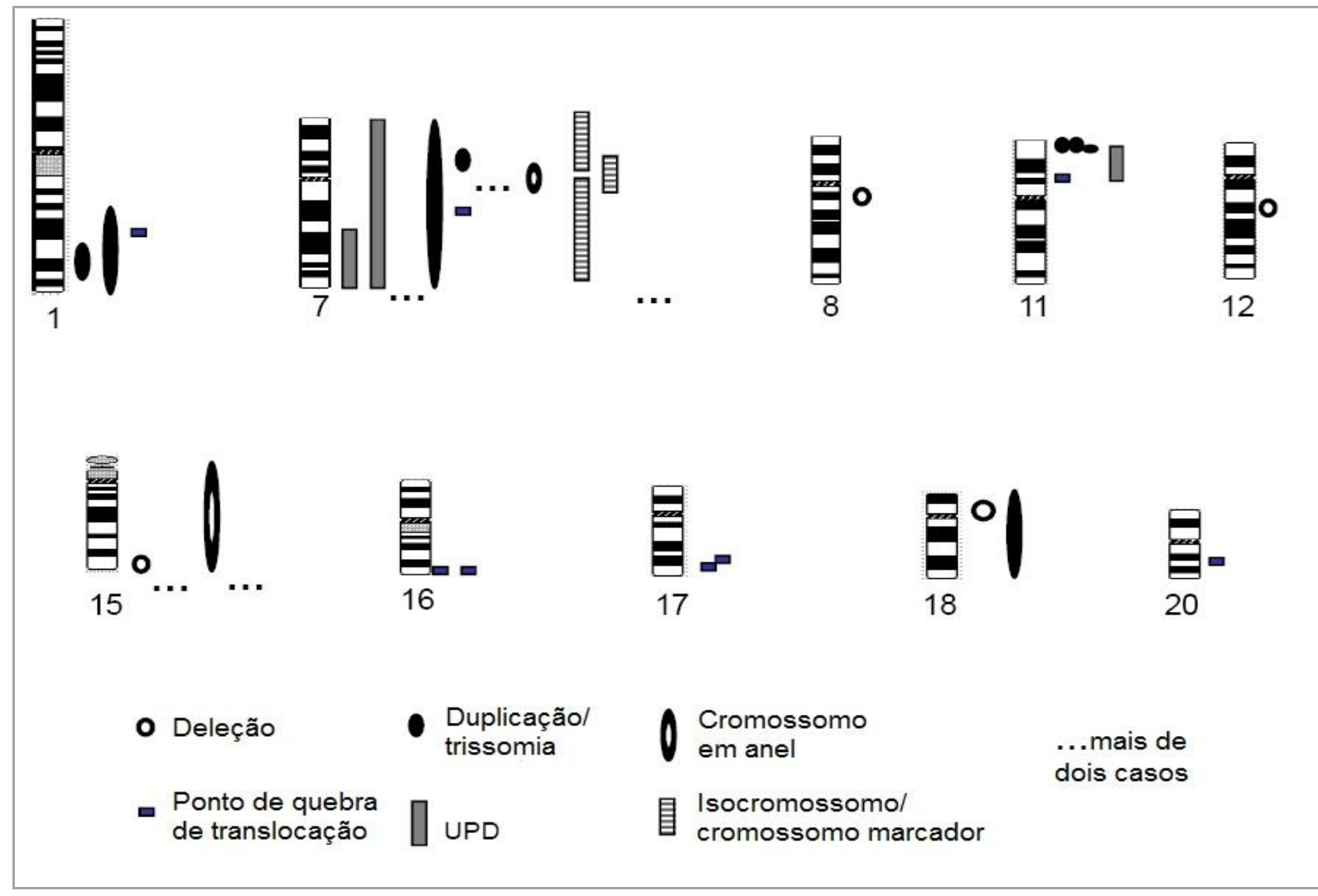

Figura I.2 - Alterações cromossômicas descritas em pacientes com SRS (modificada de Spengler e col., 2010). As alterações nos cromossomos humanos 7 e 11 são as mais frequentes. 


\section{I.2 A epigenética e o Imprinting Genômico}

Em sua primeira definição, epigenética significava o desenvolvimento dos fenótipos a partir dos genótipos (Waddington, 1942). O termo ganhou, entretanto, um significado molecular específico, referente aos processos de modificação da expressão gênica, sem alteração da sequência do DNA, como a metilação do DNA e modificações de histonas. Enquanto ambos os alelos da grande maioria dos genes autossômicos são expressos, existe uma porção deles que sofre imprinting genômico, ou seja, apenas um alelo é expresso, o materno ou o paterno. A transcrição dos genes sujeitos a imprinting é regulada por mecanismos epigenéticos, dos quais a metilação do DNA tem papel fundamental para diferenciar os genomas materno e paterno (revisão em Reik e Walter, 2001).

As marcas sexo-específicas de imprinting são estabelecidas na gametogênese e mantêmse inalteradas durante o desenvolvimento embrionário e pós-natal. Nos mamíferos, eutérios e marsupiais, o imprinting genômico tem papel crucial no desenvolvimento da placenta e do embrião, no crescimento fetal e no desenvolvimento e neurocomportamento após o nascimento. As alterações do imprinting genômico podem levar a diversas doenças genéticas, como a síndrome de Silver-Russell, que é o foco deste estudo.

Até a década de 80, acreditava-se que a informação genética de cada genitor contribuía de forma equivalente para o desenvolvimento do embrião, e a partenogênese, conhecida em várias espécies de animais, apoiava essa conclusão. No entanto, a inviabilidade da partenogênese em mamíferos levantou questões sobre a equivalência da contribuição dos pró-núcleos masculino e feminino para o desenvolvimento do embrião. A principal hipótese era que a homozigose de alelos recessivos letais seria responsável pela perda dos embriões uniparentais. Dois estudos realizados em 1984 foram cruciais para mostrar que havia de fato uma diferença funcional entre os genomas materno e paterno em mamíferos. Ambos utilizaram transplante de pró-núcleos para gerar embriões de camundongos com conjuntos de cromossomos de apenas um dos genitores.

No estudo de Surani e col. (1984), ovócitos foram usados como recipientes de prónúcleos masculinos ou femininos retirados de zigotos fertilizados. Foi demonstrado que a introdução de um pró-núcleo masculino era compatível com o desenvolvimento normal. No entanto, os poucos embriões que possuíam dois pró-núcleos femininos apresentaram retardo de 
crescimento marcante e o desenvolvimento dos tecidos extraembrionários foi particularmente reduzido. McGrath e Solter (1984) chegaram a resultados semelhantes ao realizarem transplantes de pró-núcleos entre zigotos de camundongos. Foram obtidos embriões ginogenéticos (dois prónúcleos femininos) e androgenéticos (dois pró-núcleos masculinos) e controles que receberam um pró-núcleo de cada sexo. Somente os controles se desenvolveram a termo. Os embriões androgenéticos apresentaram crescimento exacerbado dos tecidos extraembrionários, fenótipo oposto ao observado nos embriões ginogenéticos. Com base nesses resultados, os autores dos dois estudos concluíram que a homozigose de genes recessivos letais não era o principal fator responsável pela inviabilidade dos embriões ginogenéticos e androgenéticos de camundongos, mas que deveria haver um mecanismo específico de imprinting, que marcava diferencialmente os genomas parentais durante a gametogênese e que explicaria a necessidade de o zigoto possuir ambos os pró-núcleos, materno e paterno, para ter desenvolvimento normal. Apesar de terem a mesma quantidade de informação genética, a contribuição materna e paterna para o genoma do embrião não seria funcionalmente equivalente.

Esses achados foram refinados por estudos como o de Cattanach e Kirk (1985), que demonstraram que os efeitos da origem parental são específicos a certas regiões do genoma. A partir de cruzamentos entre camundongos portadores de translocações cromossômicas Robertsonianas ou recíprocas, foram gerados embriões que herdavam cromossomos ou segmentos cromossômicos específicos de apenas um genitor (dissomias uniparentais). Os camundongos produzidos apresentaram fenótipos normais ou anormais, dependendo do cromossomo ou do segmento presente em dissomia uniparental. Os fenótipos anormais descritos incluíam exacerbação ou retardo de crescimento e alterações de comportamento. Um exemplo marcante foi o segmento proximal do cromossomo 11 de camundongo: ao herdar duas cópias maternas, a prole apresentava retardo de crescimento; o fenótipo oposto era observado quando a prole herdava duas cópias paternas desse segmento. Os autores sugeriram que havia uma forma de imprinting, que afetava a atividade gênica nos cromossomos parentais de maneira recíproca e era responsável pelos fenótipos contrastantes observados nos camundongos.

No começo da década de 90, os primeiros genes sujeitos a imprinting genômico foram descobertos, entre eles o Igf2 (insulin-like growth factor 2), e foi comprovado que realmente eram expressos diferencialmente nos cromossomos materno e paterno (revisão em Reik e Walter, 
2001). Foi demonstrado também que a metilação do DNA é o principal mecanismo molecular no estabelecimento e na manutenção imprinting genômico (Li e col., 1993).

\section{I.2.1 Genes sujeitos ao imprinting e a metilação do DNA}

Atualmente, são conhecidos no genoma humano pelo menos 64 genes sujeitos a imprinting genômico, e cerca de 120 outros foram identificados como candidatos (Catalogue of Parent of Origin Effects - http://igc.otago.ac.nz/home.html; Geneimprint http://www.geneimprint.com/site/genes-by-species.Homo+sapiens.any). Um número considerável desses genes atua no desenvolvimento da placenta e do embrião e no crescimento fetal. De acordo com a "teoria do conflito genético", esses genes seriam mediadores da "batalha entre os sexos" no período fetal, apresentando funções opostas: genes de expressão paterna geralmente promovem o crescimento (por exemplo, $I G F 2$ ), enquanto genes de expressão materna o suprimem (por exemplo, CDKN1C - cyclin-dependent kinase inhibitor 1C) (Moore e Haig 1991; Moore e Reik, 1996). Em camundongos, são conhecidos pelo menos 143 genes que sofrem imprinting genômico. Esses genes estão distribuídos em 11 regiões de oito cromossomos murinos que são ortólogos a segmentos de cromossomos humanos. Um mapa completo dessas regiões e genes em camundongos está disponível em http://www.har.mrc.ac.uk/research/genomic_imprinting.

Uma característica notável dos genes sujeitos ao imprinting é que eles raramente são encontrados isolados no genoma: a grande maioria forma clusters, constituindo domínios cromossômicos (revisão em Reik e Walter, 2001). Essa organização reflete a possibilidade de regulação coordenada de todos os genes de um cluster por meio de um mecanismo epigenético comum (revisão em Verona e col., 2003). Fazendo analogia com o centro de inativação do cromossomo $\mathrm{X}$, em que o gene XIST controla o processo de silenciamento da grande maioria dos genes do cromossomo $\mathrm{X}$, centros de imprinting (Imprinting Center Region; ICR) foram identificados em vários clusters gênicos. As ICR são regiões diferencialmente metiladas (Different Methylated Region; DMR) nos alelos parentais, necessárias para o controle regional em cis da expressão dos genes que sofrem imprinting (Figura I.3). Esses domínios sujeitos a 
imprinting e seus centros reguladores são amplamente conservados entre humanos e camundongos (revisão em Reik e Walter, 2001).

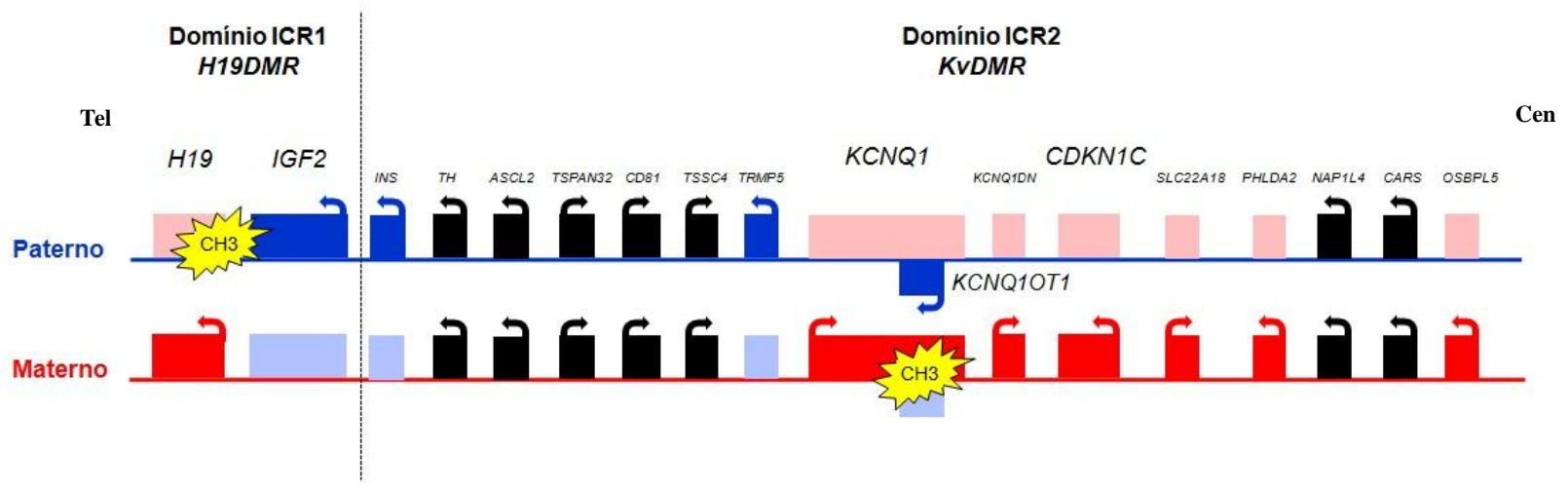

Figura I.3 - Cluster de genes sujeitos a imprinting genômico no cromossomo humano 11p15. O cluster está dividido em dois domínios gênicos, cada um regulado por uma ICR: ICR1 (H19DMR) e ICR2 $(K v D M R 11)$.

A metilação do DNA, adição de um grupo metil a resíduos de citosina dos dinucleotídeos $\mathrm{CpG}$, é a principal marca epigenética no estabelecimento e na manutenção do imprinting genômico, mas não é exclusiva a esse fenômeno. A metilação dos promotores gênicos é um mecanismo tecido-específico e reversível de silenciamento, encontrado normalmente em diversos genes. A diferença é que para os genes sujeitos a imprinting o estabelecimento de padrões de metilação contrastantes leva à inativação gênica em um dos cromossomos parentais, mas não no outro. Como consequência, os genes sujeitos a imprinting têm expressão monoalélica (revisão em Biliya e Bulla, 2010).

Existem outras propriedades que distinguem os genes que sofrem imprinting daqueles normalmente metilados no genoma: uma vez metiladas diferencialmente nas células germinativas parentais, as DMR mantêm-se metiladas em todos os estágios do desenvolvimento e tecidos, com exceção de algumas que adquirem padrões de metilação tecido e tempo-específicos; algumas DMR são metiladas em associação à cópia inativa do gene, enquanto outras são metiladas em associação com a cópia ativa (revisão em Reik e Walter, 2001). 
As duas cópias parentais de um gene sujeito a imprinting diferem quanto à estrutura da cromatina, que está relacionada com modificações específicas nas histonas (acetilações e metilações), e quanto à duplicação do DNA, que é assincrônica (revisão em Verona e col., 2003; Henckel e col., 2009). Nas células somáticas, as ICR são marcadas também por modificações de histonas, o que é indicativo de ação combinada com a metilação do DNA. Já foi relatada associação entre o alelo parental com a marca de metilação do DNA e as modificações repressivas de histonas, que atuariam na manutenção somática do imprinting (Henckel e col., 2009). De forma geral, as histonas e outras modificações da cromatina aparecem relacionadas ao imprinting genômico em associação com a metilação do DNA (revisão em Reik e Walter, 2001).

\section{I.2.2 Estabelecimento e manutenção do imprinting genômico}

O estabelecimento do imprinting genômico é um processo complexo que inclui a reprogramação do genoma. As marcas de imprinting devem ser transmitidas com precisão para a geração seguinte e são dependentes da origem parental (Figura I.4). Em outras palavras, em machos, todas as células contêm um conjunto de cromossomos com marcas de imprinting masculinas (de herança paterna) e outro conjunto com as marcas femininas (de herança materna), mas quando esses cromossomos são transmitidos para a geração seguinte, os dois conjuntos devem ser reprogramados para conter marcas de imprinting apenas masculinas, que será a contribuição paterna. As fêmeas, por sua vez, transmitem para a geração seguinte cromossomos com marcas de imprinting maternas.

A reprogramação de marcas epigenéticas do genoma ocorre em duas fases. A primeira acontece durante o desenvolvimento das células germinativas primordiais em ovócitos ou espermatócitos e compreende a desmetilação global, quando se apagam as marcas de imprinting parentais pré-existentes, seguida da metilação de novo do DNA, estabelecendo-se o novo padrão sexo-específico nos gametas. 


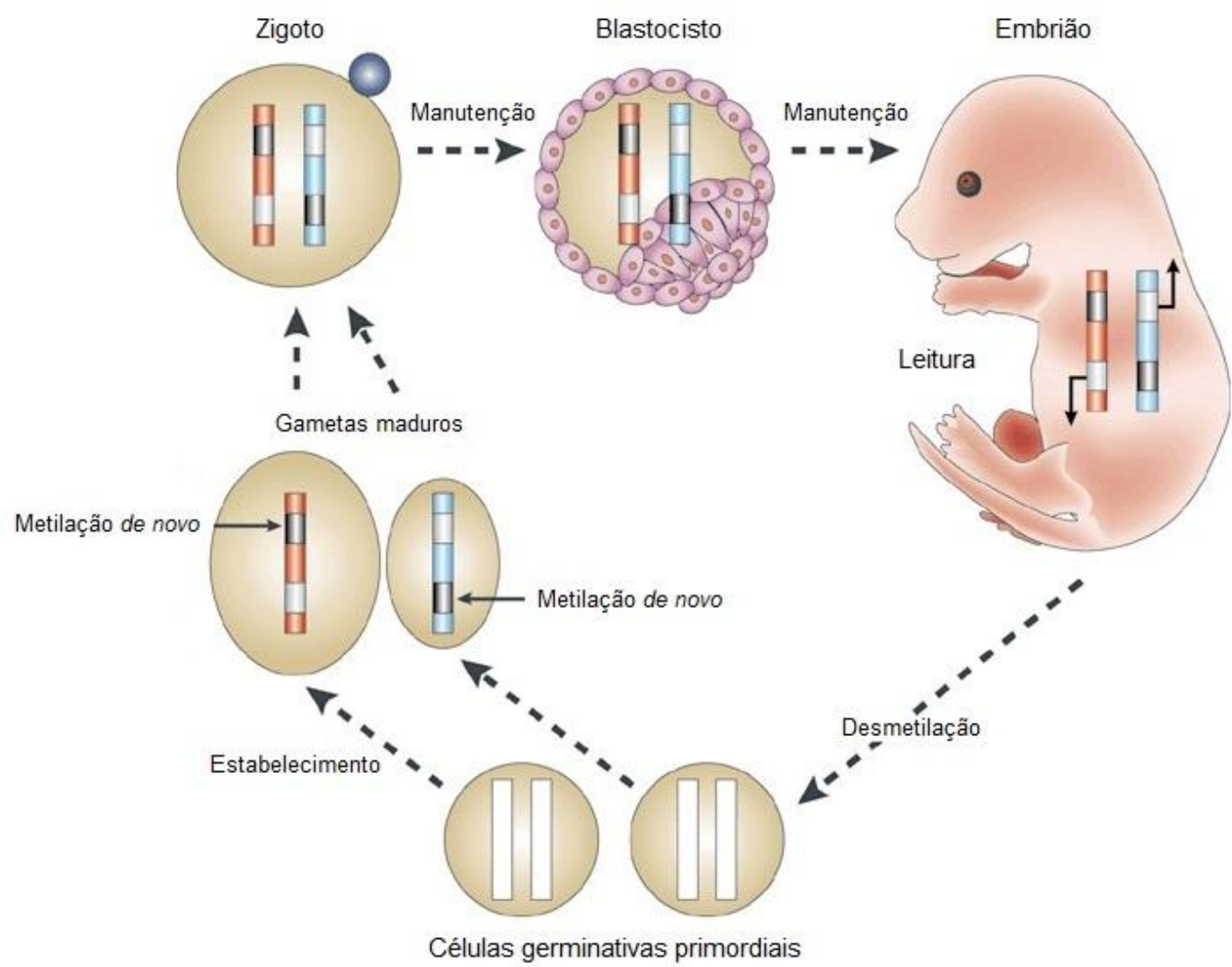

Figura I.4 - Reprogramação do genoma humano: as marcas de imprinting pré-existentes são apagadas na formação das células germinativas primordiais. Durante a gametogênese, são estabelecidas as novas marcas, de acordo com a origem parental, que são mantidas no desenvolvimento (modificada de Reik e Walter, 2001).

A segunda fase da reprogramação da metilação ocorre após a fertilização e abrange a desmetilação global do genoma antes da implantação do embrião e a remetilação global, após a implantação. Os genes sujeitos a imprinting, no entanto, escapam da segunda fase da reprogramação e suas marcas permanecem intactas durante o restante do desenvolvimento embrionário (revisão em Biliya e Bulla, 2010).

Nas células somáticas, a metilação do DNA é mantida durante o processo de duplicação dos cromossomos e transmitida para todas as células filhas, mas pode apresentar modificações tecido-específicas, em diferentes estágios do desenvolvimento. A metilação de novo do DNA é estabelecida pelas metiltransferases de citosina Dnmt3a e Dnmt3b. Quando o DNA é duplicado, os grupos metil da fita molde são reconhecidos e novos grupos metil são inseridos na fita em 
formação pela enzima Dnmt1 (revisão em Reik e Walter, 2001). Dessa forma, Dnmt1 é responsável pela manutenção da metilação, um processo complexo provavelmente relacionado ao ciclo celular e necessitando da ação combinada de múltiplos complexos enzimáticos (revisão em Delaval e col., 2006).

Na linhagem germinativa, a metilação do DNA nas ICR é realizada pela Dnmt3L, que faz parte da família Dnmt3 de metiltransferases de novo. A prole de fêmeas de camundongos Dnmt $3 l^{-1-}$ não se desenvolve e apresenta ausência completa de metilação materna do DNA nas ICR, resultando na expressão desregulada dos genes sujeitos a imprinting associados a elas, enquanto a metilação do restante do genoma aparentemente não é afetada (Henckel e col., 2009). Não se sabe como essas enzimas se ligam às DMR específicas das células germinativas femininas ou masculinas, mas provavelmente é necessária a presença de fatores que reconheçam as DMR e sejam sexo-específicos na linhagem germinativa (revisão em Reik e Walter, 2001).

\section{I.2.3 Mutações (epi)genéticas e a perda do imprinting genômico}

Genes sujeitos a imprinting têm apenas um alelo funcional e normalmente estão arranjados em clusters, com regulação comum. Assim, uma única mutação pode alterar o funcionamento de vários genes num domínio sujeito a imprinting. A perda de imprinting pode resultar de mutações genéticas (mutações de ponto, duplicações, deleções e UPD) ou epigenéticas (alterações no padrão de metilação das ICR). Qualquer dessas alterações pode desregular a expressão de gene(s) sujeito(s) a imprinting, pela ativação de um alelo inativo ou vice-versa (revisão em Biliya e Bulla, 2010).

A perda de imprinting já foi identificada como a causa de aproximadamente 30 doenças e síndromes humanas conhecidas (revisão em Biliya e Bulla, 2010). As mais bem caracterizadas são as síndromes de neurodesenvolvimento, de Angelman (AS, MIM 105830) e Prader-Willi (PWS, MIM 176270), a síndrome de Beckwith-Wiedemann (BWS, MIM 130650), de crescimento exacerbado e de Silver-Russell, com retardo no crescimento, a diabetes melito neonatal transitória (TNDM, MIM 601410) e a osteodistrofia de Albright (MAS, MIM 174800).

As síndromes de Angelman e de Prader-Willi foram as primeiras síndromes decorrentes da perda do imprinting genômico descritas em humanos. Ambas ocorrem com uma frequência de 
um em 15 mil nascimentos e estão associadas a alterações do desenvolvimento e comportamentais, além do comprometimento cognitivo. A perda de imprinting é decorrente de mutações (epi)genéticas na porção proximal do braço longo do cromossomo 15, onde está presente uma ICR que controla vários genes, como ZNF127 (makorin ring finger protein 3), NDN [necdin homolog (mouse)], SNRPN (small nuclear ribonucleoprotein polypeptide N), IPW (imprinted in Prader-Willi syndrome) e UBE3A (ubiquitin protein ligase E3A) (revisão em Eggermann e col., 2008a).

\section{I.2.4 Dissomia uniparental}

A dissomia uniparental (UPD) consiste na presença de duas cópias de um cromossomo ou de um segmento do cromossomo derivadas somente de um dos genitores e nenhuma herdada do outro. As UPD podem ocorrer como heterodissomia, quando os dois homólogos ou segmentos homólogos são herdados de um mesmo genitor, ou isodissomia, na qual as duas cópias presentes são de um mesmo homólogo materno ou paterno.

A dissomia uniparental origina-se por diferentes mecanismos (Figura I.5), resultando de erros na meiose I ou II ou de eventos pós-zigóticos: (1) correção de trissomia (por exemplo, fertilização de óvulo dissômico por espermatozoide normal e subsequente perda do cromossomo paterno no embrião trissômico); (2) complementação gamética (fertilização de gameta dissômico por um nulissômico quanto ao mesmo cromossomo); (3) UPD compensatória (evento somático no qual um cromossomo anormal ou ausente é substituído pela duplicação pós-zigótica do homólogo normal) e (4) erro mitótico (não disjunção mitótica levando a isodissomia, ou recombinação mitótica entre os homólogos materno e paterno, podendo gerar UPD segmentar). Enquanto a UPD compensatória e os erros mitóticos geram somente isodissomias, os mecanismos que dependem de erros meióticos podem gerar misturas de iso e heterodissomia, dependendo da etapa da meiose em que ocorre a não disjunção e dos eventos de permutação entre os cromossomos homólogos (revisão em Robinson, 2000; Liehr, 2010). 


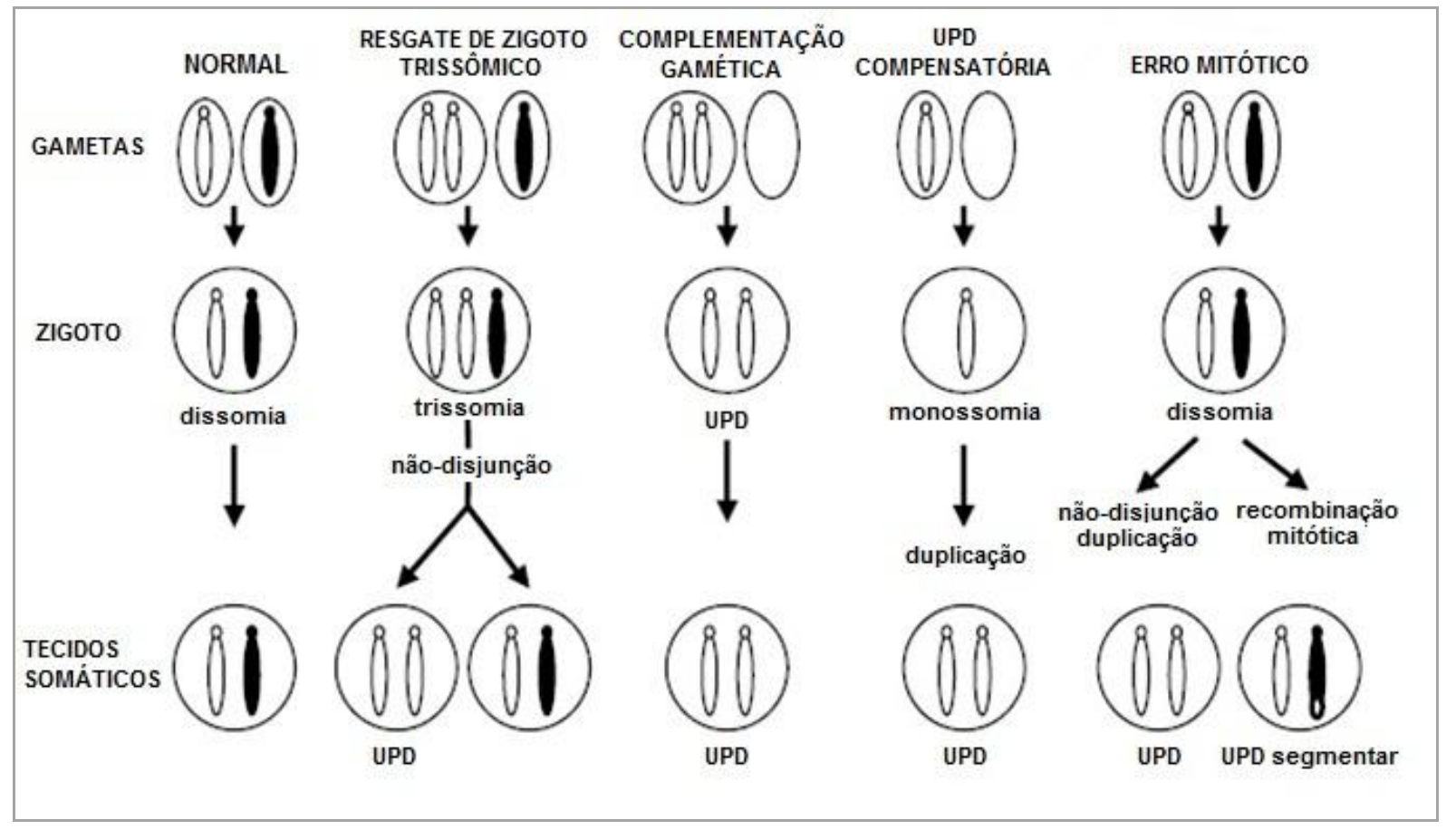

Figura I.5 - Mecanismos de formação de dissomia uniparental (UPD) (modificada de Spence e col., 1988).

Em humanos, a grande maioria dos casos de UPD foi descrita em associação com patologias e os casos de UPD em que os indivíduos não apresentam alterações fenotípicas geralmente são detectados por acaso. As condições clínicas observadas podem resultar da homozigose de mutações recessivas (UPD isodissômica) ou da desregulação da expressão de genes sujeitos a imprinting genômico (UPD iso ou heterodissômica). A Figura I.6 mostra o número de casos de UPD descritos na literatura até 2010 para cada cromossomo. A maior representação dos cromossomos humanos 15, 11, 7, 14 e 16é explicada por serem aqueles cromossomos com maior quantidade de genes sujeitos a imprinting genômico já relacionados a síndromes conhecidas (revisão em Liehr, 2010). 


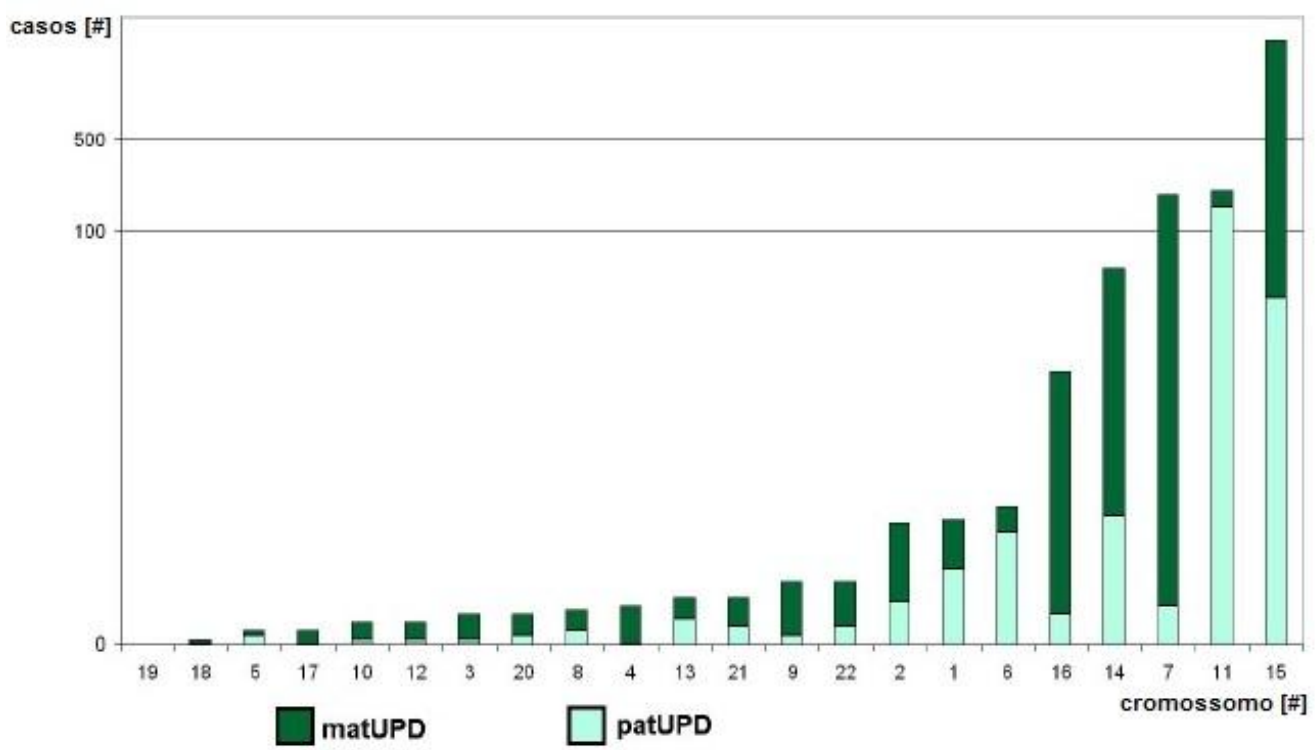

Figura I.6 - Contribuição dos cromossomos humanos para as UPD. matUPD = dissomia uniparental materna; patUPD = dissomia uniparental paterna (modificada de Liehr, 2010).

\section{I.3 Alterações (epi)genéticas na síndrome de Silver-Russell}

\section{I.3.1 Cromossomo 7}

A síndrome de Silver-Russell foi descrita na década de 50. Entretanto, a causa genética permaneceu desconhecida até o começo da década de 90, quando os estudos começaram a associar, com certa frequência, alterações no cromossomo 7, principalmente a matUPD(7), ao quadro clínico da SRS.

Os primeiros casos de $\mathrm{UPD}(7)$ descritos na literatura foram dois pacientes com fibrose cística (FC), homozigotos quanto a uma mutação no gene CFTR (cystic fibrosis transmembrane conductance regulator) (Spence e col., 1988; Voss e col., 1989). Em ambos, a mãe era heterozigota e o pai, não portador da mutação. Portanto, não havia contribuição dos alelos paternos do cromossomo 7 e a homozigose de alelos maternos indicava isodissomia materna. Além da FC, o paciente descrito por Spence e col. (1988) apresentava baixa estatura e assimetria de membros, características da SRS. O paciente de Voss e col. (1989) apresentava grave retardo 
de crescimento, desde a vida intrauterina, forte indicação de SRS. Em um terceiro paciente (Spolita e col., 1992), com distúrbio de colágeno e retardo de crescimento, foi detectada uma mistura de hetero e isodissomia materna do cromossomo 7, e ocorria mutação no gene COL1A2 (collagen, type I, alpha 2) em homozigose.

Para investigar a matUPD(7) como causa da SRS e de retardo de crescimento intrauterino isolado, Kotzot e col. (1995) analisaram duas séries de pacientes, usando microssatélites: três dos $25(12 \%)$ casos esporádicos de SRS e um dentre 10 pacientes (10\%) com retardo de crescimento intrauterino isolado apresentaram matUPD(7). Esses resultados indicaram que a matUPD(7) estava associada com o fenótipo da SRS.

Nos anos seguintes, diversos trabalhos investigaram a associação entre matUPD(7) e a SRS e mostraram que ela ocorre em 5-10\% dos casos (Tabela I.1).

Tabela I.1 - Proporção de pacientes com SRS e matUPD(7) em estudos realizados de 1995 a 2010.

\begin{tabular}{|lll|}
\hline Número de pacientes investigados & $\begin{array}{l}\text { Número de pacientes com } \\
\text { matUPD(7) (frequência) }\end{array}$ & Referência \\
\hline $\mathbf{2 5}$ & $3(12 \%)$ & Kotzot e col. (1995) \\
\hline $\mathbf{3 3}$ & $2(6 \%)$ & Preece e col. (1997) \\
\hline $\mathbf{3 7}$ & $3(8 \%)$ & Eggermann e col. (1997) \\
\hline $\mathbf{4 2}$ & $4(9,5 \%)$ & Price e col. (1999) \\
\hline $\mathbf{2 1}$ & $2(9,5 \%)$ & Bernard e col. (1999) \\
\hline $\mathbf{2 0}$ & $1(5 \%)$ & Russo e col. (2000) \\
\hline $\mathbf{7 7}$ & $3(3,9 \%)$ & Nakabayashi e col. (2002) \\
\hline $\mathbf{2 3}$ & $4(17 \%)$ & Binder e col. (2006) \\
\hline $\mathbf{5 8}$ & $3(5,2 \%)$ & Netchine e col. (2007) \\
\hline $\mathbf{4 4}$ & $5(11 \%)$ & Binder e col. (2008) \\
\hline $\mathbf{1 0 6}$ & $7(6,6 \%)$ & Bartholdi e col. (2009) \\
\hline $\mathbf{3 5}$ & $3(8,6 \%)$ & Peñaherrera e col. (2010) \\
\hline Total $=\mathbf{5 2 1}$ & $\mathbf{4 0 ( 7 , 7 \% )}$ & \\
\hline
\end{tabular}

Alguns pacientes com UPD(7) paterna foram descritos (Hoglud e col., 1994; Pan e col., 1998; Fares e col., 2006; Le Caignec e col., 2007), mas nenhum deles apresentava fenótipo de retardo de crescimento, uma indicação de que o quadro clínico da SRS não decorria da homozigose quanto a gene(s) recessivo(s). Além disso, não havia um segmento isodissômico comum entre os pacientes com matUPD(7) e grande parte das dissomias uniparentais descritas 
eram heterodissomias, duas fortes evidências que excluíam uma mutação recessiva no cromossomo 7 como responsável pelo fenótipo da SRS (Preece e col., 1999). Essas observações deram apoio à hipótese de que gene(s) sujeito(s) a imprinting genômico no cromossomo 7 humano, que controlariam o crescimento intrauterino e pós-natal, estavam associados à etiologia da SRS nos casos de matUPD(7).

A partir daí, os estudos tiveram como foco a identificação de genes sujeitos a imprinting genômico no cromossomo 7, que pudessem explicar o fenótipo dos pacientes com SRS. A síndrome poderia ser causada por (1) ausência da expressão de genes que promovem o crescimento, ativos exclusivamente no cromossomo paterno, ou (2) expressão bialélica materna de genes que restringem o crescimento.

Regiões do cromossomo 7 humano, ortólogas a regiões dos cromossomos de camundongo sujeitos a imprinting genômico, foram uma indicação da localização de genes que sofrem imprinting e que poderiam estar associados a SRS: 7p11.2-p13 e 7q21-qter, ortólogas, respectivamente, à região proximal do cromossomo 11 e à região proximal do cromossomo 6 de camundongo. Ambos os segmentos estão associados ao crescimento em camundongos (revisão em Hitchins e col., 2001a).

Quatro pacientes com as principais características clínicas da SRS, sendo um caso familial com mãe e filha afetadas, foram descritos com duplicações maternas de 7p11.2-p13 (Figura I.7) (Joyce e col., 1999; Monk e col., 2000; Monk e col., 2002a). Pelo menos quatro inversões cromossômicas e duas translocações, com ponto de quebra em 7p11.2, foram relatadas em pacientes com SRS (revisão em Monk e col., 2002a). Os genes IGFBP1 e IGFBP3 (insulinlike growth factor binding protein 1 e 3) e GRB10 (growth factor receptor-bound protein 10) incluídos nos segmentos duplicados, e o gene EGFR (epidermal growth factor receptor), localizado próximo aos demais, foram selecionados como candidatos à SRS por estarem associados ao crescimento. Dentre eles, somente o gene GRB10 sofre imprinting genômico; seu padrão de expressão durante o desenvolvimento fetal humano é preferencialmente materno, porém complexo, tecido e isoforma-específicos (revisão em Eggermann, 2009b). 


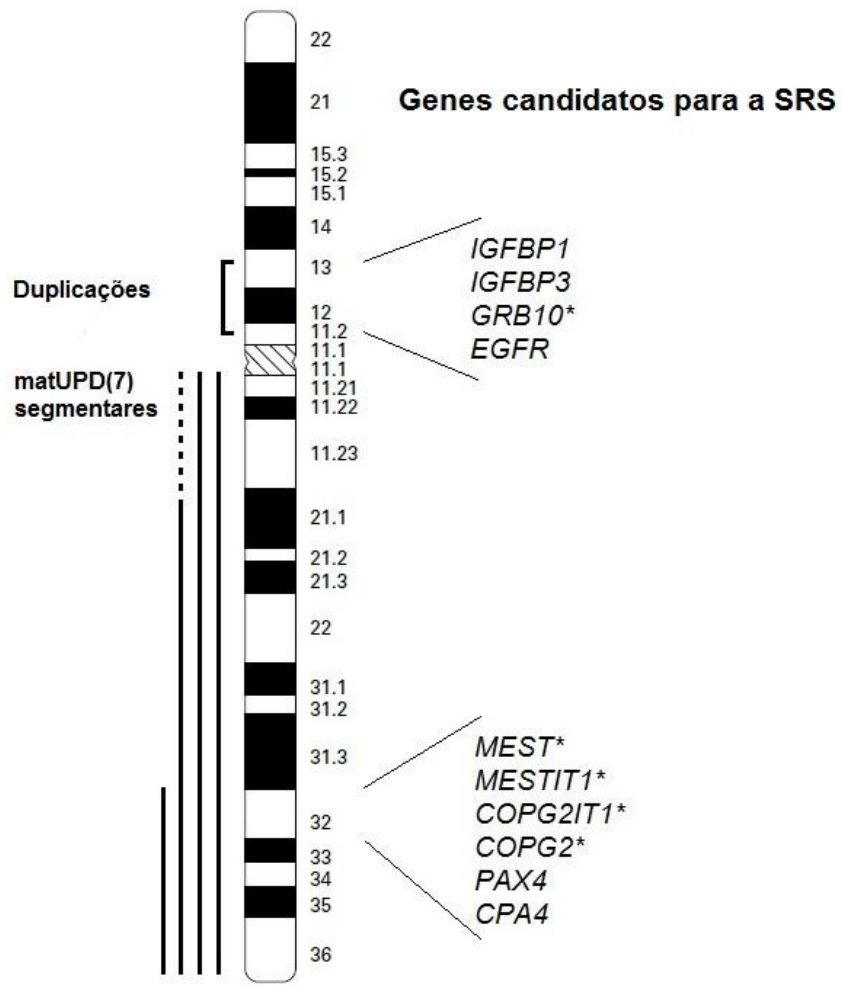

Figura I.7 - Genes candidatos a SRS localizados nos segmentos candidatos do cromossomo 7; *genes sujeitos a imprinting (modificada de Eggermann, 2010a).

A busca de mutações nesses genes os excluiu como causa comum da SRS (Eggermann e col., 1999; Monk e col., 2000; Hitchins e col., 2001b; Yoshihashi e col., 2000; Nakabayashi e col., 2002). Recentemente, a análise do padrão de metilação do gene GRB10 foi realizada em 34 pacientes com SRS e um apresentou hipometilação nesse lócus (Turner e col., 2010). Entretanto, o significado desse achado não ficou claro, uma vez que o paciente tinha alteração de metilação em outros lócus, incluindo hipometilação de ICR1 em 11p15, a causa epigenética mais comum da síndrome. Apesar disso, a participação do gene GRB10 na etiologia da SRS não pode ser descartada. Leach e col. (2007) identificaram uma duplicação materna da região 7p11.2-p12, segregando em uma família com três pacientes afetados por atraso cognitivo, mas que não apresentavam características clínicas da SRS. A duplicação não incluía o gene GRB10, o que favorece sua associação com o retardo de crescimento. 
Algumas alterações do braço longo do cromossomo 7 foram descritas na SRS. Hannula e col. (2001) detectaram uma isodissomia segmentar materna, abrangendo 7q31-qter, em paciente com quadro clínico típico da SRS. Após esse primeiro achado, três outros pacientes foram relatados com características da SRS e UPD segmentar em 7q (revisão em Eggermann, 2009b). Essa região (Figura I.7) contém um cluster de genes sujeitos a imprinting que foram previamente associados com retardo de crescimento intrauterino e pós-natal em camundongos com dissomia uniparental materna. Alguns desses genes, considerados candidatos para a SRS, foram analisados quanto a mutações, mas nenhuma alteração foi detectada: MEST [mesoderm specific transcript homolog (mouse)] e COPG2 (coatomer protein complex, subunit gamma 2), ambos sujeitos a imprinting e com expressão paterna na maioria dos tecidos; CPA4 (carboxipeptidase A4) e PAX4 (paired box homeotic gene-4) (Riesewijk e col., 1998; Blagitko e col., 1999; Mergenthaler e col., 2000; Hitchins e col., 2001a; Eggermann e col., 2008a; Eggermann, 2010a). Outros dois genes, que transcrevem RNA não codificadores, de expressão paterna, foram localizados em 7q32, COPG2IT1 (COPG2 imprinted transcript 1) e MESTIT1 (MEST intronic transcript 1), mas não há relato de busca por mutações ou alterações no padrão de imprinting (revisão em Eggermann e col., 2008a).

A descrição de camundongos com retardo de crescimento intrauterino e mutações no gene Mest herdadas do pai indicavam esse gene como candidato para a SRS. A região diferencialmente metilada do gene MEST foi extensamente investigada quanto à presença de alterações epigenéticas em cerca de 160 pacientes com SRS não portadores de matUPD(7) (Horike e col., 2009; Turner e col., 2010). Três pacientes com alteração de metilação nesse lócus foram descritos, dois apresentando alteração de metilação também em outros lócus (Horike e col., 2009; Begemann e col., 2010). Esses resultados indicaram que MEST não tem um papel principal na etiologia da SRS, mas pode contribuir para o fenótipo da síndrome em pacientes com matUPD(7) (Hitchins e col., 2001a).

Alterações no segmento 7q21 em humanos, ortólogo à região proximal do cromossomo 6 em camundongos, podem estar associadas com o fenótipo da SRS. Em camundongos, a dissomia materna desse segmento causa letalidade embrionária precoce. Vinte e dois pacientes com deleções abrangendo a banda 7q21, ou parte dela, foram descritos (revisão em Courtens e col., 2005). Em quatro casos, a deleção estava no cromossomo paterno. Esses pacientes 
compartilhavam diversas características da SRS, como retardo de crescimento intrauterino e pósnatal, face triangular, frontal amplo, micrognatia, assimetria corporal, atraso na aquisição da fala e dificuldades para alimentar-se na infância. Todos apresentavam atraso no desenvolvimento neuropsicomotor, que não é comum a SRS. Na banda 7q21 estão localizados dois genes que sofrem imprinting genômico: SGCE (sarcoglycan epsilon) e PEG10 (paternally expressed 10), ambos de expressão paterna. Turner e col. (2010) investigaram o padrão de metilação do gene PEG10 em 34 pacientes com SRS e identificaram perda de metilação nesse lócus em um deles. No entanto, o significado desse achado não ficou claro, uma vez que esse paciente apresentava alteração de metilação em outros loci, incluindo a hipometilação de ICR1 em 11p15.

\section{I.3.2 Cromossomo 11}

O braço curto do cromossomo 11 humano apresenta um cluster de genes sujeitos a imprinting genômico que têm papel crucial no controle do crescimento embrionário. Esse cluster presente na região 11p15 abrange uma região de cerca de 1 Mb e é constituído por dois domínios

gênicos, cada um regulado por uma ICR: o domínio telomérico é controlado pelo centro de imprinting ICR1 (H19DMR), enquanto o mais centromérico é regulado pela ICR2 (KvDMRl) (Figura I.3, item I.2.1). Essas ICR são diferencialmente metiladas, de acordo com a origem parental: em indivíduos normais, a ICR1 (H19DMR) está metilada exclusivamente no cromossomo paterno, enquanto a ICR2 (KvDMRl) está metilada somente no cromossomo materno (revisão em Reik e Walter, 2001; Verona e col., 2003).

Duplicações paternas, patUPD(11) ou alterações epigenéticas - hipermetilação de ICR1 ou hipometilação de ICR2 - são causas da síndrome de Beckwith-Wiedemann, caracterizada principalmente pelo crescimento intrauterino e pós-natal exacerbado (revisão em Weksberg e col., 2003; Eggermann e col., 2008a). A identificação da hipometilação de ICR1 como causa mais frequente da síndrome de Silver-Russell ilustrou de maneira muito interessante que alterações epigenéticas opostas podem estar associadas com fenótipos opostos. Antes de discutir como mutações (epi)genéticas opostas no cromossomo $11 \mathrm{p} 15$ são responsáveis por ambas as síndromes, é importante entender como as ICR1 e ICR2 regulam os genes sujeitos a imprinting nesse segmento. 


\section{Domínio ICRI (Figura I.8)}

O domínio ICR1 inclui o gene IGF2 (insulin-like growth factor 2), que codifica um fator de crescimento fetal altamente expresso em tecidos mesodérmicos e endodérmicos, o gene H19 (H19, imprinted maternally expressed transcript), cujo transcrito é um RNA não codificador (ncRNA) com função desconhecida, mas que pode ter atividade de supressor tumoral, e uma região diferencialmente metilada, ICR1 (H19DMR), que constitui o centro de imprinting desse domínio (revisão em Weksberg e col., 2003; Delaval e col., 2006; Yamazawa e col., 2008a). Os genes IGF2 e H19 competem por enhancers localizados a 3' de H19. Estudos em camundongos demonstraram que o alelo materno do ICR1 (H19DMR), não metilado e localizado $2 \mathrm{~Kb}$ upstream do promotor de $H 19$, possui sete motivos de ligação de proteínas zinc-finger chamadas CTCF (fator de ligação a CCCTC). A ligação dessas proteínas ao cromossomo materno cria um insulator que impede a aproximação dos enhancers aos promotores (mesodérmicos e endodérmico) do gene $I G F 2$. Como consequência, $I G F 2$ fica silenciado no cromossomo materno e o gene $H 19$ é expresso, uma vez que os enhancers têm acesso a ele. No início do desenvolvimento, a metilação do DNA no cromossomo paterno se estende de ICR1 (H19DMR) ao promotor do gene H19, tornando-o inativo. A metilação de ICR1 no alelo paterno impede a ligação das CTCF, permitindo o acesso aos enhancers e a expressão do gene IGF2 (revisões em Reik e Walter, 2001; Verona e col., 2003; Delaval e col., 2006).

Um estudo recente refinou a regulação gênica no domínio ICR1. Nativio e col. (2011) mostraram que a metilação de ICR1 no alelo paterno é acompanhada por modificações específicas de histonas, diferentes das observadas no alelo materno. A diferença na estrutura da cromatina entre os alelos parentais seria necessária para mediar a aproximação alelo-específica dos enhancers aos promotores de $H 19$ e IGF2, como demonstrado previamente em camundongos (Kurukuti e col., 2006). Além disso, os autores mostraram que existem outros três motivos de ligação de CTCF além daquele presente na ICR1 (H19DMR), sendo um deles localizado upstream do gene IGF2 (CTCF-AD) e outro downstream do gene H19 (CTCF-DS). Esses três sítios de CTCF estão presentes em ambos os alelos parentais e independem do estado de metilação de ICR1. No modelo proposto por Nativio e col. (2011), a interação entre as proteínas CTCF, em paralelo ao recrutamento de coesinas, às modificações das histonas e à metilação do 
DNA, seria necessária para modular a formação de loops na cromatina, de forma aleloespecífica: no cromossomo materno, a associação entre CTCF-DS e a CTCF de ICR1 não permitiria a aproximação dos enhancers aos promotores de $I G F 2$, enquanto que, no alelo paterno, a interação entre CTCF-DS e CTCF-AD direcionaria os enhancers aos promotores de $I G F 2$, ativando-o.

Em resumo, a manutenção da metilação diferencial de ICR1 (H19DMR) assegura a expressão monoalélica paterna do gene $I G F 2$ e a expressão monoalélica materna de $H 19$, na maioria dos tecidos de mamíferos. No entanto, a presença de diferentes promotores tecidoespecíficos e a ocorrência de splicing alternativo do RNA primário de IGF2 indicam que a regulação desse gene durante o desenvolvimento é mais complexa (Binder e col., 2006).

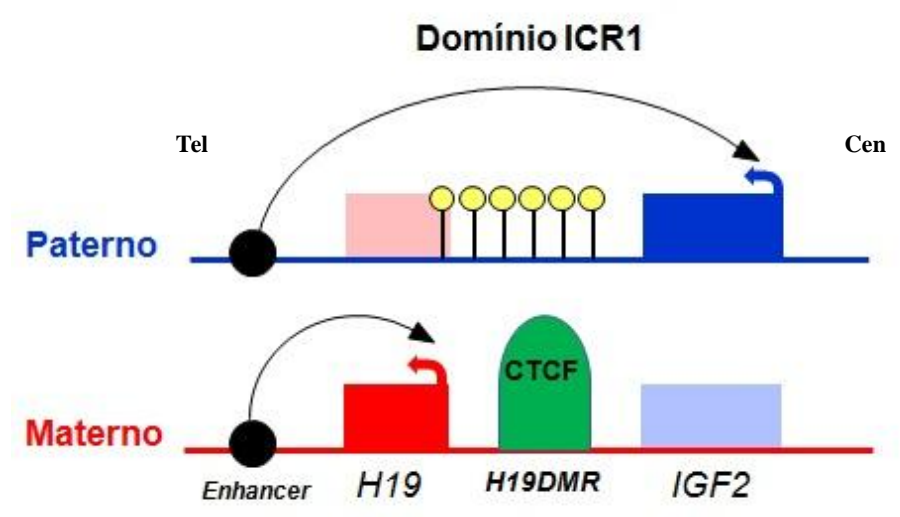

Figura I.8 - Regulação do imprinting genômico no domínio ICR1 do cromossomo humano 11p15. Os genes representados por blocos azuis têm expressão paterna e, por blocos vermelhos/cor de rosa, têm expressão materna; a transcrição desses genes está indicada pelas flechas nos blocos. A metilação da ICR1 (H19DMR) está indicada pelos círculos amarelos. Proteínas CTCF (em verde) se ligam a sequências específicas de DNA no ICR1 (H19DMR) e em outros sítios do domínio (não mostrados na figura). 


\section{Domínio ICR2 (Figura I.9)}

O domínio ICR2 abrange pelo menos sete genes sujeitos a imprinting genômico, a maioria de expressão monoalélica materna. Alguns desses genes sofrem imprinting somente em certos tecidos ou estágios específicos do desenvolvimento (revisão em Verona e col., 2003). O gene de expressão materna CDKN1C (cyclin-dependent kinase inhibitor 1C) é um regulador negativo da proliferação e do crescimento celular, altamente expresso na placenta (Matsuoka e col., 1995). Foi demonstrado que camundongos com expressão bialélica de Cdkn1c são 20-25\% menores do que os controles selvagens (Fitzpatrick e col., 2002).

O gene de expressão materna KCNQ1 (potassium voltage-gated channel, subfamily $Q$, member 1) codifica uma subunidade de canal de potássio. O centro de imprinting do domínio ICR2 (KvDMRl) está localizado no íntron 10 do gene $K C N Q 1$. O alelo paterno de ICR2, não metilado, permite a expressão monoalélica de KCNQ1OT1 (potassium voltage-gated channel, subfamily $Q$, member 1 overlapping transcript 1), que produz um longo transcrito não codificador, que se origina próximo à ICR2 $(K v D M R l)$ e se estende na direção antissenso ao gene $K C N Q 1$ (revisão em Verona e col., 2003).

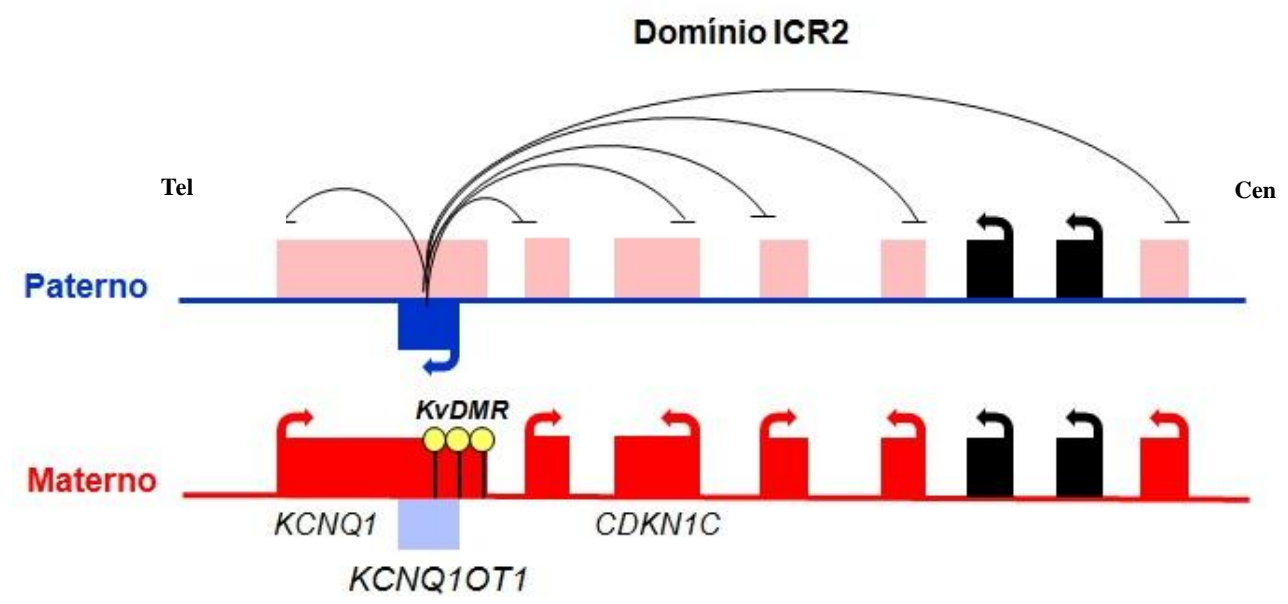

Figura I.9 - Regulação do imprinting genômico no domínio ICR2 do cromossomo humano 11p15. Os genes representados por blocos azuis têm expressão paterna e, por blocos vermelhos/cor de rosa têm expressão materna; a transcrição desses genes está indicada pelas flechas. A metilação da ICR2 $(K v D M R 1)$ está indicada pelos círculos amarelos. 
O modelo mais aceito para explicar o estabelecimento do imprinting genômico no domínio ICR2 é aquele em que o transcrito paterno de KCNQ1OT1 seria um regulador da expressão gênica ao interagir com a cromatina. Dessa forma, o próprio ncRNA seria responsável pelo silenciamento em cis de todos os genes sujeitos a imprinting no domínio, por desencadear a propagação bidirecional da heterocromatização, à semelhança do ncRNA XIST no processo de inativação do cromossomo X (revisão em Malecová e Morris, 2010). Esse modelo encontra apoio em estudo de células de galinha contendo cromossomos humanos com deleção restrita à $K v D M R 1$ no alelo paterno, que leva à perda do imprinting no domínio ICR2 e consequentemente, ausência da expressão de KCNQ1OT1 e ativação de genes que deveriam ser expressos somente no cromossomo materno, como KCNQ1 e CDKN1C (Horike e col., 2000). Outros modelos foram propostos para explicar a regulação de domínios sujeitos a imprinting por ncRNA, mas nenhum foi comprovado experimentalmente. Admite-se até a possibilidade de que a ICR2 (KvDMRI) seja um regulador molecular complexo e utilize mais de um mecanismo para silenciar genes sujeitos a imprinting nesse domínio (revisão em Pauler e col., 2007).

No cromossomo materno, em contrapartida, a metilação da ICR2 (KvDMRl) reprime a atividade de KCNQ1OT1, o que permite a expressão de vários genes de expressão materna, incluindo $K C N Q 1$ e $C D K N 1 C$ (revisão em Verona e col., 2003).

Em resumo, a manutenção da metilação diferencial na ICR2 (KvDMRl) assegura a expressão monoalélica paterna do gene KCNQ1OT1 e a expressão monoalélica materna dos demais genes sujeitos a imprinting do domínio, na maioria dos tecidos de mamíferos.

\section{I.3.2.1 Alterações (epi)genéticas em 11 15 na síndrome de Beckwith-Wiedemann} (BWS)

A síndrome de Beckwith-Wiedemann, descrita em 1963 (Beckwith, 1963; Wiedemann, 1964), é caracterizada principalmente por crescimento intrauterino exacerbado, macroglossia, assimetria corporal, onfalocele, hérnia umbilical, visceromegalia, predisposição elevada a desenvolver tumores embrionários (tumor de Wilm's e hepatoblastoma), entre outros sinais e sintomas menos frequentes. A BWS apresenta quadro clínico heterogêneo e ocorre em geral de forma isolada (aproximadamente $85 \%$ dos casos), com transmissão familial em cerca de $15 \%$ dos 
casos. A incidência da BWS foi estimada em 1 a cada 14 mil nascimentos (revisão em Weksberg e col., 2010).

A desregulação do imprinting genômico nos domínios ICR1 e ICR2 em 11p15 resulta no fenótipo da BWS principalmente por modificações epigenéticas; além disso, podem ocorrer UPD, duplicações, microdeleções, inversões, translocações e mutações no gene CDKN1C (Figura I.10).

Os primeiros casos de BWS associados a alterações no braço curto do cromossomo 11 foram descritos por Waziri e col. (1983), que identificaram uma duplicação parcial de 11p em dois pacientes não aparentados, que apresentavam características típicas da BWS e revisaram outros seis casos de duplicações semelhantes em indivíduos cujos quadros eram sugestivos de BWS (Figura I.10A). Um ano depois, Turleau e col. (1984) relataram outros dois pacientes não aparentados com diagnóstico de BWS e portadores de duplicação de 11p15 de origem paterna. Outra evidência da participação de alterações do cromossomo 11 paterno na determinação da BWS veio da descrição de três pacientes que apresentavam patUPD(11p15), dentre oito que constituíam casos esporádicos da BWS (Figura I.10B) (Henry e col., 1991).

A ocorrência de duplicações e UPD de 11p15, somente de origem paterna, associadas ao quadro clínico da BWS apoiaram a proposta de que havia desequilíbrio na participação de alelos maternos e paternos na determinação do fenótipo, indicando a participação do imprinting genômico.

Camundongos transgênicos que superexpressam Igf2 apresentaram fenótipo que inclui excesso de crescimento pré-natal e macroglossia, entre outras características (Sun e col., 1997). Uma vez que o gene IGF2 está sujeito a imprinting em camundongos sugeriu-se que, em humanos, a duplicação paterna do domínio ICR1 levaria à expressão bialélica de IGF2 em determinados tecidos, o que explicaria o fenótipo de crescimento exacerbado na BWS. Weksberg e col. (1993) demonstraram que o gene IGF2 estava de fato associado à BWS, ao estudar seu padrão de expressão em fibroblastos derivados de pele: as células de indivíduos controle tinham expressão monoalélica, enquanto os fibroblastos de quatro dentre seis pacientes com BWS apresentaram expressão bialélica de $I G F 2$. 


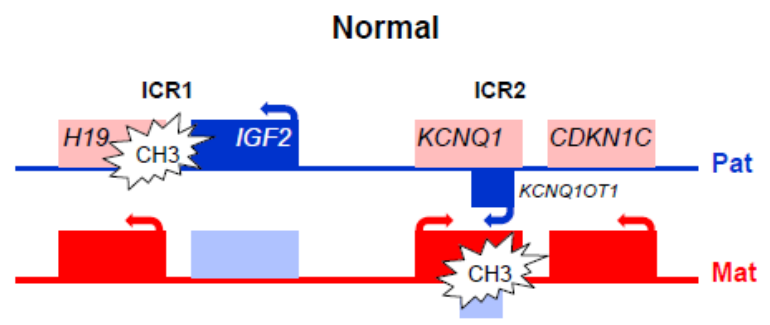

A) Duplicação paterna de 11p15

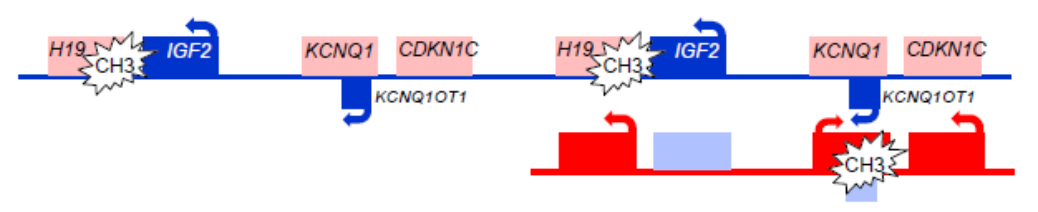

B) patUPD(11)

D) Hipermetilação de ICR1
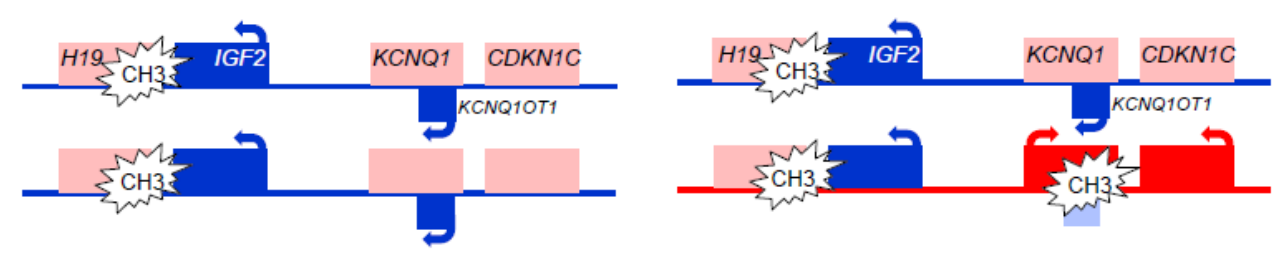

C) Mutação materna de CDKN1C

E) Hipometilação de ICR2
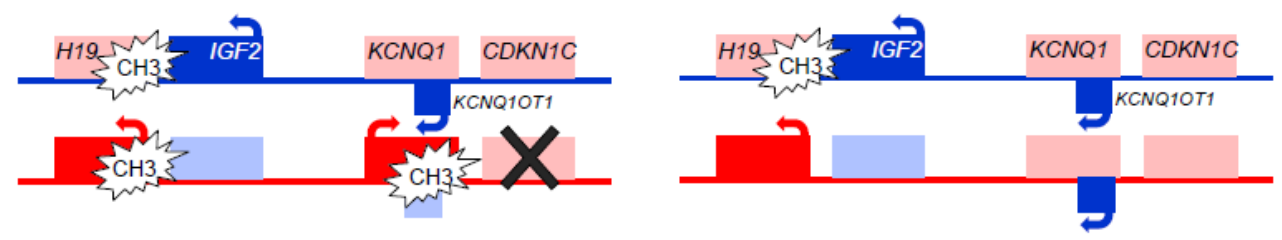

Figura I.10 - Alterações (epi)genéticas em 11p15, associadas à BWS.

Brown e col. (1996) relataram uma inversão cromossômica de origem materna, com um dos pontos de quebra em 11p15, em duas crianças afetadas pela BWS, levando à perda de imprinting do alelo materno da ICR1 (H19DMR). Essa alteração cromossômica resultava assim na expressão bialélica de $I G F 2$, semelhante ao que ocorria nas duplicações e UPD paternas de 11p15, além do silenciamento do alelo materno de H19. A perda do imprinting genômico na ICR1 poderia também explicar o fenótipo dos pacientes com BWS que herdaram de suas mães alterações cromossômicas estruturais com ponto de quebra próximo ao gene IGF2 (Norman e col., 1992; Tommerup e col., 1993). 
Estudos em camundongos mostraram que deleções de ICR1 (H19DMR), de herança materna, resultavam na perda de imprinting e, consequentemente, ganho de função do alelo materno de $I g f 2$. Os camundongos portadores dessas deleções apresentavam aumento da massa corpórea (Leighton e col., 1995; Thorvaldsen e col., 1998). Cinco pacientes com BWS foram relatados apresentando microdeleções em ICR1 (H19DMR) de origem materna, que abrangiam 1,8 a 2,2 Kb (Sparago e col., 2004; Prawitt e col., 2005). De modo semelhante ao que ocorria nos camundongos, o alelo materno de IGF2 estava ativo, decorrente da perda de imprinting na ICR1, e a expressão elevada de $I G F 2$ podia explicar o fenótipo dos pacientes.

A participação do domínio ICR2 na síndrome de Beckwith-Wiedemann foi demonstrada pela primeira vez por Hatada e col. (1996), que sequenciaram a região codificadora do gene CDKN1C em nove pacientes com BWS e detectaram, em dois deles, mutações de troca de sentido e de mudança de quadro de leitura. A mutação de troca de sentido foi transmitida pela mãe e, portanto, no paciente, o alelo materno estava mutado e o alelo paterno estava normalmente silenciado, devido ao imprinting genômico. No outro paciente, os autores mostraram que havia redução da expressão de $C D K N 1 C$ em tecido de glândula adrenal. Assim, concluíram que havia pouco ou nenhum produto do gene CDKN1C nos pacientes portadores de mutações, que provavelmente era responsável pelo fenótipo de crescimento exacerbado. Posteriormente, outros estudos comprovaram a associação entre mutações do gene $C D K N 1 C$ no cromossomo materno e o fenótipo da BWS (Figura I.10C), sendo frequente entre os casos familiais (Lam e col., 1999).

A primeira indicação da existência de mutações epigenéticas na BWS veio de estudo realizado por Reik e col. (1995), que identificaram, em pacientes com BWS, alteração no padrão de metilação dos genes IGF2 e H19, em que o cromossomo materno continha as marcas de imprinting do cromossomo paterno; esses pacientes não haviam herdado qualquer alteração cromossômica equilibrada ou que afetasse o número de cópias de DNA do segmento. Analisando fibroblastos dos pacientes, os autores mostraram que o gene $I G F 2$ tinha expressão bialélica e que o H19 não era expresso, padrão compatível com o ganho de metilação no alelo materno de ICR1 (H19DMR) (Figura I.10D).

Bliek e col. (2001) estudaram o padrão de metilação de ambas as ICR, em 115 pacientes com diagnóstico clínico de BWS, e os classificaram em quatro grupos de acordo com o tipo de 
alteração: (1) 20\% dos pacientes apresentaram patUPD segmentar que incluía 11p15, e portanto metilação alterada de ICR1 e ICR2 (Figura I.10B); (2) 7\% tinham hipermetilação de ICR1 (Figura I.10D); (3) 55\% possuíam hipometilação de ICR2 (Figura I.10E) e (4) 18\% dos pacientes não apresentaram alterações de metilação nas ICR em 11p15.

A hipometilação de ICR2 (KvDMRl) (Figura I.10E) está associada com a expressão bialélica do gene KCNQ1OT1 e a diminuição na expressão de CDKN1C (Delaval e col., 2006). A redução na expressão desse gene foi comprovada anteriormente em fibroblastos de pacientes com BWS, em que havia hipometilação de ICR2 (Diaz-Meyer e col., 2003).

Desde o trabalho de Bliek e col. (2001) até hoje, vários estudos contribuíram para determinar as frequências das alterações (epi)genéticas na BWS. A distribuição mais recente é mostrada na Figura I.11 (revisão em Weksberg e col., 2010).

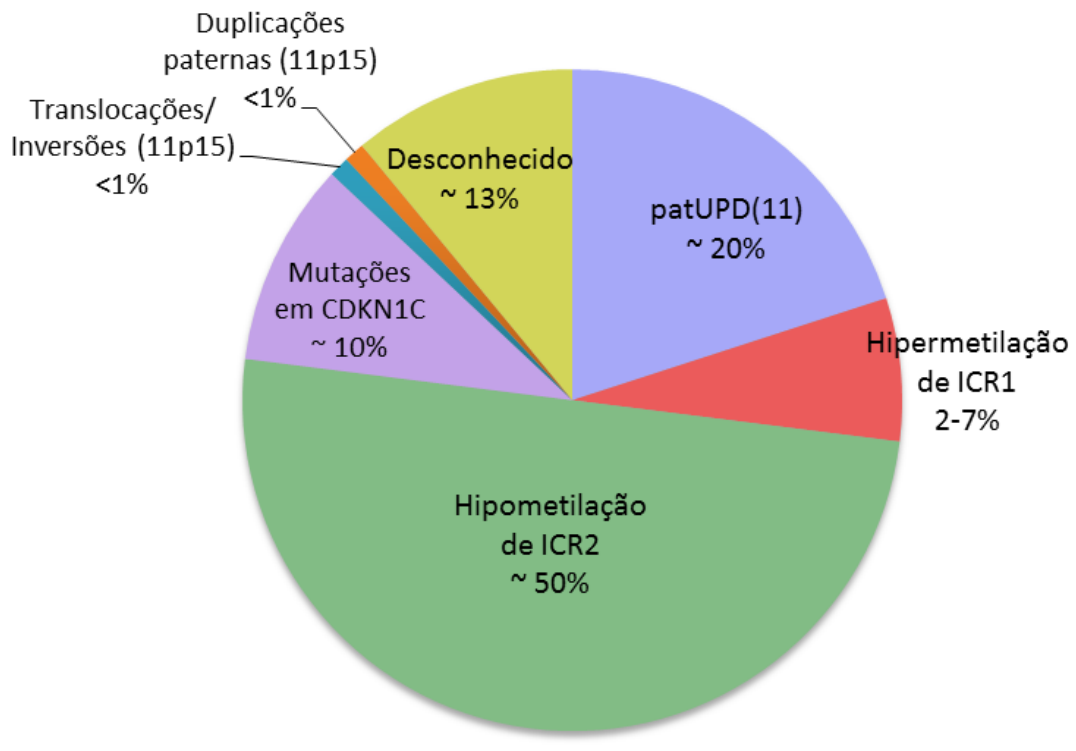

Figura I.11 - Frequência das mutações (epi)genéticas na síndrome de Beckwith-Wiedemann (adaptada de Weksberg e col., 2010). 


\section{I.3.2.2 Alterações (epi)genéticas em 11p15 na SRS}

\section{Alterações do domínio ICRI}

O primeiro indício de que os domínios sujeitos a imprinting no braço curto do cromossomo 11 estariam relacionados também com a etiologia da síndrome de Silver-Russell veio da descrição de três pacientes portadores de duplicação de origem materna em 11p15, associada a retardo de crescimento e características dismórficas (Figura I.12A) (Fisher e col., 2002). Posteriormente, Eggermann e col. (2005) relataram dois outros pacientes com características típicas da SRS, apresentando duplicação materna da região 11p15, num total de 46 pacientes investigados.

Uma vez que a associação entre alteração do crescimento e modificações no padrão de metilação em 11 p15 já era bem conhecida em pacientes com BWS, foi postulado que a hipometilação de ICR1 $(H 19 D M R)$, que resultasse na alteração da expressão do gene $I G F 2$, poderia ser um dos mecanismos moleculares responsáveis pela SRS (Gicquel e col., 2005). O

primeiro estudo que abordou a questão foi conduzido por Gicquel e col. (2005), no qual foram descritos cinco, de um total de nove pacientes diagnosticados com SRS, que apresentaram hipometilação em vários sítios do domínio ICR1, como no promotor do gene H19 e na ICR1 (H19DMR) (Figura I.12B). A investigação do padrão de metilação no domínio ICR2 não revelou alterações. Portanto, os autores concluíram que a hipometilação da ICR1 em 11p15 poderia ser causa importante da SRS.

A hipometilação de ICR1 na SRS é um mecanismo molecular oposto àquele encontrado na BWS, em que ocorre a hipermetilação desse centro. No entanto, o pequeno número de casos estudados por Gicquel e col. (2005) não permitiu determinar a frequência dessa alteração epigenética na SRS. Os estudos que se sucederam avaliaram um número maior de pacientes e verificou-se que a hipometilação de ICR1 ocorria em pelo menos 30\% dos casos de SRS. Eggermann e col. (2006) investigaram 51 pacientes com diagnóstico clínico de SRS, quanto a alterações no padrão de metilação dos domínios ICR1 e ICR2: 16 (31\%) apresentaram hipometilação de ICR1, mas nenhuma alteração no domínio ICR2 foi detectada. Combinando 
esses dados com aqueles das duplicações maternas em 11p15, os autores concluíram que cerca de $35 \%$ dos casos de SRS estavam associados com mutações (epi)genéticas em 11p15.

Nos anos seguintes, diversos estudos corroboraram esses achados, muitos deles utilizando critérios mais rigorosos para diagnosticar clinicamente pacientes com SRS, e firmou-se que a hipometilação de ICR1 em 11p15 é a causa genética prevalente da SRS, presente em pelo menos $40 \%$ dos casos. A Tabela I.2 lista os estudos que fizeram essa investigação desde o ano de 2005. A variação observada na frequência de pacientes com hipometilação de ICR1, de um trabalho para o outro, é decorrente do uso de critérios diferentes para diagnosticar clinicamente os pacientes com SRS, mas pode ser explicada, em parte, pelas diferentes técnicas moleculares utilizadas para detectar alterações epigenéticas (Bartholdi e col., 2009).

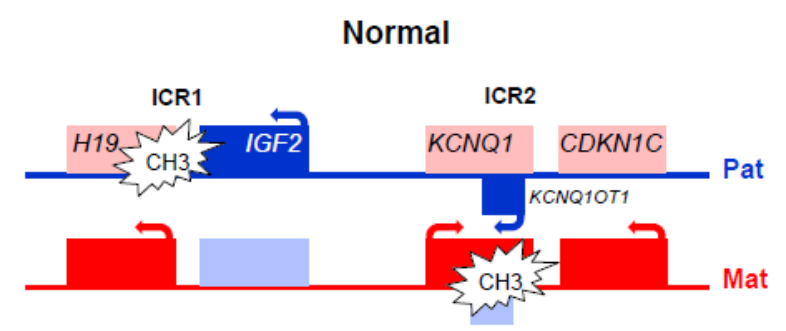

A) Duplicação materna de 11p15

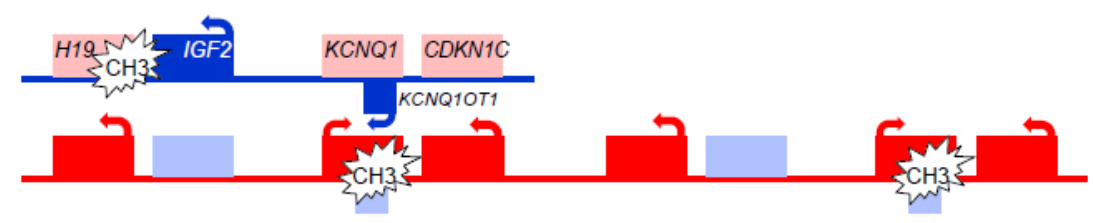

B) Hipometilação de ICR1

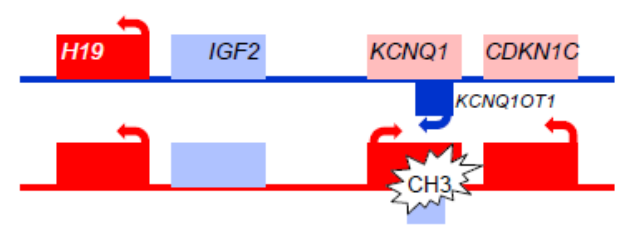

C) matUPD(11)

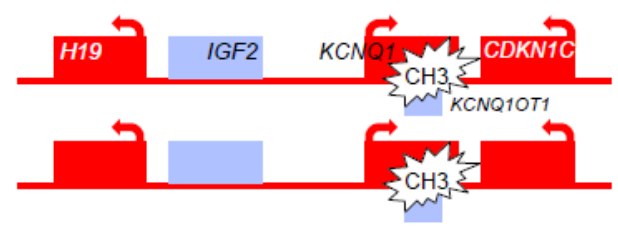

Figura I.12 - Alterações (epi)genéticas em 11p15, associadas à SRS. 
A hipometilação de ICR1 aparece restrita aos pacientes com quadro clínico da SRS e não está presente em pacientes com características isoladas, como retardo de crescimento ou assimetria corporal (Schönherr e col., 2006; Netchine e col., 2007; Binder e col., 2008; Eggermann e col., 2008b; Bartholdi e col., 2009; Eggermann e col., 2009a) Somente Bliek e col. (2006) relataram a presença de hipometilação de ICR1 em cinco pacientes com retardo de crescimento e assimetria corporal sem outras características da SRS.

Como foi enfatizado nos estudos da BWS, o gene $I G F 2$, de expressão monoalélica paterna, tem papel crucial no crescimento fetal. Em teoria, a hipometilação de ICR1 na SRS afeta a atividade dos genes $I G F 2$ e H19 (Figura I.12B), resultando na ativação de H19 no alelo paterno e na diminuição da expressão de $I G F 2$ em determinados tecidos, potencialmente relacionada ao fenótipo de retardo de crescimento. As primeiras evidências do papel fisiológico do produto do gene IGF2 no crescimento embrionário vieram de estudos em camundongos heterozigotos quanto a uma mutação no gene Igf2 (DeChiara e col., 1990; DeChiara e col., 1991). Quando a mutação tinha herança paterna, os camundongos apresentavam tamanho corpóreo cerca de $60 \%$ menor do que o normal. Fenótipo semelhante foi observado em camundongos portadores de deleções na ICR1 (H19DMR) de origem paterna, que provavelmente eram responsáveis pela perda de imprinting e consequentemente, pelo silenciamento do alelo paterno de Igf2, paralelamente à expressão do gene H19 (Thorvaldsen e col., 1998).

Recentemente, foram descritos três pacientes com SRS apresentando rearranjos cromossômicos próximos a ICR1 em 11p15 (Gronskov e col., 2011). O primeiro paciente era portador de uma microdeleção de 58,8 $\mathrm{Kb}$ no cromossomo paterno, em mosaico, abrangendo parte de ICR1, o gene H19, dois enhancers de IGF2 (endodérmico e de músculo esquelético) e parte de seu enhancer mesodérmico, localizados downstream de H19. Ele também apresentava hipometilação de ICR1, provavelmente uma consequência da microdeleção. Dois outros pacientes, irmãos, herdaram de seu pai normal uma inversão pericêntrica inv(11)(p15.5q21), associada a uma microdeleção de $8,8 \mathrm{~Kb}$, com ponto de quebra localizado na porção proximal do enhancer mesodérmico de IGF2. A separação do gene IGF2 de seu enhancer mesodérmico, como consequência da inversão cromossômica, é uma explicação para o fenótipo dos pacientes. Os autores ainda relataram um paciente com retardo de crescimento intrauterino isolado, portador de translocação equilibrada $\mathrm{t}(1 ; 11)(\mathrm{p} 36.22 ; \mathrm{p} 15.5)$, de origem paterna inferida, com ponto de 
quebra localizado no enhancer mesodérmico de $I G F 2$. Os quatro pacientes apresentaram ainda hipometilação de IGF2P0, localizado no promotor do gene IGF2, alteração descrita anteriormente em dois pacientes com SRS (Bartholdi e col., 2009). Essa perda de metilação pode ter sido consequência dos rearranjos cromossômicos que afetaram os enhancers de $I G F 2$. Ainda não se sabe até que ponto a alteração de metilação no promotor de $I G F 2$ contribui para o fenótipo da SRS.

Tabela I.2 - Frequência de hipometilação de ICR1 na SRS, em estudos desde 2005 (adaptada de AbuAmero e col., 2010).

\begin{tabular}{|c|c|c|}
\hline $\begin{array}{l}\text { Número de pacientes } \\
\text { investigados }\end{array}$ & $\begin{array}{l}\text { Número de pacientes com hipometilação } \\
\text { de ICR1 (frequência) }\end{array}$ & Referência \\
\hline 9 & $5(55 \%)$ & Gicquel e col. (2005) \\
\hline 25 & $5(25 \%)$ & Schönherr e col. (2006) \\
\hline 51 & $16(31 \%)$ & Eggermann e col. (2006) \\
\hline 9 & $4(44 \%)$ & Binder e col. (2006) \\
\hline 58 & $37(64 \%)$ & Netchine e col. (2007) \\
\hline 44 & $19(43 \%)$ & Binder e col. (2008) \\
\hline 60 & $20(33 \%)$ & Yamazawa e col. (2008a) \\
\hline $\begin{array}{l}201 \text { com suspeita de SRS* } \\
106 \text { com diagnóstico de SRS }\end{array}$ & $\begin{array}{l}46(23 \%) * \\
42(40 \%)\end{array}$ & Bartholdi e col. (2009) \\
\hline 42 & $26(62 \%)$ & Bruce e col. (2009) \\
\hline 64 & $15(24 \%)$ & Abu-Amero e col. (2010) \\
\hline 34 & $21(62 \%)$ & Turner e col. (2010) \\
\hline 34 & $13(38 \%)$ & Lin e col. (2010) \\
\hline 35 & $13(37 \%)$ & Penãherrera e col. (2010) \\
\hline Total $=571$ & $236(41 \%)$ & \\
\hline
\end{tabular}

*valores não incluídos no total.

À medida que se expandia o conhecimento sobre as causas genéticas da SRS e da BWS, uma questão importante era como as alterações no padrão de metilação surgiam nos pacientes. As hipóteses eram que as alterações epigenéticas resultariam da deficiência na aquisição da metilação durante a gametogênese ou da não manutenção da metilação, após a fertilização. Geralmente, a perda da metilação de ICR1 é parcial nos pacientes com SRS, sugerindo que essa alteração epigenética ocorra após a fertilização e resulte em uma distribuição em mosaico durante 
o desenvolvimento (Gicquel e col., 2005). Essa interpretação encontra apoio na identificação de alguns pares de gêmeos monozigóticos discordantes quanto ao fenótipo de SRS ou BWS e à alteração de metilação correspondente (Yamazawa e col., 2008b; Eggermann, 2010a).

Foi demonstrado que a hipometilação de ICR1 em pacientes com SRS está associada à diminuição na expressão do gene IGF2 em fibroblastos (Gicquel e col., 2005), porém a quantidade de IGF2 no soro de portadores dessa mutação epigenética é aparentemente normal (Binder e col., 2006; Netchine e col., 2007). O gene IGF2 apresenta diferentes promotores, tecido-específicos, com expressão regulada de acordo com o estágio de desenvolvimento (van Dijk e col., 1992); permanece sujeito a imprinting após o nascimento e sua expressão é monoalélica em alguns tecidos. A dose de IGF2 no soro, após o nascimento, é compatível com aquela de origem hepática, que resulta da expressão bialélica de $I G F 2$ no fígado, possivelmente regulada por um promotor que independe do padrão de metilação de ICR1 (Yamazawa e col., 2008a). Isso pode explicar a quantidade inalterada de IGF2 no soro de pacientes com hipometilação de ICR1. Além disso, nos pacientes com SRS a produção de IGF2 pode variar, dependendo da distribuição do mosaicismo da mutação epigenética (Netchine e col., 2007).

Por outro lado, existe evidência robusta de que IGF2 é mais importante para o crescimento fetal do que para o pós-natal, sendo a placenta a principal fonte de produção de IGF2 durante a gestação. Yamazawa e col. (2008a) mostraram que as placentas de três pacientes com SRS e hipometilação de ICR1 apresentavam diminuição na expressão de $I G F 2$.

\section{Alterações do domínio ICR2}

As alterações na região 11p15 não estão restritas ao domínio ICR1 nos pacientes com SRS. Pelo menos nove casos de duplicações de 11p15 de origem materna que incluem os domínios ICR1 e ICR2 foram descritos em pacientes com SRS, alguns familiais (Figura I.12A) (Fisher e col., 2002; Eggermann e col., 2005; South e col., 2008; Bliek e col., 2009; Eggermann e col., 2009a; Eggermann e col., 2010b) e há um relato de paciente com duplicação materna de um segmento que continha o domínio ICR2, mas não o ICR1 (Schönherr e col., 2007). Esses achados levaram à conclusão de que a superexpressão de um ou mais genes presentes no domínio ICR2 era responsável pelo fenótipo dos pacientes. A perda de função do gene $C D K N 1 C$ por 
mutação de ponto no alelo materno é responsável por cerca de $10 \%$ dos casos de BWS. Considerando seu efeito negativo sobre o crescimento e por ter apenas o alelo materno expresso na maioria dos tecidos, o gene $C D K N 1 C$ foi considerado forte candidato para o fenótipo da SRS naqueles pacientes que herdaram duplicações maternas do cromossomo 11 abrangendo o domínio ICR2. Foi demonstrado que a superexpressão de $C d k n 1 c$ em camundongos leva à parada do ciclo celular na fase G1 (Fisher e col., 2002). Além disso, a deleção da ICR2 (KvDMRl) de origem paterna em camundongos resulta na ativação dos genes do domínio ICR2 que antes estavam reprimidos no cromossomo paterno; os camundongos que herdaram essa deleção apresentaram expressão bialélica de Cdknlc e eram 20-25\% menores que os controles selvagens (Fitzpatrick e col., 2002). Portanto, a superexpressão do gene $C D K N 1 C$ pode explicar o retardo de crescimento nos pacientes com SRS.

$\operatorname{mat} U P D(11)$

Diante da frequência elevada da dissomia uniparental paterna do cromossomo 11 entre os indivíduos com BWS (10-20\%), era possível que a alteração genética oposta, ou seja, a matUPD(11), estivesse presente em pacientes com SRS. Apenas um estudo detectou matUPD(11), em mosaico, em um paciente com diagnóstico clínico da SRS (Figura I.12C) (Bullman e col., 2008). Nele foi detectada leve hipometilação de ICR1 e hipermetilação de ICR2, tanto em amostras de sangue como de células de mucosa oral, resultado compatível com a presença de matUPD(11) em mosaico. Os autores sugeriram que a matUPD(11) em mosaico possa ser uma causa genética da SRS mais comum do que aparenta, sendo sua detecção difícil por motivos técnicos ou porque frequentemente está presente em outros tecidos que não o sangue periférico, o mais utilizado nos testes genéticos. Entretanto, deve-se considerar que a desregulação simultânea dos domínios ICR1 e ICR2 (duas cópias maternas e nenhuma paterna) resultaria na expressão bialélica de $C D K N 1 C$ e na ausência da expressão de $I G F 2$, uma combinação que, quando presente em determinados tecidos, pode ser letal, devido ao efeito drástico de supressão do crescimento.

Erros da disjunção cromossômica ocorrem com maior frequência na formação dos gametas femininos e erros pós-zigóticos afetam cromossomos paternos e maternos com igual 
frequência. Isso contraria a menor frequência de matUPD(11) na SRS em relação a patUPD(11) na BWS. A seleção contra os conceptos portadores de matUPD(11), devido à restrição no crescimento, é uma explicação possível.

Levando em consideração a importância dos genes IGF2 e CDKN1C na etiologia da SRS, um estudo investigou 40 pacientes na busca de mutações nesses dois genes. No entanto, nenhuma variante com importância funcional foi detectada, excluindo esse tipo de alteração genética como causa comum da SRS (Obermann e col., 2004).

A Tabela I.3 resume os dados sobre frequências de mutações (epi)genéticas em 11p15, na SRS e na BWS.

Tabela I.3 - Frequências das mutações (epi)genéticas em 11p15 na SRS e na BWS.

\begin{tabular}{|lll|}
\hline Tipo de mutação (epi)genética em 11p15 & Frequência na SRS & Frequência na BWS \\
\hline Duplicação de 11p15 & $1-2 \%$ (mat) & $1-2 \%$ (pat) \\
\hline UPD 11p15 & 1 caso (mat) & $10-20 \%$ (pat) \\
\hline Mutação epigenética na ICR1 $(H 19 D M R)$ & $\sim 41 \%$ & $2-7 \%$ \\
\hline Mutação epigenética na ICR2 $(K v D M R I)$ & 0 & $50 \%$ \\
\hline
\end{tabular}

Em resumo, as mutações epigenéticas em 11p15 nos pacientes com diagnóstico clínico de SRS são restritas à ICR1, sendo a hipometilação detectada em pelo menos $40 \%$ dos afetados. A matUPD(11), que leva à alteração de ambas as ICR em 11p15, foi relatada, em mosaico, em um único paciente e não há descrição de mutação epigenética restrita à ICR2 em pacientes com SRS. O mecanismo responsável pela perda de metilação de ICR1 (SRS) e de ICR2 (BWS), ou ganho de metilação de ICR1 (BWS), ainda é desconhecido. Duplicações de origem materna abrangendo a região 11p15 em pacientes com SRS mostraram que alterações genéticas do domínio ICR2 também devem ser consideradas para a etiologia da síndrome. A diminuição da expressão do gene $I G F 2$ ou a superexpressão de $C D K N 1 C$ aparecem como as alterações moleculares para explicar o fenótipo dos pacientes com SRS. 


\section{I.3.3 Hipometilação em múltiplos lócus sujeitos a imprinting na SRS}

Nas doenças relacionadas a alteração do imprinting, observa-se alteração de metilação ou mutação em lócus específicos como causa dessas condições. Assim, foi surpreendente que pacientes com diabetes melito neonatal transitória (TNDM) possam apresentar hipometilação em outros lócus sujeitos a imprinting além da alteração em 6q24, específica dessa doença. Fenotipicamente, pacientes com TNDM e hipometilação em múltiplos lócus apresentam peso médio ao nascer ligeiramente maior do que aqueles que possuem alterações restritas a 6q24, alguns apresentando ainda características clínicas atípicas da TNDM (Mackay e Temple, 2010). Recentemente, mostrou-se que a alteração de metilação em múltiplos lócus não ocorre exclusivamente na TNDM, com a descrição de pacientes com BWS e SRS que apresentavam hipometilação em múltiplos lócus, além dos defeitos epigenéticos em 11p15.

Azzi e col. (2009) investigaram 99 pacientes com SRS quanto ao padrão de metilação em sete lócus sujeitos a imprinting previamente associados com doenças humanas, cinco deles metilados no cromossomo materno e dois no paterno. Dentre 74 pacientes com hipometilação de ICR1, sete $(9,5 \%)$ apresentaram hipometilação em outros lócus. Regiões sujeitas a imprinting genômico materno ou paterno estavam alteradas nos linfócitos desses pacientes. Nenhum dos 25 pacientes com padrão de metilação normal em 11p15 apresentou alteração de metilação em outros lócus. Em estudo posterior, onze lócus sujeitos a imprinting genômico foram analisados em 34 pacientes com SRS (Turner e col., 2010); dentre 21 pacientes com hipometilação de ICR1, quatro (19\%) apresentaram alteração de metilação em outros lócus. Nesses estudos, nenhuma diferença fenotípica marcante entre os pacientes com SRS e hipometilação em múltiplos loci e aqueles com hipometilação restrita ao ICR1 foi observada. Portanto, o significado dessas alterações de metilação em múltiplos loci em uma parcela dos pacientes com SRS não está claro.

Uma descoberta interessante foi que cerca de $4 \%$ dos pacientes com SRS e hipometilação de ICR1 apresentam também hipometilação de ICR2 no cromossomo materno, alteração responsável por metade dos casos de BWS (Azzi e col., 2009; Turner e col., 2010; Begemann e col., 2010). Além disso, já foram descritos pacientes com BWS e perda da metilação em ambas as ICR. 
Dada à coexistência de hipometilação em lócus maternos e paternos e à ocorrência em mosaico dessas alterações epigenéticas, Azzi e col. (2009) as consideram como apoio à hipótese de que esses defeitos de metilação em múltiplos lócus ocorram após a fertilização e estejam relacionados a defeitos de manutenção do imprinting parental. Os autores não descartam, entretanto, a possibilidade da participação de fatores gaméticos na manutenção do imprinting pós-zigótico. Não se sabe ainda se o mecanismo responsável pelo erro epigenético em pacientes com defeito de metilação em múltiplos lócus ou restrito a um único lócus é o mesmo. A observação de graus variados de hipo ou hipermetilação em indivíduos com defeito de metilação em múltiplos lócus foi considerada evidência de que o mecanismo é o mesmo nos dois grupos de pacientes. Sendo assim, apenas a expressão do defeito epigenético seria variável, indo desde a alteração em lócus mais suscetíveis, como 11p15 e 6q24, até alterações mais globais (Rossignol e col., 2006). É possível que erros de metilação, que alterem inúmeros lócus, não sejam viáveis.

\section{I.3.4 Outras alterações cromossômicas em pacientes com SRS}

A maioria dos pacientes com SRS tem cariótipo normal. No entanto, em um pequeno número deles foram descritas alterações de cromossomos outros que não o 7 e o 11 .

Uma trissomia do cromossomo 18 em mosaico foi relatada em pacientes com quadro clínico sugestivo da SRS (SRS-like). Os pacientes apresentavam características típicas da SRS, como baixo peso ao nascer, baixa estatura e face triangular, além de outros sinais clínicos que se sobrepõem ao quadro da trissomia do cromossomo 18. Um paciente com quadro clínico SRS-like foi descrito apresentando uma deleção no braço longo do cromossomo 8 (8q11-13), de origem paterna. Ele possuía as principais características da SRS, mas era microcefálico e apresentava outras características não usuais na SRS. O mais provável é que esses pacientes com alterações nos cromossomos 8 e 18 sejam afetados por outras entidades clínicas, que compartilham algumas das características da SRS (revisão em Hitchins e col., 2001a).

Foram descritos pacientes com suspeita de SRS portadores de deleção na porção distal do braço longo do cromossomo 15 , associada ou não à presença de anel do cromossomo 15 . Além dos principais sinais da SRS, os pacientes apresentavam outras características, como microcefalia, hipertelorismo e deficiência mental, típicas da síndrome do anel de 15. Quando as 
deleções em 15q incluíam o gene IGF1R (insulin-like growth factor 1 receptor), que tem papel na regulação do crescimento e do desenvolvimento fetal e pós-natal, os pacientes apresentavam retardo grave de crescimento intrauterino e pós-natal. No entanto, trabalhos posteriores excluíram mutações nesse gene como causa frequente da SRS (revisão em Hitchins e col., 2001a).

Alterações no cromossomo 17 foram descritas em associação com a SRS: dois casos de translocações com pontos de quebra localizados em 17q24 ou 17q25 (revisão em Hitchins e col., 2001a) e outro com deleção do segmento 17q22-q24 de origem paterna (Eggermann e col., 1998). Genes localizados nessa região, como GRB2, GRB7 (growth factor receptor-bound protein 2 e 7), GH (growth hormone), CSH1 e CSH2 (chorionic somatomammotropin hormone 1 e 2) podem ter relação com o fenótipo da SRS. Mutações nesses genes foram excluídas como causa comum da síndrome (revisão em Hitchins e col., 2001a).

Fonseca (2005) descreveu uma translocação aparentemente equilibrada entre os cromossomos 5 e 6 em uma paciente com quadro clínico de SRS. Uma das quebras que originou a translocação interrompeu o gene CDKAL1 (cyclin-dependent kinase 5 regulatory subunit associated protein 1-like 1), que foi considerado candidato para a síndrome (ver item I.5).

Não está clara, portanto, a relação entre esses rearranjos cromossômicos e o fenótipo de SRS.

\section{I.3.5 Microrrearranjos cromossômicos em pacientes com SRS}

No passado, a investigação de microrrearranjos utilizando-se técnicas da citogenética convencional era dificultada pela baixa resolução. O desenvolvimento de técnicas baseadas em array para a cariotipagem molecular permite agora a identificação de desequilíbrios cromossômicos que antes não eram detectáveis. Nos últimos anos, as técnicas de hibridação genômica comparativa em microarray (a-CGH) ou de hibridação em microarray de SNP (singlenucleotide polymorphisms - polimorfismos de base única) têm sido utilizadas com sucesso em diversos estudos para detectar alteração no número de cópias de DNA (Copy Number Variation, CNV) em pacientes com cariótipo normal e quadros clínicos diversos (Krepischi-Santos e col., 2006; Shinawi e col., 2008; Edelmann e col., 2009). Normalmente as CNV patogênicas aparecem de novo. No entanto, sabe-se que as CNV podem estar presentes em indivíduos fenotipicamente 
normais e mesmo ocorrer com alta frequência na população, constituindo polimorfismos. Essas variantes estruturais são geralmente herdadas e podem abranger até $12 \%$ do genoma humano (Rendon e col., 2006). Um dos desafios atuais é descobrir como as CNV contribuem para a variabilidade genética, incluindo a patogênica (Shinawi e col., 2008; Edelmann e col., 2009).

A identificação de microrrearranjos recorrentes é importante para a caracterização de novas síndromes, indicando que um ou mais genes na região afetada são sensíveis à dosagem e, portanto, constituem candidatos aos quadros clínicos associados. Diversos estudos investigaram a frequência com que as alterações cromossômicas são identificadas por a-CGH em populações específicas de pacientes. Dentre os pacientes com deficiência mental, 8-17\% apresentaram microdeleções ou microduplicações de novo como as mais prováveis causas de seus fenótipos clínicos (Krepischi-Santos e col., 2006; Shinawi e col., 2008; Edelmann e col., 2009). Uma proporção menor dos pacientes (5-10\%) portava alterações não descritas anteriormente em indivíduos normais, mas que também estavam presentes em seus pais fenotipicamente normais. Resta determinar qual a proporção dessas alterações herdadas que representa variantes não patogênicas e qual é a proporção relacionada a fenótipos anormais, por mecanismos mais complexos de manifestação, como penetrância incompleta, expressividade variável, expressão de mutações recessivas ou imprinting genômico (Krepischi-Santos e col., 2006).

Recentemente, três estudos investigaram alterações submicroscópicas por microarray em pacientes com SRS. No primeiro deles (Bruce e col., 2010), dentre 12 pacientes em que foi afastada a matUPD(7) e alterações epigenéticas em 11p15, três apresentaram alterações submicroscópicas consideradas potencialmente patogênicas, em 15q26.3, 22q11.2 e na região pseudoautossômica do cromossomo X. No segmento 15q26.3 deletado, está mapeado o gene $I G F 1 R$, cuja função está associada ao crescimento celular. Deleções abrangendo esse gene foram descritas anteriormente em associação com o fenótipo da SRS (ver item I.3.4). No segmento 22q11.2, deletado em outro paciente, localiza-se o gene MAPK1 (mitogen-activated protein kinase 1), que pode estar relacionado à via IGF. Em outro trabalho (Spengler e col., 2010), 20 pacientes com SRS e causa genética desconhecida foram investigados e um deles apresentou uma microdeleção em 12q14, segmento no qual está mapeado o gene HMGA2 (high mobility group $A T$-hook 2), que já foi associado a retardo de crescimento. Em estudo mais recente (Lin e col., 2010), 34 pacientes com SRS foram investigados; dentre aqueles 21 com causa genética 
desconhecida, cinco apresentaram microdeleções de novo, potencialmente patogênicas, em diferentes cromossomos e abrangiam entre 1,3 e 10,7 Mb. Genes mapeados em três dessas microdeleções podem estar associados com o retardo de crescimento dos pacientes: IGF2BP3 (insulin-like growth factor 2 mRNA binding protein 3) em 7p15; GPC5 (glypican 5), em 13q31.3 e IGF1R, em 15q26.2.

A Figura I.13 resume as frequências das diferentes causas (epi)genéticas da SRS.

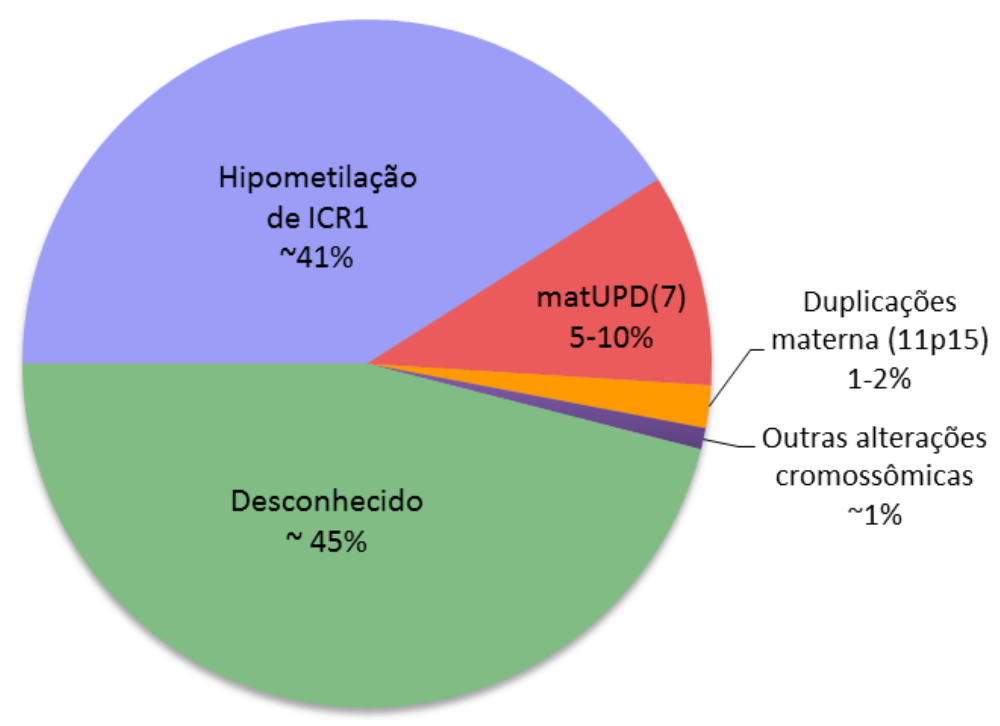

Figura I.13 - Frequência das mutações (epi)genéticas na SRS. 


\section{I.4 O gene CDKAL1 como candidato para a SRS}

Em estudo anterior no Laboratório de Genética Humana (LGH), IB-USP, Fonseca (2005) identificou uma translocação aparentemente equilibrada entre os cromossomos 5 e 6 em uma paciente com quadro clínico de SRS (Figura I.14). Uma das quebras que originou a translocação interrompia o gene CDKAL1 (cyclin-dependent kinase 5 regulatory subunit associated protein 1like 1), que foi considerado candidato para a síndrome. Esse gene está localizado em 6p22.3 e codifica uma proteína de $65-\mathrm{kD}$. A proteína CDKAL1 é evolutivamente conservada entre os eucariotos, apresentando pelo menos $90 \%$ de identidade com a proteína ortóloga em camundongo, boi e macaco. Apesar de apresentar menor identidade com as proteínas de peixe e drosófila, os dois domínios ativos da proteína são conservados (HomoloGene, NCBI). Em humanos, o mRNA de CDKAL1 foi detectado no cérebro, no músculo esquelético e nas ilhotas pancreáticas. Embora tenha função desconhecida, CDKAL1 compartilha um domínio com CDK5RAP1 (CDK5 regulatory subunit associated protein 1), uma proteína neural que inibe a ativação de CDK5 (cyclin-dependent kinase 5), necessária para o desenvolvimento do sistema nervoso central em mamíferos (Zeggini e col., 2007). O gene CDKAL1 não está sujeito a imprinting genômico, de acordo com os bancos de dados Catalogue of Parent of Origin Effects e Geneimprint. Estudos de associação identificaram diversos SNP em CDKAL1 que podem estar associados com o risco para diabetes tipo 2, por afetarem a secreção de insulina pelas célulasbeta pancreáticas (Stancáková e col., 2008).
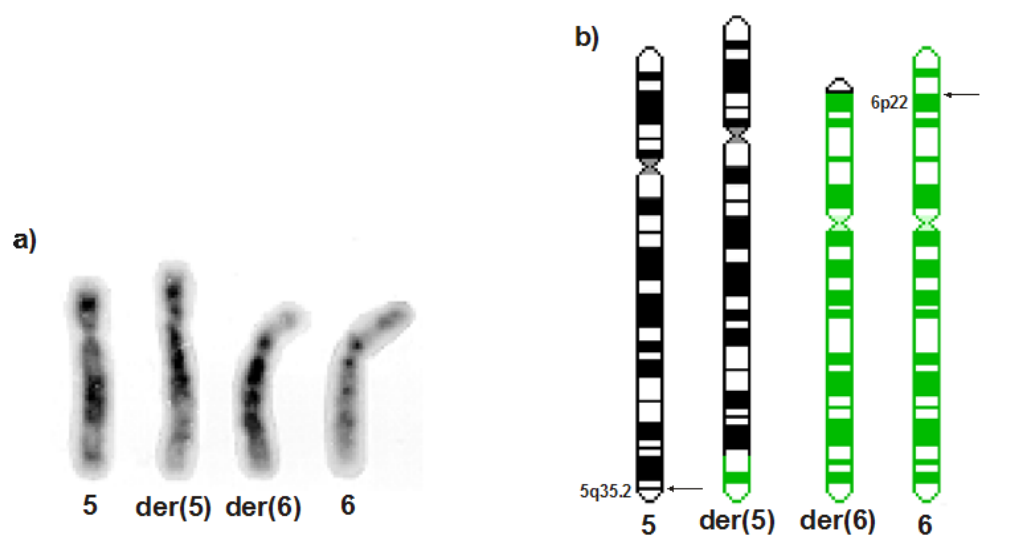

Figura I.14 - Translocação entre os cromossomos 5 e 6, que interrompeu o gene CDKAL1 no cromossomo 6, identificada em paciente com diagnóstico clínico da SRS (Fonseca, 2005). 


\section{I.5 Aspectos clínicos da SRS}

Devido à heterogeneidade clínica, existe certa dificuldade em se estabelecer critérios precisos para o diagnóstico clínico da síndrome de Silver-Russell. Diferentes grupos sugeriram

critérios para auxiliar no diagnóstico clínico da síndrome, mas a acurácia do diagnóstico é normalmente influenciada pela experiência do clínico.

Em 1999, Price e col. definiram um conjunto de sinais clínicos para o diagnóstico da SRS: (1) retardo de crescimento intrauterino (comprimento ou peso abaixo do $3^{\circ}$ percentil), (2) retardo de crescimento pós-natal (altura abaixo do $3^{\circ}$ percentil), (3) macrocrania relativa ao tamanho do corpo ao nascimento, (4) sinais faciais típicos e (5) assimetria corporal. Pacientes que apresentassem pelo menos quatro dessas características seriam considerados afetados pela SRS. Muitos dos estudos recentes utilizam esse critério de diagnóstico. No entanto, alguns autores consideram que o retardo de crescimento intrauterino é obrigatório para o diagnóstico clínico (Netchine e col., 2007; Yamazawa e col., 2008a), enquanto outros incluem também o retardo de crescimento pós-natal como característica diagnóstica mandatória (Binder e col., 2006; Eggermann e col., 2006).

Bartholdi e col. (2009) criaram um sistema de pontuação detalhado que leva em consideração uma maior quantidade de características clínicas, subdivididas em cinco grupos: parâmetros ao nascimento, desenvolvimento pós-natal, assimetria, características faciais e outras. Para cada grupo é dada uma nota de 0-3, de acordo com os sinais clínicos presentes, sendo 15 a pontuação máxima. Pacientes que atingem pelo menos oito pontos são classificados como SRS. Um critério mais rigoroso para diagnosticar os pacientes com SRS foi utilizado no estudo de Bruce e col. (2009): foram selecionados apenas aqueles que apresentaram retardo de crescimento intrauterino e pós-natal, macrocrania relativa, face típica com, no mínimo, três sinais da SRS e pelo menos mais uma característica clínica da SRS (assimetria corporal, clinodactilia de quinto dedo, atraso na aquisição da fala, entre outros).

Estudos que correlacionam genótipo e fenótipo mostraram que os pacientes com SRS podem ser divididos em diferentes subgrupos (Netchine e col., 2007; Kotzot, 2008; Bruce e col., 2010; Wakeling e col., 2010). Em geral, pacientes que apresentam hipometilação de ICR1 têm quadro clínico mais grave do que aqueles com matUPD(7) ou cuja causa genética é 
desconhecida. Eles tendem a apresentar retardo de crescimento intrauterino e pós-natal mais acentuado, face mais típica, com frontal amplo e, com maior frequência, possuem assimetria corporal, macrocrania relativa, clinodactilia de quintos dedos e anomalias congênitas diversas. Além disso, as placentas dos pacientes com SRS e hipometilação de ICR1 tendem a ser menores e mais frequentemente hipoplásicas, quando comparadas às dos pacientes sem o defeito de metilação em 11p15 (Yamazawa e col., 2008a). Por outro lado, o atraso na aquisição da fala, anomalias de orelhas e atraso global no desenvolvimento são características mais frequentemente observadas nos pacientes com matUPD(7). A idade materna está significativamente elevada nesse último subgrupo comparado aos outros, o que reflete o mecanismo de formação da dissomia uniparental materna, a partir de não disjunção meiótica. Apesar de existir certa correlação genótipo/fenótipo, o diagnóstico baseado apenas no quadro clínico ainda é difícil, uma vez que muitas características não são específicas de um grupo ou de outro. Além disso, os sinais clínicos são mais marcantes durante a infância, o que dificulta o diagnóstico de pacientes mais velhos.

Especulou-se que pacientes com fenótipo mais brando, nos quais não foi possível determinar a causa genética, podem ser portadores de defeitos de metilação em $11 \mathrm{p} 15 \mathrm{em}$ mosaico, cuja identificação pode escapar às análises no sangue periférico. A assimetria corporal, presente em mais de 50\% dos pacientes com SRS, seria uma manifestação do mosaicismo (Bartholdi e col., 2009; Eggermann e col., 2010c).

Alguns trabalhos relataram que o grau de hipometilação de ICR1 pode influenciar a gravidade do fenótipo; pacientes com grau de hipometilação maior podem, inclusive, apresentar alterações do desenvolvimento genital. No entanto, Wakeling e col. (2010) não observaram correlação significativa entre o grau de hipometilação de ICR1 e a gravidade do fenótipo. Essas análises podem ser dificultadas pela variação na distribuição do mosaicismo da hipometilação entre os diferentes tecidos. Além disso, a hipometilação em múltiplos lócus também pode contribuir para a variação clínica desses pacientes. 


\section{OBJETIVOS}




\section{OBJETIVOS}

Com a identificação da hipometilação de ICR1 em 11p15, matUPD(7) e desequilíbrios (sub)microscópicos, a confirmação molecular para o diagnóstico clínico da SRS tornou-se possível em aproximadamente $50 \%$ dos pacientes. Isso deixa metade dos casos com causa genética desconhecida. Neste estudo buscamos mecanismos genéticos que expliquem a SRS, além da matUPD(7) e das alterações de metilação em 11p15. Para isso, este trabalho compreendeu (a) a busca de genes ou regiões cromossômicas relacionadas à síndrome, investigando alterações cromossômicas submicroscópicas e (b) a avaliação da contribuição de mutações no gene candidato CDKAL1 para a SRS, em pacientes em que os mecanismos causais conhecidos foram afastados. 


\section{PACIENTES E MÉTODOS}




\section{PACIENTES E MÉTODOS}

\section{III.1 Pacientes}

Nossa amostra foi constituída por 64 pacientes brasileiros não aparentados (31 do sexo masculino e 33 do sexo feminino) com diagnóstico clínico da síndrome de Silver-Russell, 32 deles com estudo iniciado ou realizado durante nossa Iniciação Científica (Processo FAPESP 2007/04337-9). Em dois casos, havia outros afetados na família. Os pacientes ou o material para análise foram encaminhados por diferentes serviços médicos, a maioria pelo Instituto da Criança da Faculdade de Medicina da Universidade de São Paulo e pelo Laboratório de Genética Humana da Universidade de Brasília. O diagnóstico clínico baseou-se na presença obrigatória de grave retardo de crescimento intrauterino e pós-natal, face típica e pelo menos mais um sinal clínico da SRS.

Fomos solicitados pelos serviços médicos de encaminhamento para testar a hipótese diagnóstica de SRS, via testes genéticos. O exame cromossômico após bandamento $\mathrm{G}$ foi realizado, segundo a rotina do laboratório (LGH - IB-USP). O DNA foi extraído de leucócitos de sangue periférico, dos pacientes e de seus pais. A investigação incluiu a busca de alterações no cromossomo 11 (MS-MLPA) e de matUPD(7) (genotipagem de microssatélites) para afastar as causas mais comuns da SRS. Em pacientes em que essas alterações frequentes não foram detectadas, foi investigada a presença de microdeleções e microduplicações genômicas (a-CGH) e de mutações no gene candidato CDKAL1 (sequenciamento direto), objetivos deste estudo. Como as alterações de 11p15 são a causa mais frequente de SRS, planejamos iniciar o estudo por essa análise, seguida da investigação de matUPD(7). Entretanto, em alguns pacientes a UPD(7) já tinha sido investigada antes da análise do cromossomo 11.

Este estudo das causas genéticas da SRS foi aprovado pelo Comitê de Ética em Pesquisa - Seres Humanos do Instituto de Biociências - USP (CEP-IBUSP 098/2009) e o consentimento livre e esclarecido foi obtido dos responsáveis legais pelos pacientes. 


\section{III.2 Métodos}

O DNA foi extraído de leucócitos de sangue periférico, utilizando-se o aparelho Autopure LS (Gentra Systems, Minneapolis, USA). As amostras foram quantificadas utilizando-se o NanoDrop ND-1000 (Nanodrop Technologies, Rockland, USA).

\section{III.2.1 Investigação de alterações (epi)genéticas em $11 p 15$}

A análise da metilação nas regiões reguladoras do imprinting [ICR1 (H19DMR) e ICR2 $(K v D M R l)]$ do cromossomo 11 foi feita por MS-MLPA (Methylation-Specific Multiplex Ligation-dependent Probe Amplification), numa variação da técnica originalmente descrita por Nygren e col. (2005). Essa técnica permite, além da quantificação do número de cópias de DNA, verificar o padrão de metilação das regiões de interesse. Foram utilizados os kits SALSA MLPA ME030 BWS/RSS (2007), SALSA MLPA ME030-A1 BWS/RSS (2008), SALSA MLPA ME030-B1 BWS/RSS (2008) e SALSA MLPA ME030-B2 BWS/RSS (2009) (MRC Holland, Amsterdam, NE). O kit mais recente contém uma mistura de 45 sondas, 19 delas constituindo referências em cromossomos diversos e 26 específicas para a região SRS/BWS em 11p15, sendo que 11 contêm um sítio de reconhecimento para a enzima Hha I, sensível a metilação. Os kits anteriores são semelhantes ao atual, apenas com pequenas diferenças nas sondas e em sua nomenclatura. Todos os kits incluem os reagentes necessários para a reação do MS-MLPA.

Condições de hibridização e amplificação (de acordo com o fabricante): 100 ng DNA genômico foram diluídos em $5 \mu \mathrm{L}$ de TE (Tris $10 \mathrm{mM}$ - EDTA $1 \mathrm{mM}$ ) e desnaturados a $98^{\circ} \mathrm{C}$ por 10 min. Foram adicionados 1,5 $\mu \mathrm{L}$ de MLPA Buffer e 1,5 $\mu \mathrm{L}$ de SALSA probe mix, seguindo-se desnaturação a $95^{\circ} \mathrm{C}$ por 1 min e hibridação overnight a $60^{\circ} \mathrm{C}$ (entre 16-18 h). Após a hibridação, foram adicionados $10 \mu \mathrm{L}$ de $\mathrm{H}_{2} \mathrm{O}$ e $3 \mu \mathrm{L}$ de Ligase Buffer A, totalizando cerca de $20 \mu \mathrm{L}$. A amostra foi dividida em dois volumes iguais (10 $\mu \mathrm{L}$ cada), sendo uma parte submetida à ligação (tubo 1) e a outra, à ligação e digestão com a enzima Hha I (tubo 2). Uma mistura de 1,5 $\mu \mathrm{L}$ de Ligase Buffer $\mathrm{B}, 8,25 \mu \mathrm{L}$ de $\mathrm{H}_{2} \mathrm{O}$ e $0,25 \mu \mathrm{L}$ da enzima Ligase foi adicionada ao tubo 1 e uma mistura de $1,5 \mu \mathrm{L}$ de Ligase Buffer $\mathrm{B}, 7,75 \mu \mathrm{L}$ de $\mathrm{H}_{2} \mathrm{O}, 0,25 \mu \mathrm{L}$ da enzima Ligase e $0,5 \mu \mathrm{L}$ 
da enzima Hha I foi adicionada ao tubo 2. Os tubos foram incubados por $30 \mathrm{~min}$ a $49^{\circ} \mathrm{C}$ e $5 \mathrm{~min}$ a $98^{\circ}$ C. Em seguida, foi realizada a amplificação por PCR (Polymerase Chain Reaction Reação em cadeia de polimerase). Para o volume final de $25 \mu \mathrm{L}$, foram misturados $5 \mu \mathrm{L}$ da reação de ligação (tubo 1 ou 2), $2 \mu \mathrm{L}$ de SALSA PCR Buffer, $1 \mu \mathrm{L}$ de iniciadores SALSA PCR, $1 \mu \mathrm{L}$ de SALSA Enzyme Dilution Buffer, 0,25 $\mu \mathrm{L}$ de SALSA polimerase e 15,75 $\mu \mathrm{L}$ de $\mathrm{H}_{2} \mathrm{O}$. As condições da amplificação foram: 35 ciclos de $30 \mathrm{~s}$ a $95^{\circ} \mathrm{C}$, hibridação a $60^{\circ} \mathrm{C}$ por $30 \mathrm{~s}$ e extensão $72^{\circ} \mathrm{C}$ por $60 \mathrm{~s}$, seguidos de extensão final a $72^{\circ} \mathrm{C}$ por $20 \mathrm{~min}$. Nas amostras tratadas com Hha I, são amplificadas apenas as sequências metiladas, que não são digeridas. A reação de MS-MLPA é realizada em amostras teste (pacientes) e controle (indivíduos fenotipicamente normais).

Eletroforese e análise dos produtos de PCR: cada $1 \mu \mathrm{L}$ do produto da amplificação foi diluído em $7 \mu \mathrm{L}$ de Tween a $0,1 \%$, adicionando-se $0,25 \mu \mathrm{L}$ do padrão de peso molecular MegaBACE $^{\mathrm{TM}}$ ET 550-R Size Standard. Os fragmentos foram separados por meio de eletroforese em capilar no aparelho MegaBACE $^{\mathrm{TM}} 1000$ (Amersham Biosciences, GE Healthcare, UK). Inicialmente avaliamos a eficiência da PCR, utilizando o programa Fragment Profiler (Amersham Biosciences, GE Healthcare). O programa fornece valores de altura e área dos picos dos produtos da amplificação de cada sonda do kit. A análise dos valores obtidos foi executada em uma planilha modificada do Excel, desenvolvida para a análise de MLPA (Eggermann e col., 2008c). Primeiramente foi realizada a normalização dos valores obtidos das amostras teste e controle: o valor de altura dos picos de cada sonda amplificada foi dividido pela soma dos valores dos picos das sondas referência. No caso das amostras controle, a normalização foi feita a partir da média dos valores de três amostras, para cada sonda. Em seguida, dividiramse os valores normalizados de cada amostra teste pelos valores normalizados das amostras controle. A partir dos valores obtidos, foram construídos dois gráficos: (1) para a quantificação do número de cópias de DNA, primeira etapa da técnica, e (2) para verificar o padrão de metilação das regiões de interesse, que constitui a segunda etapa da técnica. 


\section{III.2.2 Investigação de matUPD(7)}

Para a investigação da matUPD(7), foram escolhidos segmentos do cromossomo 7 humano que têm homologia com regiões cromossômicas de camundongo sujeitas ao imprinting genômico: 7p11.2-p13 no braço curto e 7q21-qter no braço longo. Os marcadores de microssatélites inicialmente utilizados foram D7S506 (7p12.1), D7S519 (7p13), D7S1870 (7q11.23) e D7S486 (7q31.2); os lócus D7S493 (7p15.3), D7S657 (7q21.3) e D7S515 (7q22.1) foram analisados quando os primeiros não foram informativos. Pacientes que apresentaram um alelo materno e um paterno em pelo menos um marcador de cada braço do cromossomo 7 foram considerados como tendo herança biparental.

Genotipagem dos lócus de microssatélites: para a amplificação dos alelos por PCR foram utilizados iniciadores fluorescentes do kit ABI PRISM ${ }^{\circledR}$ Linkage Mapping Sets v.2.5 (Applied Biosystems, California, USA). O volume final de reação foi de $10 \mu \mathrm{L}$, contendo entre 50 ng e 100 ng de DNA genômico, 0,8 $\mu \mathrm{L}$ de uma mistura de iniciadores a $10 \mu \mathrm{M}, 1,5 \mathrm{U}$ de Taq polimerase e 0,27 mM dCTP, 0,27 mM dTTP, 0,27 mM dGTP e 0,27 mM dATP; 10\% do volume final, constituído de tampão confeccionado no laboratório (LGH - IB-USP) [300mM Tris pH=8,5, 100 $\mathrm{mM}$ Hepes $\left(\mathrm{C}_{8} \mathrm{H}_{18} \mathrm{O}_{4} \mathrm{~S}\right.$ - N-2-hidroxietilpiperazina-N'-2-ácido etanosulfonico - variação do pH:6,8-8,2), $\left.25 \mathrm{mM} \mathrm{MgCl} 2,100 \mathrm{mM} \mathrm{KCL} \mathrm{e} 100 \mathrm{mM}\left(\mathrm{NH}_{4}\right)_{2} \mathrm{SO}_{4}\right]$. As condições de amplificação foram: desnaturação inicial por $12 \min$ a $95^{\circ} \mathrm{C}, 10$ ciclos de $15 \mathrm{~s}$ a $94^{\circ} \mathrm{C}$, hibridação a $55^{\circ} \mathrm{C}$ ou $54^{\circ} \mathrm{C}$ por $15 \mathrm{~s}$ e $30 \mathrm{~s}$ a $72^{\circ} \mathrm{C}, 20$ ciclos de $15 \mathrm{~s}$ a $89^{\circ} \mathrm{C}$, hibridação a $55^{\circ} \mathrm{C}$ ou $54^{\circ} \mathrm{C}$ por $15 \mathrm{~s}$ e extensão a $72^{\circ} \mathrm{C}$ por $30 \mathrm{~s}$, seguidos de extensão final a $72^{\circ} \mathrm{C}$ por $10 \mathrm{~min}$.

Eletroforese e análise dos produtos de PCR: para separação dos produtos amplificados por eletroforese em capilar no aparelho MegaBACE ${ }^{\mathrm{TM}} 1000$ (Amersham Biosciences, GE Heathcare), $2 \mu \mathrm{L}$ de Tween a $0,1 \%$ e $0,25 \mu \mathrm{L}$ do padrão de peso molecular MegaBACE ${ }^{\mathrm{TM}}$ ET 550-R Size Standard foram adicionados a $2 \mu \mathrm{L}$ do produto da amplificação. A análise foi realizada, utilizando o programa Genetic Profiler (Amersham Biosciences, GE Heathcare). 


\section{III.2.3 Investigação de alterações cromossômicas submicroscópicas por array-CGH}

Para a investigação de alterações cromossômicas por a-CGH usamos as plataformas Human Genome 4x44K, SurePrint G3 Human CGH 8x60K, Human Genome 2x105K ou SurePrint G3 Human CGH 4x180K (Agilent Technologies, California, USA), dependendo de sua disponibilidade no laboratório. Esses oligoarrays contém, respectivamente, quatro áreas com 44.000 oligonucleotídeos de 60 pb, oito áreas com 60.000 oligonucleotídeos de 60 pb, duas áreas com $\sim 105.000$ oligonucleotídeos de 60 pb e quatro áreas com $~ 180.000$ oligonucleotídeos de $60 \mathrm{pb}$. Os procedimentos de digestão, marcação, purificação, precipitação, hibridação e lavagem das amostras estão descritos a seguir.

Digestão do DNA genômico (de acordo com o protocolo da Agilent Technologies): para as plataformas 44K, 105K e 180K, utilizaram-se 800 ng de DNA genômico, em volume final da reação de $22 \mu \mathrm{L}$, contendo $5 \mathrm{U}$ de cada enzima Alu I e Rsa I, 1,7 $\mu$ g de BSA (albumina de sangue bovino) e Buffer C 10X (10\% do volume final). Para a plataforma 60K, utilizaram-se 500 ng de DNA genômico, em volume final da reação de $13 \mu \mathrm{L}$, contendo $5 \mathrm{U}$ de cada enzima Alu I e Rsa $I, 1,0 \mu \mathrm{g}$ de BSA e Buffer $C 10 \mathrm{X}$ (10\% do volume final). As amostras foram digeridas por $2 \mathrm{~h}$ a $37^{\circ} \mathrm{C}$ em estufa, seguida da inativação das enzimas por 20 min a $65^{\circ} \mathrm{C}$.

Marcação: foram utilizados os kits Bioprime DNA labeling (Invitrogen, California, USA), para a plataforma 44K; Agilent Labelling mix (Agilent Technologies), para a $60 \mathrm{~K}$ e a $180 \mathrm{~K}$, e Fluorescent Labelling System (BlueGnome, Cambridge, UK), para a 105K. Os procedimentos e quantidades de cada reagente seguiram as instruções do fabricante dos kits. Em resumo, foram adicionados random primers à reação da digestão, seguindo-se desnaturação do DNA por 5 min a $95^{\circ} \mathrm{C}$ e incubação em gelo por 5 min. Para a marcação, foi adicionada uma mistura contendo tampão, dNTP, Cy3-dCTP (para a amostra teste) ou Cy5-dCTP (para a amostra referência) e enzima Klenow. As amostras foram mantidas por $2 \mathrm{~h}$ a $37^{\circ} \mathrm{C}$ em estufa, procedendo-se em seguida à inativação da enzima por $10 \min$ a $65^{\circ} \mathrm{C}$. 
Purificação: após hibridação, as amostras foram purificadas, utilizando-se o kit Illustra $^{T M}$ ProbeQuant ${ }^{T M}$ G-50 Micro Columns (GE Healthcare), de acordo com o protocolo do fabricante. Nas amostras analisadas na plataforma $60 \mathrm{~K}$, foram adicionados $25 \mu \mathrm{L}$ de TE, antes da etapa de purificação. A quantificação do DNA genômico marcado e da atividade específica dos fluorocromos Cy3-dCTP e Cy5-dCTP foi realizada no espectrofotômetro NanoDrop ND-1000 (NanoDrop Technologies).

Precipitação (modificação do protocolo da Agilent Technologies): a $50 \mu \mathrm{L}$ do DNA teste (marcado com Cy3) e $50 \mu \mathrm{L}$ do DNA referência (marcado com Cy5) foram adicionados $5 \mu \mathrm{g}$ (plataformas 44K, 60K e 180K) ou $25 \mu \mathrm{g}$ (plataforma 105K) de Human Cot-1 DNA (Invitrogen), para o volume final de $105 \mu \mathrm{L}(44 \mathrm{~K}, 60 \mathrm{~K}$ e $180 \mathrm{~K})$ ou $125 \mu \mathrm{L}(105 \mathrm{~K})$. Em seguida, foram adicionados $\mathrm{NaAc}(3 \mathrm{M}, \mathrm{pH} 5,0 ; 10 \%$ do volume final) e etanol $100 \%$ gelado (2,5X o volume final). As amostras foram precipitadas, por $15 \mathrm{~min}$ a $-80^{\circ} \mathrm{C}$ ou $2 \mathrm{~h} \mathrm{a}-20^{\circ} \mathrm{C}$.

Hibridação (de acordo com o protocolo da Agilent Technologies): após centrifugação por 15-20 min a $13.200 \mathrm{rpm}$ a $4^{\circ} \mathrm{C}$, adicionou-se etanol $70 \%$ gelado às amostras e procedeu-se a centrifugação por mais 5 min a $13.200 \mathrm{rpm}$, descartando-se o sobrenadante. Seguiu-se nova centrifugação por $1 \mathrm{~min}$, descartando-se o sobrenadante. O DNA marcado foi então ressuspendido em TE previamente aquecido a $72^{\circ} \mathrm{C}$, e mantido por 5 min a $72^{\circ} \mathrm{C}$, seguindo-se nova ressuspensão em vórtex. Foram adicionadas as soluções blocking solution 10X e hybridization buffer $2 \mathrm{X}$, e procedeu-se a desnaturação por $3 \min$ a $95^{\circ} \mathrm{C}$ e $30 \min$ a $37^{\circ} \mathrm{C}$ em banho-maria. Adicionou-se todo o volume das amostras às lamelas da lâmina de suporte do microarray, e colocou-se a lâmina de microarray sobre ela. As amostras foram então hibridadas a $65^{\circ} \mathrm{C}$ por $16-48 \mathrm{~h}$, dependendo da plataforma.

Lavagem (de acordo com o protocolo da Agilent Technologies): a lâmina de microarray foi mergulhada em soluções tampão, Buffer 1 por 5 min e Buffer 2 (previamente aquecido a $37^{\circ}$ C) por $1 \mathrm{~min}$, seguindo $10 \mathrm{~s}$ em acetonitrila e $30 \mathrm{~s}$ em Stabilization Drying Solution. 
As imagens do array obtidas com o uso do Agilent High-Resolution Microarray scanner foram processadas e analisadas, utilizando o pacote de programas Feature Extraction e Agilent Genomic Workbench (ambos da Agilent Technologies), usando o algoritmo estatístico ADM-2 e limiar de sensibilidade 6.7. Apenas as alterações abrangendo no mínimo três oligonucleotídeos consecutivos com razão $\log _{2}$ alterada foram consideradas pelo programa como possível alteração no número de cópias de determinado segmento genômico. Usando esses critérios, o tamanho mínimo das CNV detectadas foi de aproximadamente 145-220 Kb, 100-160 Kb, 60-90 Kb e 35$55 \mathrm{~Kb}$ pelas plataformas $44 \mathrm{~K}, 60 \mathrm{~K}, 105 \mathrm{~K}$ e $180 \mathrm{~K}$, respectivamente. As CNV identificadas nos pacientes foram comparadas àquelas presentes em amostra controle de estudos por a-CGH do laboratório (A. C. Krepischi e C. Rosenberg, comunicação pessoal) às variações documentadas no banco de dados Database of Genomic Variants (DGV, http://projects.tcag.ca/variation/), que compila as CNV presentes em indivíduos normais. As variantes também foram cotejadas com os dados do DECIPHER (DatabasE of Chromosomal Imbalance and Phenotype in Humans using Ensembl Resources, http://decipher.sanger.ac.uk/perl/application/), que documenta desequilíbrios genômicos identificados em indivíduos afetados por diferentes patologias. A presença das variantes únicas ou raras detectadas foi investigada, sempre que possível, nos genitores dos afetados.

\section{III.2.4 Investigação de mutações no gene $C D K A L 1$}

A análise do gene CDKAL1 foi realizada por sequenciamento direto. Os iniciadores para a amplificação das regiões codificadoras, incluindo os segmentos de junção intron/exons, foram desenhados, utilizando o programa Primer3 (http://fokker.wi.mit.edu/primer3) (Tabela III.1). A especificidade dos oligonucleotídeos foi avaliada usando o programa BLAT (BLAST-like Alignment Tool).

As reações de PCR foram realizadas utilizando-se cerca de 100 ng de DNA genômico, em volume final da reação de $25 \mu \mathrm{L}$, na presença de Tris- $\mathrm{HCl} 20 \mathrm{mM}(\mathrm{pH} 8,4), \mathrm{Kcl} 50 \mathrm{mM}, \mathrm{MgCl}_{2}$ 2,5 mM, $150 \mu \mathrm{M}$ de cada dNTP, $\mathrm{DMSO}_{4}$ (10\% do volume final), 0,4 $\mu \mathrm{M}$ dos iniciadores foward e reverse e 1,5 U de Taq polimerase. As condições de amplificação foram: desnaturação inicial por 1 min a $94^{\circ} \mathrm{C}$, seguida de 34 ciclos de $45 \mathrm{~s}$ a $94^{\circ} \mathrm{C}$, hibridação a $58^{\circ} \mathrm{C}$ por $45 \mathrm{~s}$, extensão a 
$72^{\circ} \mathrm{C}$ por $1 \mathrm{~min}$, seguidos de extensão final a $72^{\circ} \mathrm{C}$, por $10 \mathrm{~min}$. Como tivemos dificuldades para amplificar o exon 4, desenhamos dois pares de iniciadores, um mais externo (par A) e outro mais interno (par B). Primeiramente foi realizada amplificação por PCR de 20 ciclos, utilizando o par de iniciadores A. Os produtos amplificados foram diluídos em $\mathrm{H}_{2} \mathrm{O}$ (1:4), e foi feita nova amplificação por PCR, de 25 ciclos, utilizando o par de iniciadores B.

A amplificação dos segmentos de interesse foi verificada após eletroforese em gel de agarose 2\% em tampão TBE 1X (Tris-base 68 mM; ácido bórico 89 mM; EDTA 2 mM, pH 8,0), utilizando o low DNA mass ladder (Invitrogen), como marcador de peso molecular.

Os produtos amplificados por PCR foram submetidas a purificação, utilizando-se o kit Illustra $^{T M}$ GFX ${ }^{T M}$ PCR DNA and Gel Band Purification (GE Healthcare), de acordo com o protocolo do fabricante.

A reação de sequenciamento foi realizada conforme o protocolo do fabricante do sequenciador ABI-3730 (Applied Biosystems), em volume final de reação de $10 \mu \mathrm{L}$, contendo entre 10 e 30 ng de DNA, 0,5 $\mu \mathrm{M}$ do iniciador foward ou reverse, $1 \mu \mathrm{L}$ de BigDye Terminator v3.1 5X Sequencing Buffer e $2 \mu \mathrm{L}$ de BigDye Terminator v3.1 Cycle Sequencing Ready Reaction Mix (ambos da Applied Biosystems). Os produtos amplificados foram submetidos a uma segunda purificação, com SephadexTM G-50 Fine (GE Heatlhcare), e então separados por meio de eletroforese em capilar no aparelho ABI-3730 (Applied Biosystems). A análise das sequências foi realizada utilizando os programas Sequencher ${ }^{T M}$ (Gene Codes, Michigan, USA) e BioEdit versão 7.0.5 (Hall, 1999). 
Tabela III.1 - Pares de iniciadores, desenhados com o programa Primer3, para o sequenciamento dos 16 exons do gene CDKAL1: sequência de bases, tamanho do segmento amplificado e temperatura de hibridação.

\begin{tabular}{|c|c|c|c|}
\hline Pares de iniciadores & Sequência de bases $5^{\prime} \rightarrow 3^{\prime}$ & $\begin{array}{l}\text { Tamanho do segmento } \\
\text { amplificado (pb) }\end{array}$ & $\begin{array}{l}\text { Temperatura de } \\
\text { hibridação }\left({ }^{\circ} \mathbf{C}\right)\end{array}$ \\
\hline exon1F & CCAGAACTAGCGCTTTCAGC & \multirow{2}{*}{249} & \multirow{2}{*}{58} \\
\hline exon1R & AGGCTTGGCCATAAAAGGAG & & \\
\hline exon2F & CAAGTAGTATGGAGCATCATTAATCC & \multirow{2}{*}{240} & \multirow{2}{*}{58} \\
\hline exon2R & AACATGCAGAAATACGCACAG & & \\
\hline exon3F & CCTTGGAATGTCCCATTGTC & \multirow{2}{*}{757} & \multirow{2}{*}{58} \\
\hline exon3R & GAATATAATTTCGGCCGTGC & & \\
\hline exon4F_A & GCAACAGAGCAAGACCCTG & \multirow{2}{*}{304} & \multirow{2}{*}{58} \\
\hline exon4R_A & TCACCTTAAAATCACTGTCATGC & & \\
\hline exon4F_B & GCAAGACCCTGGATCAAAAA & \multirow{2}{*}{292} & \multirow{2}{*}{58} \\
\hline exon4R_B & AAATCACTGTCATGCTAAAATACCC & & \\
\hline exon5F & TGTTTTTCTCTCCCCTACCG & \multirow{2}{*}{356} & \multirow{2}{*}{58} \\
\hline exon5R & AAAAGCATCATTCTGTATCAGACAA & & \\
\hline exon6F & AGGCCTGTTATTATTTGGAGAAC & \multirow{2}{*}{343} & \multirow{2}{*}{58} \\
\hline exon6R & TCAGGGACAATAAGGAAAATATG & & \\
\hline exon7F & AAGGAAACCTGCATTGATGTG & \multirow{2}{*}{322} & \multirow{2}{*}{58} \\
\hline exon7R & ACTGGCAAATTCATGAAGCC & & \\
\hline exon8F & CCCGAAAAGAAGTTAAATGAACA & \multirow{2}{*}{300} & \multirow{2}{*}{58} \\
\hline exon8R & TCTATGTCACATGTCCAAGAAAAA & & \\
\hline exon9F & TGTGTATGTTTTGAGGTATCCCC & \multirow{2}{*}{427} & \multirow{2}{*}{58} \\
\hline exon9R & TCAAAATATGTCATTTACCTTAGAGTG & & \\
\hline exon10F & GCAGCTGTATGATGAAGGAAAC & \multirow{2}{*}{292} & \multirow{2}{*}{58} \\
\hline exon10R & GCCACACTGTCTGGACTGG & & \\
\hline exon11F & TTTATTTGCTTGCGCTTGTG & \multirow{2}{*}{330} & \multirow{2}{*}{58} \\
\hline exon11R & CCTTTAATTGTAAGGCTGCAATAAG & & \\
\hline exon12F & GGTTTCCCTGGAAATGGC & \multirow{2}{*}{518} & \multirow{2}{*}{58} \\
\hline exon12R & CTGACCCCAACTTGGAAATC & & \\
\hline exon13F & GCCTCCACAAAGGAAGAATC & \multirow{2}{*}{307} & \multirow{2}{*}{58} \\
\hline exon13R & TTGGTAAGTGTATTTCAGAATCACC & & \\
\hline exon14F & CTTGGTCCAGACCTACCTGG & \multirow{2}{*}{270} & \multirow{2}{*}{58} \\
\hline exon14R & АСТСТССССТTTAAATGCCC & & \\
\hline exon15F & TGGGAGTTAGGTATACAGGAGC & 365 & 58 \\
\hline exon15R & GAAACATGGCCTGGAATCAC & 500 & Jo \\
\hline exon16F & GTACATAAAAGGCGGCACC & 536 & 58 \\
\hline exon16R & AAAGCAGTTTAATTTGAAGGATGTG & & (50 \\
\hline
\end{tabular}




\section{RESULTADOS E DISCUSSÃO}




\section{RESULTADOS E DISCUSSÃO}

\section{IV.1 Investigação de alterações (epi)genéticas em 11 p15}

A análise da metilação e da variação do número de cópias nos domínios ICR1 e ICR2 em 11 15 foi realizada por MS-MLPA (MRC Holland). A Tabela IV.1 resume os resultados da investigação de 11p15. A Figura IV.1 mostram os três tipos de alterações detectados em nossos pacientes com SRS por meio desse teste.

$\mathrm{Na}$ amostra de 64 pacientes com diagnóstico clínico da SRS, 49 foram analisados quanto ao padrão de metilação em 11p15. Duas pacientes, com matUPD(7) previamente identificada, foram excluídas dessa análise (pacientes P e AP, Tabela IV.1). De 13 pacientes, cujo DNA nos foi enviado, tivemos problemas quanto à eficiência da PCR. A técnica é extremamente sensível à qualidade do DNA. Novas amostras de DNA desses pacientes foram solicitadas, mas não nos foram enviadas.

Detectamos hipometilação de ICR1 (H19DMR) em 21 dos 49 pacientes (43\%) (Figura IV.1A). Em um desses pacientes (AM, Tabela IV.1) ambos os centros, ICR1 (H19DMR) e ICR2 $(K v D M R 1)$, estavam hipometilados (Figura IV.1B). Uma sonda que evidenciou hipermetilação correspondia a uma sequência do exon 15 do gene $K C N Q 1$, e não a ICR2 (KvDMRl), não podendo ser utilizada para quantificar o padrão de metilação de ICR2, de acordo com o protocolo da MRC Holland. Em outro paciente, caso familial (Y, Tabela IV.1), a análise de 11p15 revelou uma microduplicação de origem materna que incluía o domínio ICR2, mas não ICR1 (Figura IV.1C). Nos demais pacientes testados, incluindo um dos casos familiais (AF, Tabela IV.1) não detectamos alteração no número de cópias de DNA ou no padrão de metilação em 11p15.

\section{Hipometilação de ICRI}

A frequência (43\%) de pacientes com SRS e hipometilação de ICR1 em 11p15 que identificamos entre os 49 pacientes testados está de acordo com a literatura (revisão em Eggermann e col., 2008a). Devemos levar em consideração que o teste de MS-MLPA foi realizado somente em DNA genômico extraído de sangue periférico. Como já sugerido (Gicquel 
e col., 2005), as alterações de metilação provavelmente ocorrem após a fertilização e resultam em uma distribuição em mosaico, durante o desenvolvimento. Diante disso, a frequência de pacientes com SRS que apresentam hipometilação de ICR1 pode ser maior, uma vez que o diagnóstico de rotina, baseado na análise de sangue periférico, não detecta o subgrupo de pacientes que tenha apenas outros tecidos alterados. Alguns pesquisadores já sugeriram testar outros tecidos quanto às alterações de metilação, além do sangue periférico (Eggermann e col., 2008a).

\section{Hipometilação de ICR1 e de ICR2}

Na paciente AM, detectamos hipometilação de ICR1 e de ICR2, alteração epigenética complexa que foi relatada em cerca 4\% dos pacientes com SRS (Azzi e col., 2009; Turner e col., 2010; Begemann e col., 2010). A hipometilação de ICR2 é responsável por cerca da metade dos casos de BWS e a perda de metilação em ambas as ICR foi descrita também nesses pacientes (Azzi e col., 2009).

A razão de pacientes com hipometilação de ICR1 e de ICR2, diagnosticada em linfócitos de sangue periférico, apresentarem fenótipo de SRS ou de BWS é desconhecida. A distribuição do mosaicismo dos defeitos epigenéticos entre os diferentes tecidos poderia explicar a dominância de um fenótipo ou de outro (Azzi e col., 2009). Uma observação interessante foi a de dois pacientes com SRS e hipometilação de ICR1 e de ICR2, que apresentavam hérnia umbilical, um dos sinais clínicos da BWS, que poderia representar a manifestação da alteração epigenética de ICR2 no fenótipo da SRS, decorrente da hipometilação de ICR1 (Begemann e col., 2010).

Os pacientes com SRS e hipometilação de ICR1 e de ICR2 apresentam, com maior frequência do que aqueles com hipometilação apenas em ICR1, alteração do padrão de metilação em outros lócus sujeitos a imprinting (Azzi e col., 2009; Turner e col., 2010). Assim, dentre os nossos pacientes com SRS, a paciente AM é especialmente candidata a apresentar alterações de metilação em múltiplos lócus. O padrão de metilação do gene SNURF/SNRPN (região PWS/AS), foi avaliado pela Dra. Monica de Castro Varela (Unidade de Aconselhamento Genético - IB-USP) e não mostrou alteração. 
Tabela IV.1 - Resultados da análise do número de cópias de segmentos de DNA e do padrão de metilação em 11 p15 por MS-MLPA.

\begin{tabular}{|c|c|c|c|c|c|}
\hline Paciente & $\begin{array}{l}\text { Número de cópias de } \\
\text { segmentos de DNA } \\
\text { em } 11 \text { p15 }\end{array}$ & $\begin{array}{l}\text { Padrão de metilação } \\
\text { em } 11 \text { p15 }\end{array}$ & Paciente & $\begin{array}{l}\text { Número de cópias de } \\
\text { segmentos DNA em } \\
11 p 15\end{array}$ & $\begin{array}{l}\text { Padrão de metilação } \\
\text { em } 11 \text { p15 }\end{array}$ \\
\hline $\mathbf{A}^{1}$ & & & $\mathbf{A H}$ & Normal & Hipometilação de ICR1 \\
\hline B & Normal & Hipometilação de ICR1 & AI & Normal & Hipometilação de ICR1 \\
\hline $\mathbf{C}^{3}$ & Normal & Normal & AJ & Normal & Normal \\
\hline D & Normal & Normal & $\mathbf{A} \mathbf{K}^{2}$ & Normal & Normal \\
\hline $\mathbf{E}$ & Normal & Normal & $\mathbf{A L}$ & Normal & Hipometilação de ICR1 \\
\hline $\mathbf{F}^{1}$ & & & $\mathbf{A M}$ & Normal & $\begin{array}{l}\text { Hipometilação de ICR1 e } \\
\text { ICR2 }\end{array}$ \\
\hline $\mathbf{G}^{1}$ & & & $\mathbf{A N}$ & Normal & Hipometilação de ICR1 \\
\hline $\mathbf{H}$ & Normal & Hipometilação de ICR1 & AO & Normal & Normal \\
\hline $\mathbf{I}^{1}$ & & & $\mathbf{A} \mathbf{P}^{2}$ & & \\
\hline $\mathbf{J}$ & Normal & Normal & AQ & Normal & Hipometilação de ICR1 \\
\hline $\mathbf{K}$ & Normal & Hipometilação de ICR1 & $\mathbf{A R}$ & Normal & Hipometilação de ICR1 \\
\hline $\mathbf{L}$ & Normal & Hipometilação de ICR1 & $\mathbf{A S}$ & Normal & Hipometilação de ICR1 \\
\hline $\mathbf{M}^{1}$ & & & $\mathbf{A T}$ & Normal & Normal \\
\hline $\mathbf{N}^{1}$ & & & $\mathbf{A U}$ & Normal & Normal \\
\hline $\mathbf{O}^{1}$ & & & $A V^{1}$ & & \\
\hline $\mathbf{P}^{2}$ & & & $\mathbf{A W}$ & Normal & Hipometilação de ICR1 \\
\hline $\mathbf{Q}^{1}$ & & & $\mathbf{A} \mathbf{X}^{1}$ & & \\
\hline $\mathbf{R}^{1}$ & & & $\mathbf{A Y}$ & Normal & Normal \\
\hline $\mathbf{S}$ & Normal & Normal & $\mathbf{A Z}$ & Normal & Normal \\
\hline $\mathbf{T}$ & Normal & Normal & $\mathbf{B A}$ & Normal & Normal \\
\hline $\mathbf{U}$ & Normal & Normal & BB & Normal & Hipometilação de ICR1 \\
\hline $\mathbf{V}^{1}$ & & & BC & Normal & Normal \\
\hline $\mathbf{W}^{1}$ & & & BD & Normal & Normal \\
\hline $\mathbf{X}$ & Normal & Normal & BE & Normal & Normal \\
\hline $\mathbf{Y}$ & $\begin{array}{l}\text { Duplicação do } \\
\text { segmento controlado } \\
\text { por ICR2 }\end{array}$ & ICR1 normal & $\mathbf{B F}$ & Normal & Normal \\
\hline $\mathbf{Z}$ & Normal & Hipometilação de ICR1 & BG & Normal & Hipometilação de ICR1 \\
\hline $\mathbf{A A}$ & Normal & Normal & BH & Normal & Hipometilação de ICR1 \\
\hline AB & Normal & Hipometilação de ICR1 & BI & Normal & Hipometilação de ICR1 \\
\hline $\mathbf{A C}$ & Normal & Normal & BJ & Normal & Hipometilação de ICR1 \\
\hline AD & Normal & Hipometilação de ICR1 & BK & Normal & Normal \\
\hline $\mathbf{A E}$ & Normal & Normal & BL & Normal & Normal \\
\hline $\mathbf{A F}$ & Normal & Normal & BM & Normal & Normal \\
\hline $\mathbf{A G}$ & Normal & Normal & & & \\
\hline
\end{tabular}

${ }^{1}$ Qualidade da amostra de DNA recebida não permitiu análise por MS-MLPA; ${ }^{2}$ pacientes com matUPD(7); ${ }^{3}$ paciente portadora de $\mathrm{t}(5 ; 6)$ (Fonseca, 2005), não incluída nas estimativas. 
A)

Hipometilação de ICR1

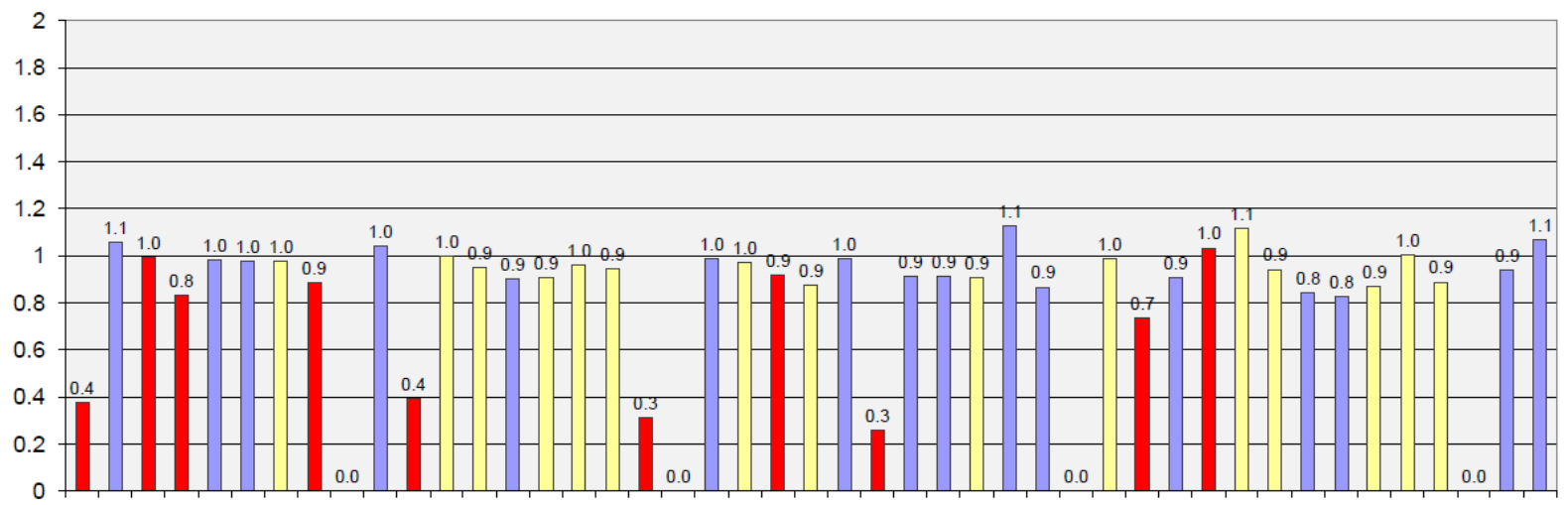

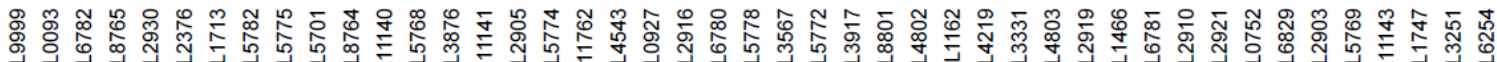

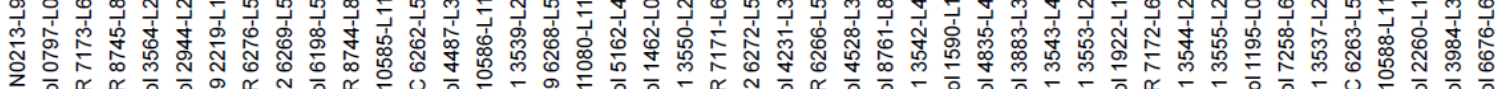

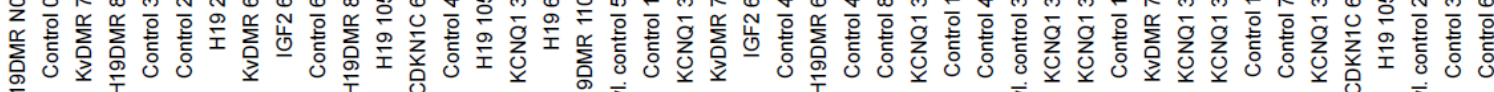

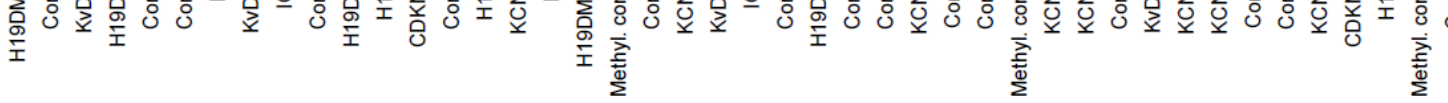

B)

Hipometilação de ICR1 e ICR2

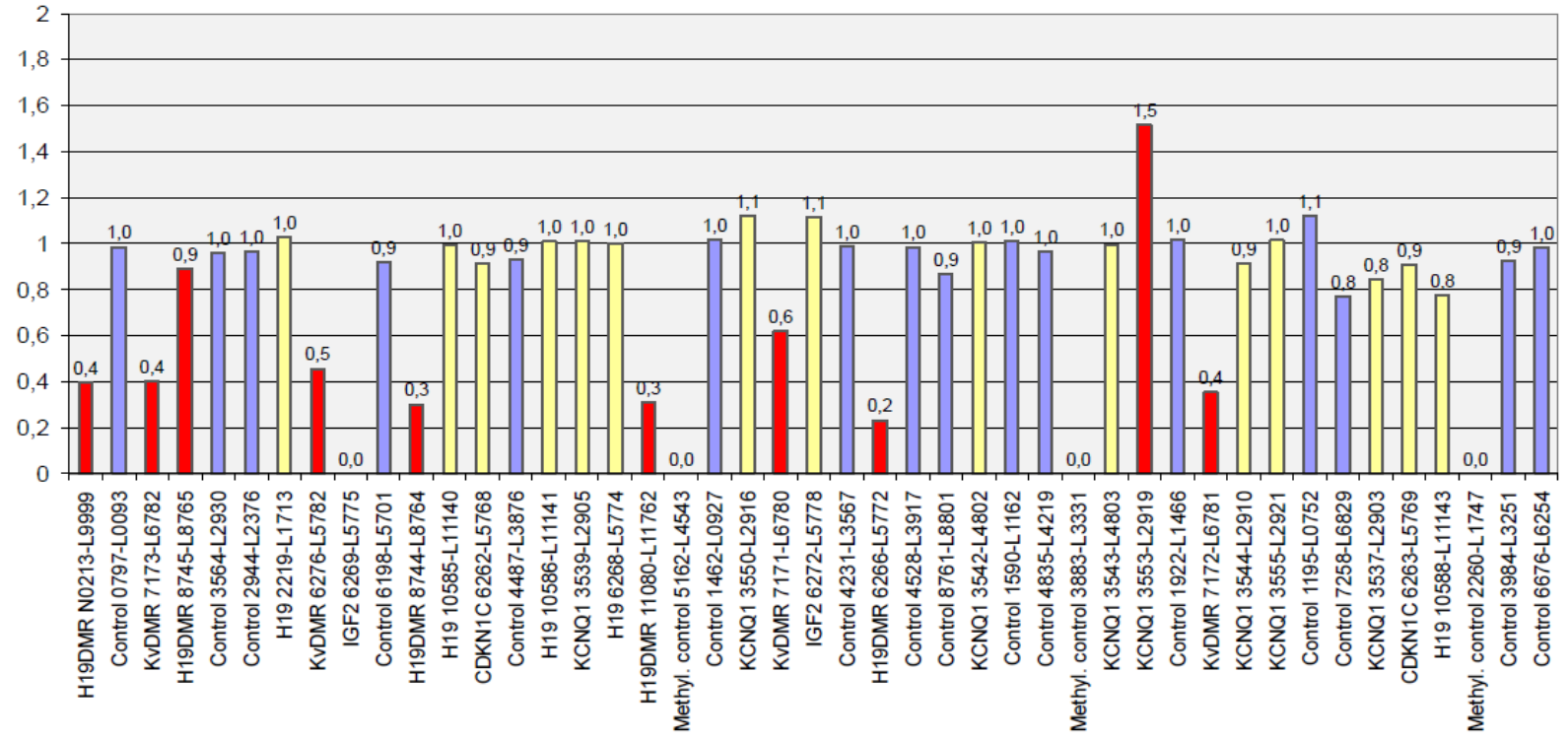

C)

Duplicação do domínio ICR2

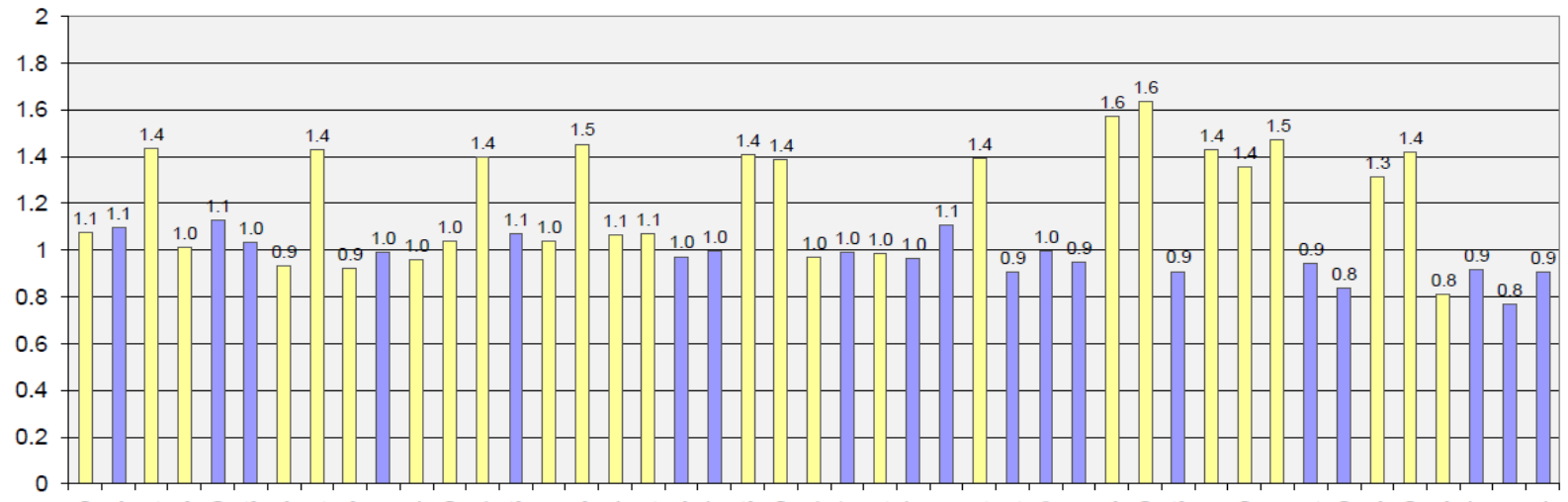

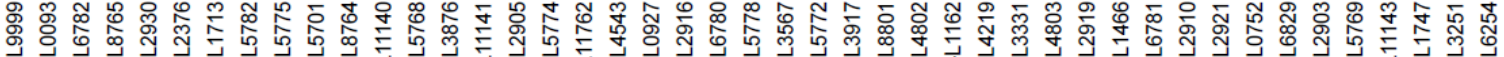

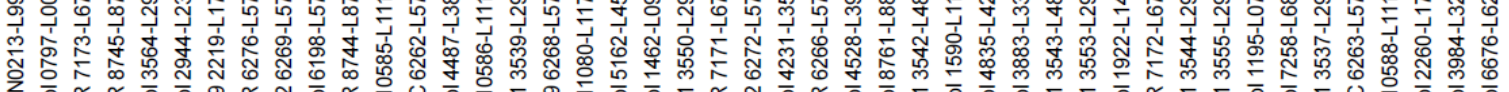

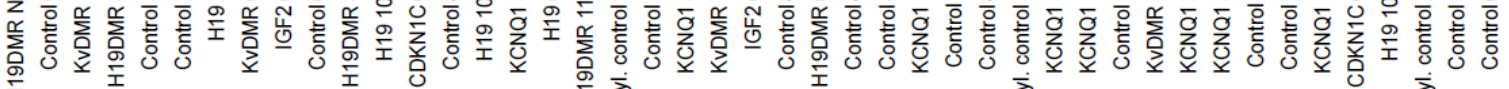

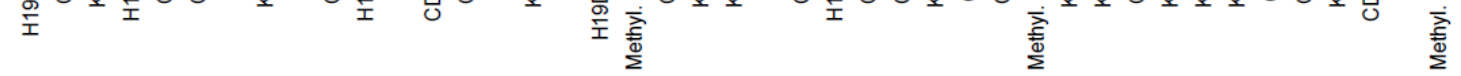


Figura IV.1 - Gráficos representativos dos resultados da análise do número de cópias de DNA e do padrão de metilação em 11p15, utilizando planilha de Excel desenvolvida para análise de MLPA. Barras em azul representam as sondas referência em lócus de outros cromossomos; as sondas de dosagem (em amarelo) mostram o número de cópias em 11p15 (<0,7 = deleção; >1,3 = duplicação); as sondas com o sítio de restrição da enzima Hha I (em vermelho) para H19DMR e KvDMRl mostram o padrão de metilação ( $<0,7=$ hipometilado; $>1,3=$ hipermetilado). As quatro colunas zeradas em $\mathbf{A}$ e $\mathbf{B}$ confirmam a digestão por Hha I em sondas controle de segmentos hipometilados. A) Paciente com SRS e hipometilação de ICR1: redução de amplificação das sondas de H19DMR; B) Paciente (AM) com SRS e hipometilação de ICR1 e de ICR2: redução de amplificação das sondas de H19DMR e KvDMRl; C) Paciente (Y) com SRS e duplicação restrita ao domínio ICR2: aumento de amplificação das sondas de $K C N Q 1, K v D M R 1$ e $C D K N 1 C$; as sondas do domínio ICR1 não apresentam alteração $(H 19, H 19 D M R$ e $I G F 2$ ).

\section{Microduplicação de ICR2}

Em nosso projeto de estudo da síndrome de SRS, durante a Iniciação Científica, identificamos uma microduplicação de origem materna que incluía o domínio ICR2, mas não ICR1 (paciente Y, Tabela IV.1; III-7, Figura IV.2). Detectamos a mesma duplicação em outra paciente que nos foi encaminhada independentemente e constatamos que era prima em primeiro grau de III-7 (III-11, Figura IV.2). Verificamos que essa microduplicação segrega em uma família com cinco crianças afetadas pela SRS e a manifestação da síndrome depende da transmissão via materna (Figura IV.2). Cinco crianças com fenótipo da SRS, dois meninos (III-7 e 9) e três meninas (III-8, 11 e 12), herdaram a microduplicação de suas mães clinicamente normais (II-4 e 5); o desequilíbrio estava presente também em dois tios maternos fenotipicamente normais (II-1 e 6) e sete parentes clinicamente normais das crianças não apresentaram a duplicação: a avó materna (I-2), um tio materno (II-2), uma tia materna (II-3), três primos maternos (III-1-3) e uma irmã (III-10). Esses achados permitiram inferir que o avô dos afetados, já falecido, era o portador da microduplicação e que, quando ele a transmitia, sua prole não apresentava SRS. 


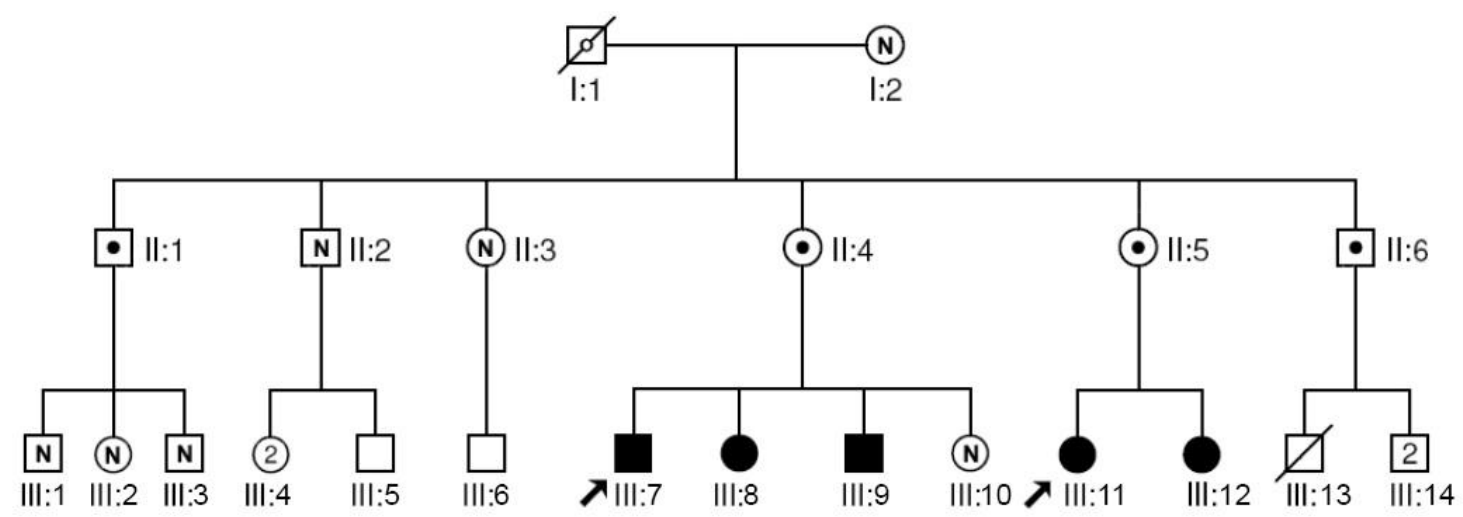

SRS; portadores da duplicação

- Portador inferido da duplicacão

$\bullet$ Clinicamente normais; portadores da duplicação

(N) N Clinicamente normais; não portadores

$\bigcirc$ Clinicamente normais; não testados

Figura IV.2 - Transmissão da microduplicação restrita ao domínio ICR2 em uma família com cinco crianças afetadas pela SRS. Quando herdada via materna, a microduplicação está associada à SRS.

Mapeamos os limites do rearranjo utilizando a plataforma SurePrint G3 Human CGH Microarray 180K (Agilent Technologies). A microduplicação tem aproximadamente 1,6 Mb e abrange todos os genes sujeitos a imprinting conhecidos do domínio ICR2 (Figura IV.3).

Uma microduplicação de origem materna também restrita ao domínio ICR2 e associada com SRS foi descrita anteriormente (Schönherr e col., 2007). O segmento duplicado tinha entre 0,76 e $1 \mathrm{Mb}$ e abrangia os mesmos genes sujeitos a imprinting que a duplicação identificada por nós. Entre os genes duplicados, $C D K N 1 C$ aparece como candidato para o fenótipo da SRS, como sugerido previamente, devido a seu efeito negativo sobre o crescimento celular e expressão elevada na placenta (Schönherr e col., 2007; Bliek e col., 2009). 


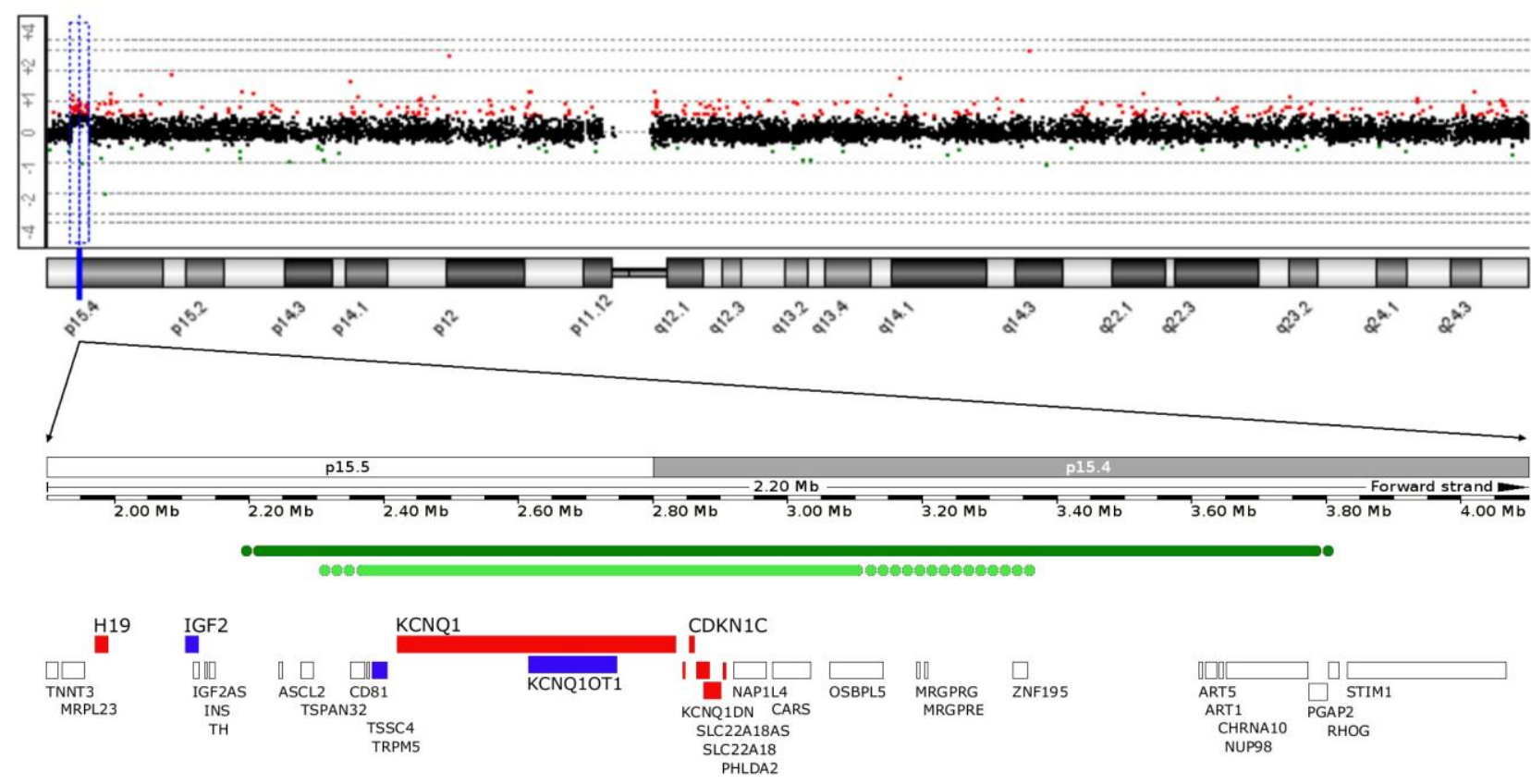

Figura IV.3 - Mapeamento da microduplicação restrita ao domínio ICR2 em 11p15 por a-CGH, utilizando a plataforma 180K (Agilent Technologies): a microduplicação de $\sim 1,6 \mathrm{Mb}$ (paciente III-9, Figura IV.2) está representada pela linha horizontal verde escura; a microduplicação de 0,76-1,0 Mb restrita a ICR2, descrita anteriormente (Schönherr e col., 2007), está mostrada para comparação (linha verde clara); linhas pontilhadas representam segmentos que podem estar duplicados. Genes mapeados na região estão representados por barras na parte de baixo: em vermelho, genes de expressão materna e em azul, os de expressão paterna.

Uma das características comuns aos pacientes com SRS e hipometilação de ICR1 é a assimetria corporal, que foi atribuída ao mosaicismo do defeito epigenético, presente na maioria dos pacientes (Gicquel e col., 2005; Eggermann e col., 2008a). A ausência de assimetria corporal em nossos pacientes e em outros portadores de duplicações de herança materna, que não estão em mosaico, apóia a associação entre assimetria corporal e mosaicismo da hipometilação de ICR1 na SRS (Fisher e col., 2002; Eggermann e col., 2005; South e col., 2008; Bliek e col., 2009; Eggermann e col., 2009a; Eggermann e col., 2010b).

Esse novo caso familial (Bonaldi e col. 2011) vem confirmar que a duplicação restrita ao domínio ICR2, de herança materna, está causalmente associada com a SRS; além disso, nenhuma alteração fenotípica visível está presente quando a duplicação é herdada via paterna. Somente 
duplicações paternas que incluem o domínio ICR1 estão associadas com o fenótipo da BWS (Bliek e col., 2009).

Em casos familiais da SRS, um desequilíbrio cromossômico deve ser suspeitado, principalmente afetando o segmento 11p15, uma vez que a matUPD(7) é sempre um evento de novo e o mesmo ocorre na quase totalidade dos casos de hipometilação de ICR1 em 11p15. Somente três casos familiais de hipometilação de ICR1 foram descritos (Bartholdi e col., 2009). Duas famílias, cada uma delas com duas crianças com fenótipo clássico da SRS e hipometilação de ICR1 foram relatadas. Os autores postularam que esses casos provavelmente se originaram de gameta paterno com erro de metilação, presente como mosaicismo germinativo. Numa terceira família, foi descrita transmissão vertical de hipometilação de ICR1 de pai para filha, ambos com diagnóstico clínico de SRS clássica. Obviamente, o pai afetado tem perda de metilação de ICR1 nas células somáticas e germinativas. A reprogramação das marcas epigenéticas em suas células germinativas primordiais não levaram à correção e o defeito permaneceu durante a espermatogênese. Os autores admitem a possibilidade de mutação em um dos genes relacionados com a metilação do DNA, apesar de considerarem pouco provável diante do efeito restrito. Consideramos, entretanto, mais provável, nesse caso, a presença de mutação ou microdeleção restrita à ICR1 ou aos enhancers de IGF2 no alelo paterno, herdado do avô, que levaria à perda do imprinting e consequentemente, silenciamento do gene $I G F 2$ em pai e filha, à semelhança do que já foi descrito em dois pacientes não aparentados com SRS (Grønskov e col., 2011).

Uma mutação epigenética que teoricamente teria o mesmo efeito das duplicações do domínio ICR2 de herança materna na SRS seria a hipermetilação de ICR2 (KvDMR1), exatamente oposta à alteração epigenética mais comumente detectada na ICR2 dos pacientes com BWS. Entretanto, nenhum estudo encontrou qualquer alteração no padrão de metilação do alelo paterno da ICR2 em pacientes com SRS. É provável que o ganho de metilação seja um fenômeno mais difícil de acontecer do que a hipometilação, visto que além de não ocorrer na SRS, somente 2-7\% dos casos de BWS estão associados com a hipermetilação de ICR1. 


\section{IV.2 Investigação de matUPD(7)}

Para a análise da matUPD(7), foram utilizados primeiramente quatro marcadores de microssatélites: D7S506 e D7S519, mapeados no braço curto, e os marcadores D7S1870 e D7S486, no braço longo do cromossomo 7. Nos pacientes com resultados não informativos, novos marcadores foram adicionados à análise, D7S493, no braço curto, e D7S657 e DS7515, no braço longo.

A Tabela IV.2 resume os resultados da investigação de matUPD(7). A Figura IV.4 mostra um exemplo da genotipagem de marcadores em um paciente com matUPD(7) e em um paciente com herança biparental.

Foram testados 53 dos 64 pacientes da amostra total. Dezesseis desses pacientes tiveram a matUPD(7) investigada previamente a este estudo, sendo cinco em exames realizados em nosso laboratório (LGH - IB-USP) e 11, em exames realizados na Universidade de Brasília. Onze pacientes em que tinham sido detectadas alterações em 11 p15 foram excluídos dessa análise, confirmando-se o diagnóstico clínico de SRS. Assim, no total de 64 pacientes, três $(4,7 \%)$ apresentaram matUPD(7) (P, AK e AP, Tabela IV.2). Esse resultado está de acordo com a literatura, que mostra a matUPD(7) como causa genética de 5-10\% dos casos (revisão em Eggermann e col., 2008a). Uma vez que consideramos como tendo herança biparental os pacientes que apresentaram um alelo materno e um paterno em pelo menos um lócus de cada braço do cromossomo 7, não podemos afastar a possibilidade de que determinadas UPD segmentares não tenham sido detectadas. Entretanto, UPD segmentar do cromossomo 7 é considerada rara, havendo descritos apenas quatro pacientes com SRS portadores de UPD parcial do cromossomo 7 - mat(UPD7q) (Eggermann e col., 2008d; revisões em Eggermann e col., 2008a; Eggermann e col., 2010a).

A paciente C (Tabelas IV.1, IV.2 e IV.5) é aquela em que foi detectada a translocação equilibrada que levou a identificar o gene CDKAL1 como candidato para a SRS (Fonseca, 2005). Nela afastamos a matUPD(7) e alterações em 11p15. A paciente não foi incluída nas estimativas. 
Tabela IV.2 - Resultados da investigação de matUPD(7) por genotipagem de microssatélites. Os números representam os alelos identificados. C-paciente, M- mãe, P- Pai. Nas famílias L e M não tínhamos amostras do pai e seus genótipos foram inferidos com base nos genótipos do afetado e de seu irmão normal (In). Na família Y, as letras Ia1 e Ia2 representam dois irmãos afetados. Na família AF, a letra Ia representa um irmão afetado. Nas famílias $\mathrm{S}, \mathrm{Y}, \mathrm{AB}, \mathrm{AD}, \mathrm{AJ}, \mathrm{BC}, \mathrm{BD}$ e BL não tínhamos amostras de um dos pais, cujo genótipo foi inferido, quando possível.

\begin{tabular}{|c|c|c|c|c|c|c|c|c|}
\hline Paciente & D7S 506 & D7S 519 & D7S 1870 & D7S 486 & D7S 493 & D7S 657 & D7S 515 & Resultado \\
\hline $\mathbf{A}$ & $\begin{array}{l}\mathrm{M}-2 / 4 \\
\mathrm{C}-3 / 4 \\
\mathrm{P}-1 / 3 \\
\end{array}$ & $\begin{array}{l}\text { M- } 1 / 1 \\
\text { C- } 1 / 1 \\
\text { P- } 1 / 1\end{array}$ & $\begin{array}{l}\text { M- } 2 / 2 \\
\text { C- } 2 / 2 \\
\mathrm{P}-1 / 2\end{array}$ & $\begin{array}{l}\mathrm{M}-2 / 3 \\
\mathrm{C}-2 / 3 \\
\mathrm{P}-1 / 3 \\
\end{array}$ & & $\begin{array}{l}\mathrm{M}-2 / 3 \\
\mathrm{C}-2 / 3 \\
\mathrm{P}-1 / 3\end{array}$ & $\begin{array}{l}\text { M- } 2 / 2 \\
\text { C- } 1 / 2 \\
\text { P- } 1 / 3 \\
\end{array}$ & Biparental \\
\hline $\mathbf{B}^{1}$ & & & & & & & & Biparental \\
\hline $\mathbf{C}^{3}$ & $\begin{array}{l}\text { M- } 1 / 2 \\
\text { C- } 1 / 1 \\
\text { P- } 1 / 1\end{array}$ & $\begin{array}{l}\text { M- } 1 / 2 \\
\text { C- } 1 / 3 \\
\text { P- } 1 / 3\end{array}$ & $\begin{array}{l}\text { M- 2/4 } \\
\text { C- } 3 / 4 \\
\text { P- } 1 / 3\end{array}$ & $\begin{array}{l}\text { M- } 1 / 2 \\
\text { C- } 1 / 2 \\
\text { P- } 2 / 3\end{array}$ & & & & Biparental \\
\hline $\mathbf{D}^{1}$ & & & & & & & & Biparental \\
\hline $\mathbf{E}$ & $\begin{array}{l}\text { M- } 2 / 3 \\
\text { C- } 2 / 3 \\
\text { P- } 1 / 2\end{array}$ & $\begin{array}{l}\text { M- } 1 / 3 \\
\text { C- } 3 / 3 \\
\text { P- } 2 / 3\end{array}$ & $\begin{array}{l}\text { M- } 1 / 3 \\
\text { C- } 2 / 3 \\
\text { P- } 1 / 2\end{array}$ & $\begin{array}{l}\text { M- } 1 / 2 \\
\text { C- } 2 / 2 \\
\mathrm{P}-2 / 2\end{array}$ & & & & Biparental \\
\hline $\mathbf{F}^{1}$ & & & & & & & & Biparental \\
\hline $\mathbf{G}$ & $\begin{array}{l}\text { M- } 2 / 3 \\
\text { C- } 1 / 3 \\
\text { P- } 1 / 4\end{array}$ & $\begin{array}{l}\text { M- 2/4 } \\
\text { C- } 3 / 4 \\
\text { P- } 1 / 3\end{array}$ & $\begin{array}{l}\text { M- } 1 / 3 \\
\text { C- } 1 / 1 \\
\text { P- } 1 / 2\end{array}$ & $\begin{array}{l}\text { M- } 1 / 3 \\
\text { C- } 2 / 3 \\
\text { P- } 2 / 2\end{array}$ & & & & Biparental \\
\hline $\mathbf{H}$ & $\begin{array}{l}\text { M- } 1 / 2 \\
\text { C- } 2 / 3 \\
\text { P- } 3 / 3\end{array}$ & $\begin{array}{l}\mathrm{M}-2 / 4 \\
\mathrm{C}-3 / 4 \\
\mathrm{P}-1 / 3\end{array}$ & $\begin{array}{l}\text { M- } 2 / 3 \\
\text { C- } 1 / 3 \\
\text { P- } 1 / 3\end{array}$ & $\begin{array}{l}\text { M- } 1 / 3 \\
\text { C- } 1 / 2 \\
\text { P- } 2 / 2\end{array}$ & & & & Biparental \\
\hline $\mathbf{I}$ & $\begin{array}{l}\text { M- } 1 / 1 \\
\text { C- } 1 / 2 \\
\text { P- } 2 / 3 \\
\end{array}$ & $\begin{array}{l}\text { M- 3/4 } \\
\text { C- } 1 / 4 \\
\mathrm{P}-1 / 2\end{array}$ & & $\begin{array}{l}\text { M- } 2 / 4 \\
\text { C- } 3 / 4 \\
\text { P- } 1 / 3 \\
\end{array}$ & & & & Biparental \\
\hline $\mathbf{J}$ & $\begin{array}{l}\text { M- } 1 / 4 \\
\text { C- } 2 / 4 \\
\text { P- } 2 / 3\end{array}$ & $\begin{array}{l}\text { M- } 2 / 4 \\
\text { C- } 1 / 4 \\
\mathrm{P}-1 / 3\end{array}$ & $\begin{array}{l}\text { M- } 1 / 2 \\
\text { C- } 2 / 3 \\
\text { P- } 3 / 3\end{array}$ & $\begin{array}{l}\text { M- } 1 / 4 \\
\text { C- } 1 / 2 \\
\text { P- } 2 / 3\end{array}$ & & & & Biparental \\
\hline $\mathbf{K}$ & $\begin{array}{l}\text { M- } 1 / 3 \\
\text { C- } 1 / 1 \\
\text { P- } 1 / 2 \\
\end{array}$ & $\begin{array}{l}\text { M- } 1 / 2 \\
\text { C- } 1 / 2 \\
\text { P- } 2 / 3\end{array}$ & $\begin{array}{l}\text { M- } 1 / 3 \\
\text { C- } 1 / 3 \\
\text { P- } 2 / 3\end{array}$ & $\begin{array}{l}\text { M- 2/4 } \\
\text { C- } 1 / 2 \\
\mathrm{P}-1 / 3\end{array}$ & $\begin{array}{l}\mathrm{M}-1 / 2 \\
\mathrm{C}-2 / 3 \\
\mathrm{P}-1 / 3\end{array}$ & & & Biparental \\
\hline $\mathbf{L}$ & $\begin{array}{l}\text { M- } 1 / 2 \\
\text { C- } 1 / 2 \\
\text { In- } 2 / 2\end{array}$ & $\begin{array}{l}\text { M- } 1 / 3 \\
\text { C- } 2 / 3 \\
\text { In- } 1 / 3 \\
\text { P- } 2 / ?\end{array}$ & $\begin{array}{l}\text { M- } 1 / 1 \\
\text { C- } 1 / 1 \\
\text { In- } 1 / 1\end{array}$ & $\begin{array}{l}\text { M- } 1 / 1 \\
\text { C- } 1 / 2 \\
\text { In- } 1 / 2 \\
\text { P- } 2 / ?\end{array}$ & & & & Biparental \\
\hline $\mathbf{M}$ & $\begin{array}{l}\text { M- } 1 / 2 \\
\text { C- } 1 / 1 \\
\text { In- } 1 / 2\end{array}$ & $\begin{array}{l}\text { M- } 2 / 3 \\
\text { C- } 1 / 2 \\
\text { In- } 1 / 3 \\
\text { P- } 1 / ?\end{array}$ & $\begin{array}{l}\text { M- } 1 / 2 \\
\text { C- } 2 / 2 \\
\text { In- } 1 / 2\end{array}$ & $\begin{array}{l}\text { M- } 1 / 3 \\
\text { C- } 1 / 2 \\
\text { In- } 1 / 2 \\
\text { P- } 2 / ?\end{array}$ & & & & Biparental \\
\hline $\mathbf{N}$ & $\begin{array}{l}\text { M- } 1 / 2 \\
\text { C- } 1 / 3 \\
\text { P- } 2 / 3 \\
\end{array}$ & $\begin{array}{l}\text { M- 2/3 } \\
\text { C- } 3 / 3 \\
\text { P- } 1 / 3\end{array}$ & $\begin{array}{l}\text { M- } 2 / 2 \\
\text { C- } 1 / 2 \\
\text { P- } 1 / 3\end{array}$ & $\begin{array}{l}\text { M- } 1 / 2 \\
\text { C- } 1 / 2 \\
\text { P- } 2 / 2 \\
\end{array}$ & & & & Biparental \\
\hline $\mathbf{O}$ & $\begin{array}{l}\text { M- } 1 / 3 \\
\text { C- } 1 / 3 \\
\text { P- } 1 / 2\end{array}$ & $\begin{array}{l}\mathrm{M}-2 / 2 \\
\mathrm{C}-2 / 3 \\
\mathrm{P}-1 / 3\end{array}$ & $\begin{array}{l}\text { M- } 2 / 3 \\
\text { C- } 2 / 4 \\
\text { P- } 1 / 4\end{array}$ & $\begin{array}{l}\text { M- } 1 / 1 \\
\text { C- } 1 / 2 \\
\text { P- } 1 / 2\end{array}$ & & & & Biparental \\
\hline $\mathbf{P}$ & $\begin{array}{l}\text { M- } 1 / 4 \\
\text { C- } 4 / 4 \\
\text { P- } 2 / 3\end{array}$ & $\begin{array}{l}\mathrm{M}-1 / 4 \\
\mathrm{C}-1 / 1 \\
\mathrm{P}-2 / 3\end{array}$ & $\begin{array}{l}\text { M- } 2 / 3 \\
\text { C- } 3 / 3 \\
\text { P- } 1 / 3\end{array}$ & $\begin{array}{l}\text { M- } 1 / 4 \\
\text { C- } 1 / 4 \\
\text { P- } 2 / 3 \\
\end{array}$ & & & & matUPD \\
\hline $\mathbf{Q}$ & $\begin{array}{l}\text { M- } 1 / 1 \\
\text { C- } 1 / 3 \\
\text { P- } 2 / 3\end{array}$ & $\begin{array}{l}\text { M- } 1 / 1 \\
\mathrm{C}-1 / 2 \\
\mathrm{P}-2 / 2\end{array}$ & $\begin{array}{l}\text { M- } 1 / 2 \\
\text { C- } 1 / 2 \\
\text { P- } 1 / 2\end{array}$ & $\begin{array}{l}\text { M- } 1 / 2 \\
\text { C- } 1 / 2 \\
\text { P- } 2 / 2 \\
\end{array}$ & & & & Biparental \\
\hline $\mathbf{R}$ & $\begin{array}{l}\text { M- } 1 / 2 \\
\text { C- } 1 / 1 \\
\text { P- } 1 / 3\end{array}$ & $\begin{array}{l}\text { M- } 2 / 3 \\
\text { C- } 1 / 3 \\
\text { P- } 1 / 1\end{array}$ & & $\begin{array}{l}\text { M- } 1 / 4 \\
\text { C- } 3 / 4 \\
\text { P- } 2 / 3\end{array}$ & & & & Biparental \\
\hline $\mathbf{S}$ & $\begin{array}{l}\text { M- ? } \\
\text { C- } 1 / 1 \\
\text { P- } 1 / 1\end{array}$ & $\begin{array}{l}\mathrm{M}-3 / ? \\
\mathrm{C}-1 / 3 \\
\mathrm{P}-1 / 2\end{array}$ & $\begin{array}{l}\text { M- } 3 / ? \\
\text { C- } 2 / 3 \\
\text { P- } 1 / 2\end{array}$ & $\begin{array}{l}\text { M- ? } \\
\text { C- } 2 / 2 \\
\text { P- } 1 / 2\end{array}$ & & & & Biparental \\
\hline
\end{tabular}

${ }^{1}$ Análise de matUPD(7) realizada previamente; ${ }^{2}$ excluído da análise, uma vez que determinamos alteração em 11p15 (Tabela IV.1); ${ }^{3}$ paciente portadora de t(5; 6) (Fonseca, 2005), não incluída nas estimativas. 
Tabela IV.2 - continuação

\begin{tabular}{|c|c|c|c|c|c|c|c|c|}
\hline Paciente & D7S 506 & D7S 519 & D7S 1870 & D7S 486 & D7S 493 & D7S 657 & D7S 515 & Resultado \\
\hline $\mathbf{T}^{1}$ & & & & & & & & Biparental \\
\hline $\mathbf{U}^{1}$ & & & & & & & & Biparental \\
\hline \multirow{3}{*}{ V } & M- $1 / 3$ & M- $1 / 3$ & M- $1 / 3$ & M- $1 / 3$ & & & & \multirow{3}{*}{ Biparental } \\
\hline & C- $1 / 3$ & C- $1 / 2$ & C- $2 / 3$ & C- $2 / 3$ & & & & \\
\hline & P- $2 / 3$ & P- $2 / 4$ & P- $2 / 4$ & P- $1 / 2$ & & & & \\
\hline \multirow{3}{*}{$\mathbf{W}$} & M- $1 / 1$ & M- $1 / 3$ & M- $2 / 3$ & M- $1 / 2$ & & & & \multirow{3}{*}{ Biparental } \\
\hline & C- $1 / 3$ & C- $1 / 3$ & C- $1 / 3$ & C- $1 / 1$ & & & & \\
\hline & P- $2 / 3$ & $\mathrm{P}-1 / 2$ & $\mathrm{P}-1 / 1$ & $\mathrm{P}-1 / 1$ & & & & \\
\hline \multirow{3}{*}{$\mathbf{X}$} & M- $2 / 4$ & M- $1 / 1$ & M- $2 / 3$ & M- $1 / 3$ & & & & \multirow{3}{*}{ Biparental } \\
\hline & C $-1 / 2$ & C- $1 / 1$ & C $-1 / 2$ & C- $3 / 4$ & & & & \\
\hline & P- $1 / 3$ & $\mathrm{P}-1 / 2$ & P- $1 / 3$ & P- $2 / 4$ & & & & \\
\hline \multirow{5}{*}{$\mathbf{Y}$} & M- $1 / 2$ & M- $2 / 3$ & M- $1 / 2$ & M- $3 / 4$ & & & & \multirow{5}{*}{ Biparental } \\
\hline & C- $2 / 2$ & C- $1 / 3$ & C- $1 / 3$ & C- $1 / 3$ & & & & \\
\hline & Ia1- $2 / 2$ & Ia1- $1 / 2$ & Ia1- $1 / 3$ & Ial- $2 / 3$ & & & & \\
\hline & Ia2- $1 / 2$ & Ia2- $1 / 2$ & Ia2- $2 / 3$ & Ia2- $2 / 3$ & & & & \\
\hline & P- ? & $\mathrm{P}-1 / ?$ & P- $3 / ?$ & P- $1 / 2$ & & & & \\
\hline \multicolumn{9}{|l|}{$\mathbf{Z}^{2}$} \\
\hline \multirow{3}{*}{$\mathbf{A A}$} & & M- $2 / 4$ & M- $1 / 2$ & M- $2 / 2$ & & & M- $2 / 4$ & \multirow{3}{*}{ Biparental } \\
\hline & & C- $2 / 3$ & C- $1 / 2$ & C- $2 / 2$ & & & C- $1 / 4$ & \\
\hline & & P- $1 / 3$ & P- $1 / 2$ & P- $1 / 2$ & & & P- $1 / 3$ & \\
\hline \multirow{3}{*}{ AB } & M- 3/? & M- ? & M- 3/? & M- ? & & & & \multirow{3}{*}{ Biparental } \\
\hline & C- $2 / 3$ & C- $2 / 2$ & C- $2 / 3$ & C- $2 / 2$ & & & & \\
\hline & P- $1 / 2$ & $\mathrm{P}-1 / 2$ & P- $1 / 2$ & P- $1 / 2$ & & & & \\
\hline \multirow{3}{*}{$\mathrm{AC}$} & M- $2 / 4$ & M- $1 / 2$ & M- $1 / 2$ & M- $2 / 3$ & & M- $1 / 3$ & M- $2 / 4$ & \multirow{3}{*}{ Biparental } \\
\hline & C- $3 / 4$ & C- $1 / 2$ & C- $1 / 2$ & C- $2 / 3$ & & C- $1 / 1$ & C- $1 / 4$ & \\
\hline & P- $1 / 3$ & P- $1 / 3$ & P- $2 / 3$ & P- $1 / 2$ & & P- $1 / 2$ & P- $1 / 3$ & \\
\hline \multirow{3}{*}{ AD } & & M- $1 / 3$ & M- $1 / 3$ & M- $1 / 1$ & & & & \multirow{3}{*}{ Biparental } \\
\hline & & C- $1 / 2$ & C- $1 / 2$ & C- $1 / 1$ & & & & \\
\hline & & P- $2 / ?$ & P- $2 / ?$ & P-? & & & & \\
\hline \multirow{3}{*}{$\mathbf{A E}$} & & M- $1 / 1$ & & M- $3 / 3$ & & & & \\
\hline & & C- $1 / 3$ & & C- $1 / 3$ & & & & Biparental \\
\hline & & P- $2 / 3$ & & P- $1 / 2$ & & & & \\
\hline & M- $1 / 2$ & M- $1 / 3$ & & M- $3 / 4$ & M- $2 / 4$ & & M- $1 / 2$ & \\
\hline & C- $2 / 3$ & C- $1 / 2$ & & C- $2 / 4$ & C- $3 / 4$ & & C- $1 / 4$ & \\
\hline AF & P- $2 / 3$ & P- $1 / 2$ & & P- $1 / 2$ & P- $1 / 3$ & & P- $3 / 4$ & Biparental \\
\hline & Ia- $1 / 3$ & Ia- $2 / 3$ & & Ia- $1 / 3$ & Ia- ? & & Ia- $2 / 3$ & \\
\hline & M- $1 / 3$ & M- $1 / 2$ & & M- $2 / 4$ & & & & \\
\hline $\mathbf{A G}$ & C- $3 / 4$ & C- $2 / 4$ & & C- $3 / 4$ & & & & Biparental \\
\hline & P- $2 / 4$ & $\mathrm{P}-3 / 4$ & & P- $1 / 3$ & & & & \\
\hline $\mathbf{A} \mathbf{H}^{2}$ & & & & & & & & \\
\hline $\mathbf{A I}^{2}$ & & & & & & & & \\
\hline & M- $1 / 2$ & M- $2 / 3$ & M- $1 / 2$ & M- $2 / 2$ & & & & \\
\hline A.J & C- $1 / 1$ & C- $1 / 3$ & C- $2 / 2$ & C- $1 / 2$ & & & & Biparental \\
\hline & P- ? & $\mathrm{P}-1 /$ ? & P-? & P- $1 /$ ? & & & & \\
\hline & M- $1 / 1$ & M- $2 / 3$ & M- $1 / 2$ & M- $2 / 3$ & & & M- $1 / 2$ & \\
\hline AK & C- $1 / 1$ & C- $2 / 3$ & C- $1 / 2$ & C- $3 / 3$ & & & C- $2 / 2$ & matUPD \\
\hline & P- $2 / 2$ & $\mathrm{P}-1 / 4$ & P- $1 / 3$ & P- $1 / 3$ & & & $\mathrm{P}-1 / 1$ & \\
\hline $\mathbf{A} \mathbf{L}^{2}$ & & & & & & & & \\
\hline $\mathbf{A M}^{2}$ & & & & & & & & \\
\hline $\mathbf{A} \mathbf{N}^{2}$ & & & & & & & & \\
\hline & M- $1 / 2$ & M- $2 / 3$ & $\mathrm{M}-2 / 2$ & M- $3 / 4$ & & & & \\
\hline AO & C- $1 / 3$ & C- $1 / 3$ & C- $2 / 3$ & C- $1 / 4$ & & & & Biparental \\
\hline & P- $3 / 3$ & $\mathrm{P}-1 / 1$ & P- $1 / 3$ & P- $1 / 2$ & & & & \\
\hline
\end{tabular}

${ }^{1}$ Análise de matUPD(7) realizada previamente; ${ }^{2}$ excluído da análise, uma vez que determinamos alteração em 11 p15 (Tabela IV.1); ${ }^{3}$ paciente portadora de $\mathrm{t}(5 ; 6)$ (Fonseca, 2005), não incluída nas estimativas. 
Tabela IV.2 - continuação

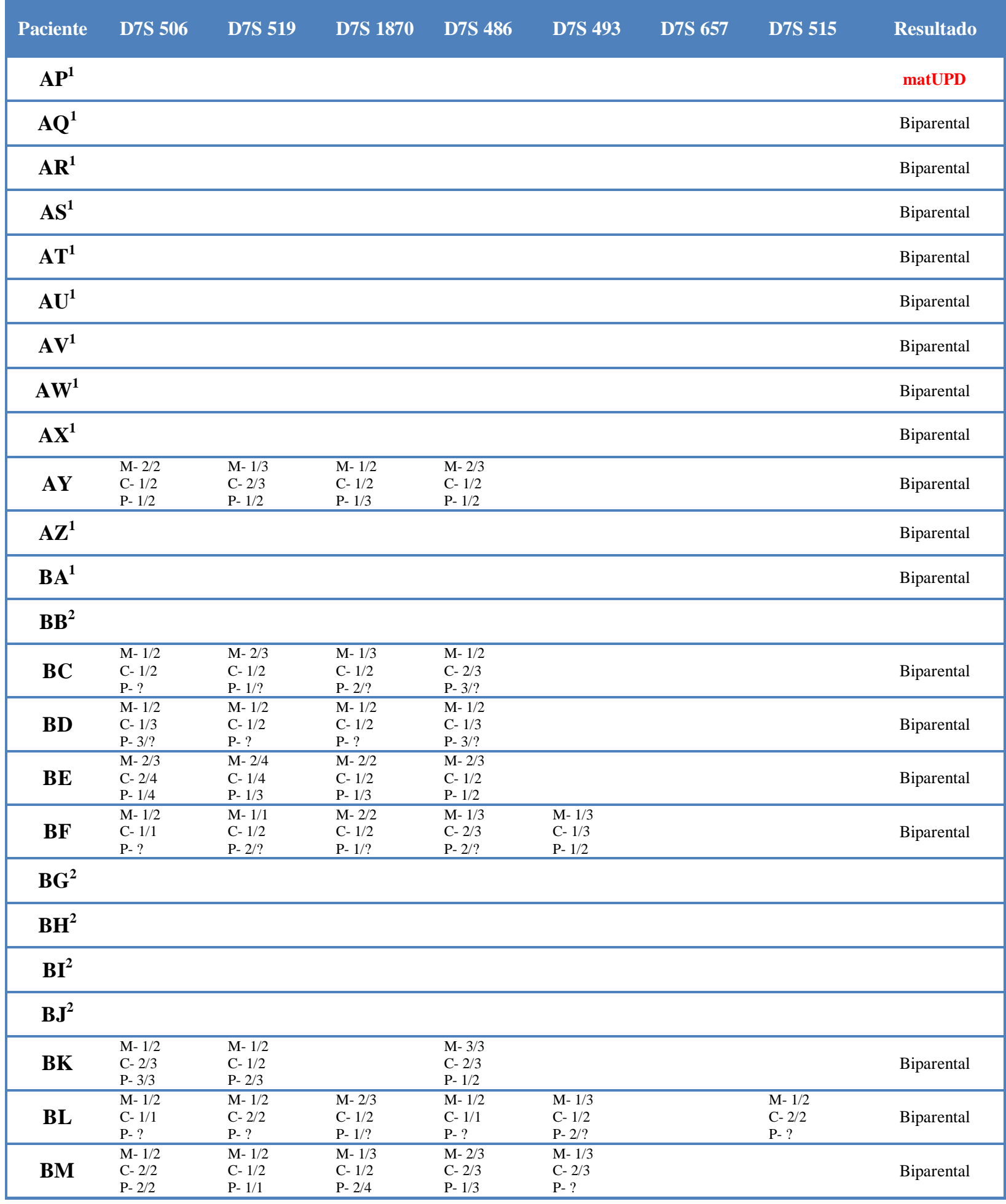

${ }^{1}$ Análise de matUPD(7) realizada previamente; ${ }^{2}$ excluído da análise, uma vez que determinamos alteração em 11 p15 (Tabela IV.1); ${ }^{3}$ paciente portadora de $\mathrm{t}(5 ; 6)$ (Fonseca, 2005), não incluída nas estimativas. 
A)

Herança Biparental
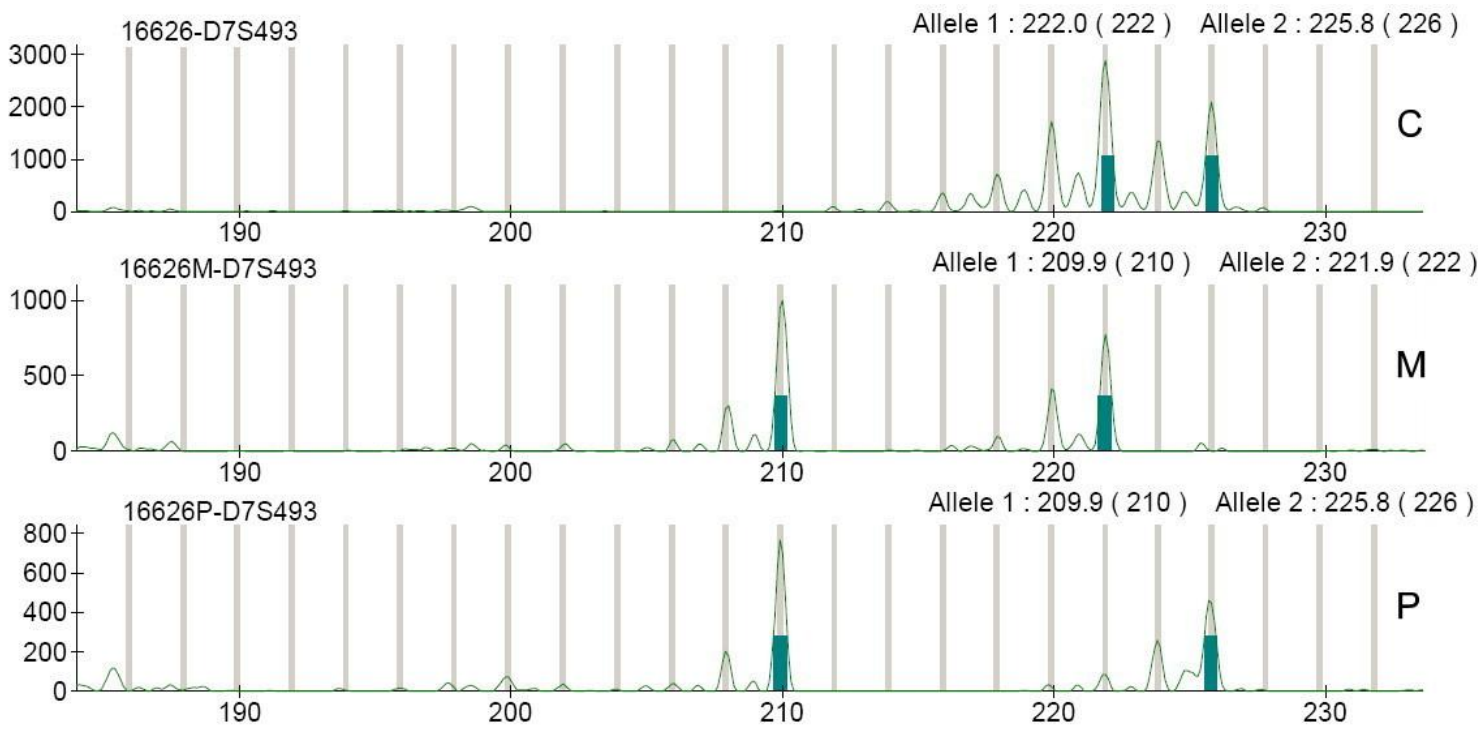

B)

Dissomia Uniparental do Cromossomo 7
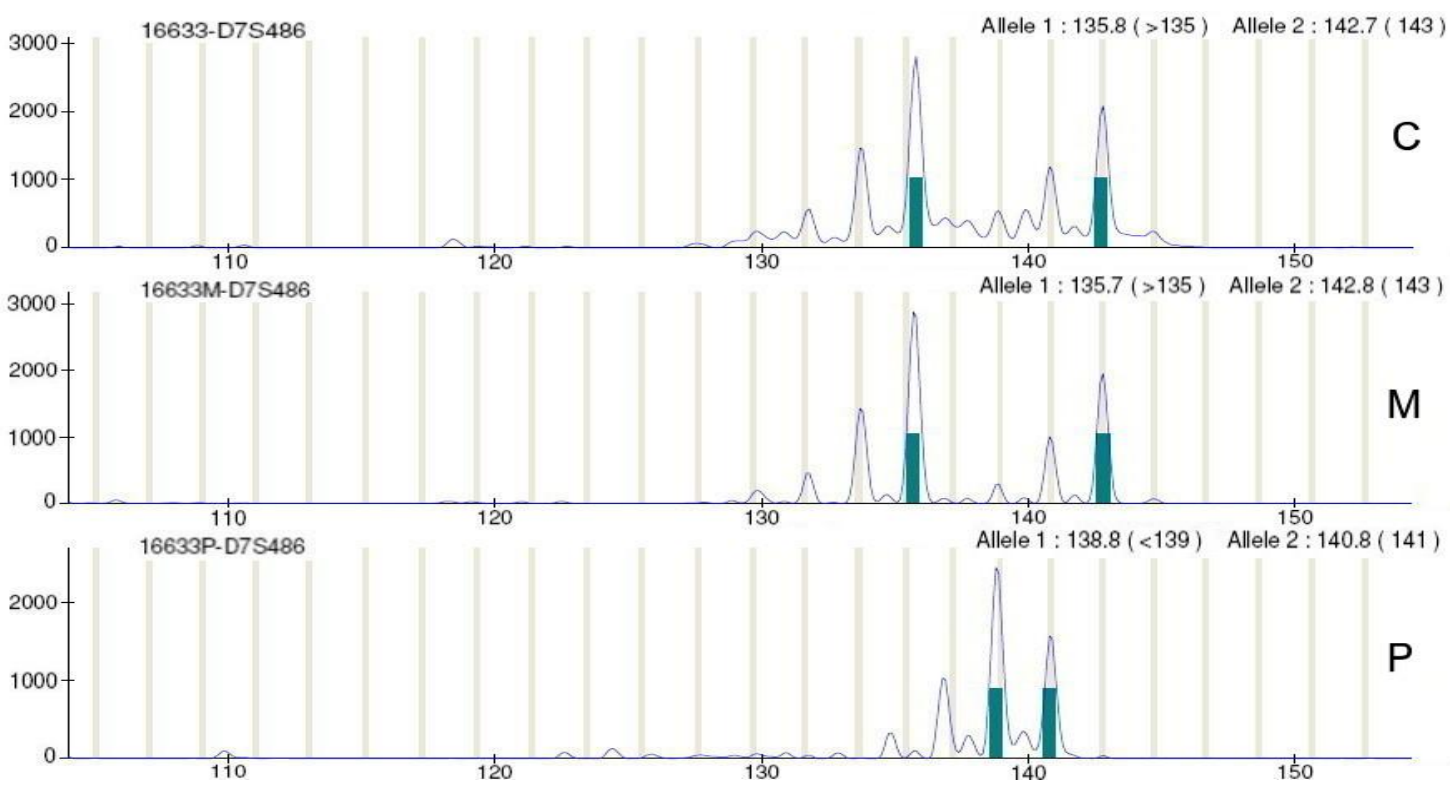

Figura IV.4 - Exemplos da análise de microssatélites, utilizando o programa Genetic Profiler, na investigação de matUPD(7): (a) Herança biparental dos alelos (b) Heterodissomia uniparental do cromossomo 7, o paciente possuindo ambos os alelos maternos, mas nenhum alelo paterno. $\mathrm{C}=$ paciente; $\mathrm{M}=$ Mãe; $\mathrm{P}=$ Pai. 


\section{IV.3 Investigação de microdeleções e microduplicações por array-CGH}

A análise com o objetivo de buscar microdeleções ou microduplicações cromossômicas submicroscópicas (CNV) que possam estar associadas à SRS foi realizada utilizando a-CGH. Foram incluídos nessa análise pacientes que não apresentaram alterações em 11 p15 ou matUPD(7). Não foram incluídos ainda sete pacientes por não haver DNA disponível para a realização do experimento.

Ao todo, 19 pacientes foram investigados (Tabela IV.3), utilizando-se as plataformas da Agilent 44K (pacientes D, X, AA, AC, AE-AG, J, S, AJ, AO), 60K (pacientes BE, BF, BK-BM) ou $105 \mathrm{~K}$ (pacientes $\mathrm{AY}, \mathrm{BC}$ e BD). As CNV identificadas foram comparadas àquelas documentadas no banco de dados DGV e DECIPHER. Verificamos no banco de dados do NCBI (National Center of Biotechnology Information, http://www.ncbi.nlm.nih.gov/gene/) as descrições e funções dos genes que estavam presentes nos segmentos cromossômicos alterados.

A maioria dos pacientes não apresentou alterações $(n=7)$ ou possuíam apenas $\mathrm{CNV}$ frequentes em indivíduos normais da população $(n=8)$ e consideradas polimorfismos, de acordo com o banco de dados DGV. Dessa forma, não podemos atribuir efeito desses desequilíbrios cromossômicos na patologia da SRS e a presença dessas alterações não foi investigada nos genitores dos pacientes.

Entretanto, identificamos quatro portadores de microdeleções não comuns, com possibilidade de efeito patogênico: em 15q11.2 (paciente AO), em 16p13.11 (paciente AY), em 13q24 (paciente D) e em 2p23.3 (paciente X) (Tabela IV.3). Esses desequilíbrios cromossômicos estão incluídos no DGV, mas tendo frequências menores do que aqueles que são considerados variações polimórficas. Dentre essas quatro alterações, a microdeleção em 2p23.3, no paciente X, é a única que não foi descrita em indivíduos normais da população. Quando possível, analisamos os genitores desses pacientes para verificar se a alteração foi herdada. 
Tabela IV.3 - Resultados da análise cromossômica molecular realizada por a-CGH em 19 pacientes em que foram afastadas UPD(7) e alterações em $11 \mathrm{p} 15$ como causa da SRS. A localização cromossômica das CNV é baseada no assembly do genoma humano de março de 2006 (NCBI36/hg18). Del = deleção; Dup = duplicação.

\begin{tabular}{|c|c|c|c|c|c|c|c|c|}
\hline Paciente & Plataforma & $\begin{array}{c}\text { Tipo de } \\
\text { alteração }\end{array}$ & Localização cromossômica & Banda & $\begin{array}{l}\mathbf{N}^{0} \text { sondas } \\
\text { alteradas }\end{array}$ & $\begin{array}{l}\text { Extensão } \\
(\mathbf{K b})\end{array}$ & $\begin{array}{c}\text { CNV } \\
\text { polimórfica }\end{array}$ & Genes \\
\hline \multirow{2}{*}{ D } & \multirow{2}{*}{$44 \mathrm{~K}$} & Del & chr13: 113810796-113905108 & q34 & 3 & 94,3 & Não & RASA3 \\
\hline & & Del & chr19: 1876757-1929500 & p13.3 & 3 & 52,7 & Sim & SCAMP4, CSNK1G2, C19orf 34 \\
\hline $\mathbf{J}$ & $44 \mathrm{~K}$ & Dup & chr14: 18864561-19365110 & $\mathrm{q} 11.1-11.2$ & 3 & 500,5 & Sim & POTEM, OR4Q3, OR4MI \\
\hline \multirow[b]{2}{*}{$\mathbf{S}$} & \multirow[b]{2}{*}{$44 \mathrm{~K}$} & Del & chr1: 195012687-195063786 & $\mathrm{q} 31.3$ & 3 & 51,1 & $\operatorname{Sim}$ & CFHR3, CFHRI \\
\hline & & Del & chr10: 46371243-47074883 & q11.22 & 6 & 703,4 & Sim & $\begin{array}{l}\text { SYT15, GPRIN2, PPYR1, ANXA8, FAM25C, } \\
\text { FAM25G, FAM25B, AGAP9, FAM } 35 B 2\end{array}$ \\
\hline $\mathbf{X}$ & $44 \mathrm{~K}$ & Del (pat) & chr2: 24107063-24426179 & p23.3 & 9 & 319,1 & Não & $\begin{array}{l}\text { C2orf } 44, \text { FKBP1B, SF3B14, TP53I3,PFN4 } \\
\text { LOC } 375190, \text { C2orf } 84, \text { ITSN2 }\end{array}$ \\
\hline $\mathbf{A A}$ & $44 \mathrm{~K}$ & Sem alteração & & & & & & \\
\hline $\mathbf{A C}$ & $44 \mathrm{~K}$ & Dup & chr5: 697411118-70424741 & q13.2 & 4 & 683,6 & Sim & $\begin{array}{l}\text { GTF2H2B, GTF2H2C, GTF2H2D, SERF1A, } \\
\text { SERF1B, SMN1, SMN2, NAIP, OCLIN }\end{array}$ \\
\hline $\mathbf{A E}$ & $44 \mathrm{~K}$ & Sem alteração & & & & & & \\
\hline $\mathbf{A F}$ & $44 \mathrm{~K}$ & Sem alteração & & & & & & \\
\hline AG & $44 \mathrm{~K}$ & Sem alteração & & & & & & \\
\hline AJ & $44 \mathrm{~K}$ & Del & chr15: 19109124-20010618 & $\mathrm{q} 11.2$ & 3 & 901,5 & Sim & $\begin{array}{l}\text { GOLGA8C, BCL8, LOC646214, CXADRP2, } \\
\text { POTEB, NF1P1, OR4M2, OR4N4, OR4N3P }\end{array}$ \\
\hline \multirow{2}{*}{ AO } & \multirow{2}{*}{$44 \mathrm{~K}$} & Del & chr12: 7915622-7979927 & p13.31 & 3 & 64,3 & $\operatorname{Sim}$ & $S L C 2 A 14, S L C 2 A 3$ \\
\hline & & Del (mat) & chr15: 20316992-20636537 & $\mathrm{q} 11.2$ & 11 & 319,5 & Não & TUBGCP5, CYFIPI, NIPA2, NIPAI \\
\hline \multirow{2}{*}{$\mathbf{A Y}$} & \multirow{2}{*}{$105 \mathrm{~K}$} & Del & chr16: 14955977-15051821 & p13.11 & 5 & 95,8 & Não & PDXDC1, NTAN1 \\
\hline & & Dup & chr17: 22989703-23134747 & $\mathrm{q} 11.1$ & 6 & 145 & Sim & LGALS9, NOS2 \\
\hline
\end{tabular}


Tabela IV.3 - continuação

\begin{tabular}{|c|c|c|c|c|c|c|c|c|}
\hline Paciente & Plataforma & $\begin{array}{l}\text { Tipo de } \\
\text { alteração }\end{array}$ & Localização cromossômica & Banda & $\begin{array}{l}\mathbf{N}^{0} \text { sondas } \\
\text { alteradas }\end{array}$ & $\begin{array}{c}\text { Extensão } \\
(\mathbf{K b})\end{array}$ & $\begin{array}{c}\text { CNV } \\
\text { polimórfica }\end{array}$ & Genes \\
\hline BC & $105 \mathrm{~K}$ & Sem alteração & & & & & & \\
\hline \multirow{3}{*}{ BD } & \multirow{3}{*}{$105 \mathrm{~K}$} & Del & chr1: 25481836-25529749 & p36.11 & 3 & 47,9 & Sim & $R H D$ \\
\hline & & Del & chr8: 39356395-39499952 & p11.23 & 7 & 143,6 & Sim & ADAM5P, ADAM3A \\
\hline & & Dup & chrX: 148694072-148834903 & $\mathrm{q} 28$ & 5 & 140,8 & Sim & MAGEA8 \\
\hline BE & $60 \mathrm{~K}$ & Dup & chr2: 242534859-242656173 & $\mathrm{q} 37$ & 5 & 121,3 & Sim & \\
\hline BF & $60 \mathrm{~K}$ & Sem alteração & & & & & & \\
\hline BK & $60 \mathrm{~K}$ & Del & chr15: 18741716-20010618 & $\mathrm{q} 11.2$ & 13 & 1268,9 & Sim & $\begin{array}{l}\text { GOLGA8C, BCL8, LOC646214, CXADRP2, } \\
\text { POTEB, NF1P1, OR4M2, OR4N4, OR4N3P }\end{array}$ \\
\hline BL & $60 \mathrm{~K}$ & Sem alteração & & & & & & \\
\hline $\mathbf{B M}$ & $60 \mathrm{~K}$ & Del & chr8: 39378051-39505315 & $\mathrm{p} 11.23$ & 4 & 127,3 & Sim & ADAM5P, АDAM3A \\
\hline
\end{tabular}


Pacientes portadores apenas de variações comuns no número de cópias de DNA (Tabela IV.3)

Na paciente J, detectamos uma microduplicação em 14q11.1-11.2, com cerca de $500 \mathrm{~Kb}$. Nesse segmento estão localizados alguns genes provisórios (Entrez Gene, NCBI; http://www.ncbi.nlm.nih.gov/gene). Centenas de microduplicações e microdeleções menores ou abrangendo parte desse segmento cromossômico e outras 250 alterações que incluem a variante presente na nossa paciente estão documentadas em indivíduos normais da população (DGV). No DECIPHER, não encontramos associação dessa variante com fenótipos patológicos.

No paciente $S$, identificamos duas microdeleções, nos segmentos 1q31.3 (51,1 Kb) e 10q11.22 (703,4 Kb). No DGV, há uma grande quantidade de duplicações e deleções cromossômicas, abrangendo a microdeleção que detectamos em 1q31.3, em indivíduos normais. Os genes localizados nessa microdeleção pertencem à família do fator $H$ do sistema complemento, cuja função não está relacionada ao crescimento (Entrez Gene, NCBI). Apesar de haver vários genes mapeados no segmento 10q11.22 deletado no paciente $\mathrm{S}$, a maioria tem função desconhecida e aqueles que foram confirmados não estão relacionados com o crescimento. Onze microdeleções e 60 microduplicações de tamanho semelhante foram documentadas em indivíduos normais; outras 65 microdeleções e 213 microduplicações abrangendo o segmento deletado em nosso paciente e também uma grande quantidade de alterações menores incluídas nesse segmento foram detectadas em pessoas normais da população (DGV). No DECIPHER, encontramos cinco pacientes portadores de deleções em 10q11.22, maiores do que aquela presente no nosso paciente, mas em associação com diversos desequilíbrios em outros cromossomos.

No paciente AC, detectamos uma microduplicação com cerca de $680 \mathrm{~Kb}$, em 5q13.2, que constitui polimorfismo conhecido. Em 5q13.2 ocorre uma duplicação invertida de segmento de cerca de $500 \mathrm{~Kb}$. Pelo menos quatro genes e vários elementos repetitivos estão mapeados nesse segmento duplicado, tornando-o propenso a rearranjos cromossômicos (Entrez Gene, NCBI). O DGV lista 257 indivíduos normais com microduplicações e microdeleções que abrangem toda essa região e outros 260 com alterações que incluem parte desse segmento, em sua maioria duplicações. 
Os pacientes AJ e BK possuem microrrearranjos muito semelhantes, em 15q11.2. A microdeleção detectada em AJ abrange aproximadamente $0,9 \mathrm{Mb}$ e aquela presente em BK, cerca de 1,27 Mb. Nesse segmento estão mapeados vários pseudogenes, alguns provisórios, e três genes codificadores de proteína, POTEB, OR4M2 e OR4N4. O primeiro desses genes não tem função conhecida e os dois últimos fazem parte da grande família de receptores olfativos (Entrez Gene, NCBI). O DGV lista uma grande quantidade de indivíduos clinicamente normais apresentando rearranjos diversos nessa região, muitos deles com mais de $2 \mathrm{Mb}$ de extensão. No DECIPHER encontramos alguns pacientes portadores de deleções ou duplicações semelhantes à dos nossos pacientes que também apresentam diversos desequilíbrios em outros cromossomos.

No paciente $\mathrm{BD}$, detectamos três desequilíbrios genômicos comuns na população geral. A microdeleção em 1p36.11, abrangendo o gene RHD (Rh blood group, D antigen), é uma variante descrita em 328 indivíduos normais no DGV. A microdeleção identificada em 8p11.23 é semelhante à que detectamos na paciente BM. Nossa busca revelou a presença dessa variante em 484 indivíduos normais (DGV). A microduplicação em Xq28 também está presente em indivíduos normais (DGV). No DECIPHER, não encontramos associação dessas variantes cromossômicas com fenótipos patológicos.

$\mathrm{Na}$ paciente BE, detectamos uma microduplicação em 2q37, num segmento que não contém genes. Deleções de segmentos maiores, que incluem este, foram descritos em 88 indivíduos fenotipicamente normais, de acordo com busca no DGV. Somente uma duplicação que inclui todo esse segmento foi descrita em indivíduo normal, mas 284 deleções e 35 duplicações de segmentos incluídos no rearranjo que identificamos, ou abrangendo parte dele, foram relatados em indivíduos normais no DGV. No DECIPHER, havia seis pacientes portando microduplicações (cinco) ou microdeleções (um) menores ou com tamanho próximo à microduplicação presente na paciente BE. No entanto, não há descrição clínica disponível e alguns pacientes são portadores de desequilíbrios em outros cromossomos além daquela no cromossomo 2. Essas informações obtidas nos bancos de dados indicam que é mais provável que a microduplicação que detectamos em 2q37 não esteja relacionada ao quadro clínico de SRS. 
Pacientes portadores de variações não comuns no número de cópias de DNA

(Tabela IV.3)

No paciente AO, detectamos uma microdeleção em 15q11.2, num segmento com cerca de $320 \mathrm{~Kb}$ que abrange os genes TUBGCP5 (tubulin, gamma complex associated protein 5), CYFIP1 (cytoplasmic FMR1 interacting protein 1), NIPA2 (non imprinted in PraderWilli/Angelman syndrome 2) e NIPA1 (non imprinted in Prader-Willi/Angelman syndrome 1) (Figura IV.5). Identificamos a mesma microdeleção na mãe do paciente. Deleções abrangendo esses quatro genes foram relatadas em 30 indivíduos normais da população, num total de aproximadamente 4500 analisados $(\sim 0,6 \%)$, de acordo com o DGV. O banco de dados lista com a mesma frequência duplicações que incluem esse segmento, presentes em indivíduos normais. Verificamos no banco de dados DECIPHER que existem vários indivíduos afetados por condições diversas que apresentam deleções ou duplicações em 15q11.2. Deleções maiores, incluindo os quatro genes, estavam presentes em um subgrupo de pacientes com síndrome de Angelman ou de Prader-Willi. Trata-se de segmentos com rearranjos recorrentes, mediados por duplicações segmentares (Figura IV.6).

Recentemente, Von der Lippe e col. (2010) relataram sete pacientes com atraso no desenvolvimento global e distúrbios de comportamento, portadores de microdeleções em $15 \mathrm{q} 11.2(\sim 350 \mathrm{~Kb})$ restritas aos genes TUBGCP5, CYFIP1, NIPA2 e NIPA1 (Figura IV.6). Os autores revisaram outros trabalhos (Murphy e col., 2006; Doornbos e col., 2009) que descreviam a associação entre esse desequilíbrio cromossômico e comprometimento mental, distúrbios de comportamento e dismorfismos diversos, totalizando 17 pacientes. Nosso paciente AO compartilha várias características com outros pacientes portadores dessa deleção, como o atraso na aquisição da fala e no desenvolvimento motor, além de alguns sinais físicos. Ele também apresenta dificuldades de aprendizado e problemas de relacionamento, frequentando escola especial, como a maioria dos outros pacientes. Entretanto, o comprometimento mental do nosso paciente pode ser explicado pelas graves intercorrências neonatais, que incluíram septicemia. O retardo de crescimento intrauterino foi relatado em três pacientes dos 17 portadores dessa microdeleção e em um deles o déficit de crescimento persistiu no período pós-natal. Como no caso de nosso paciente, a maioria das deleções presentes em afetados, descritas na literatura, foi 
herdada de um genitor clinicamente normal ou levemente afetado, sugerindo penetrância incompleta e expressividade variável.

Os quatro genes mapeados no segmento deletado em 15q11.2 não estão em segmentos sujeitos a imprinting genômico e são altamente conservados evolutivamente. TUBGCP5 é expresso no núcleo subtalâmico, enquanto os genes CYFIP1, NIPA2 e NIPA1 são altamente expressos no sistema nervoso central. Isso indica que a haploinsuficiência desses genes pode estar contribuindo para os problemas cognitivos e comportamentais dos pacientes. Após a investigação de 350 indivíduos clinicamente normais, Doornbos e col. (2009) concluíram que a microdeleção em 15q11.2, abrangendo os quatro genes, está presente com maior frequência em pacientes com problemas de aprendizado e de comportamento do que na população geral, sugerindo que a deleção é potencialmente patogênica. Os autores sugerem a existência de nova síndrome de microdeleção em 15q11.2. Em nosso paciente, alguns sinais clínicos característicos da SRS levaram a suspeitar dessa síndrome; é provável, contudo, que faça parte desse grupo de pacientes com microdeleção em 15q11.2.

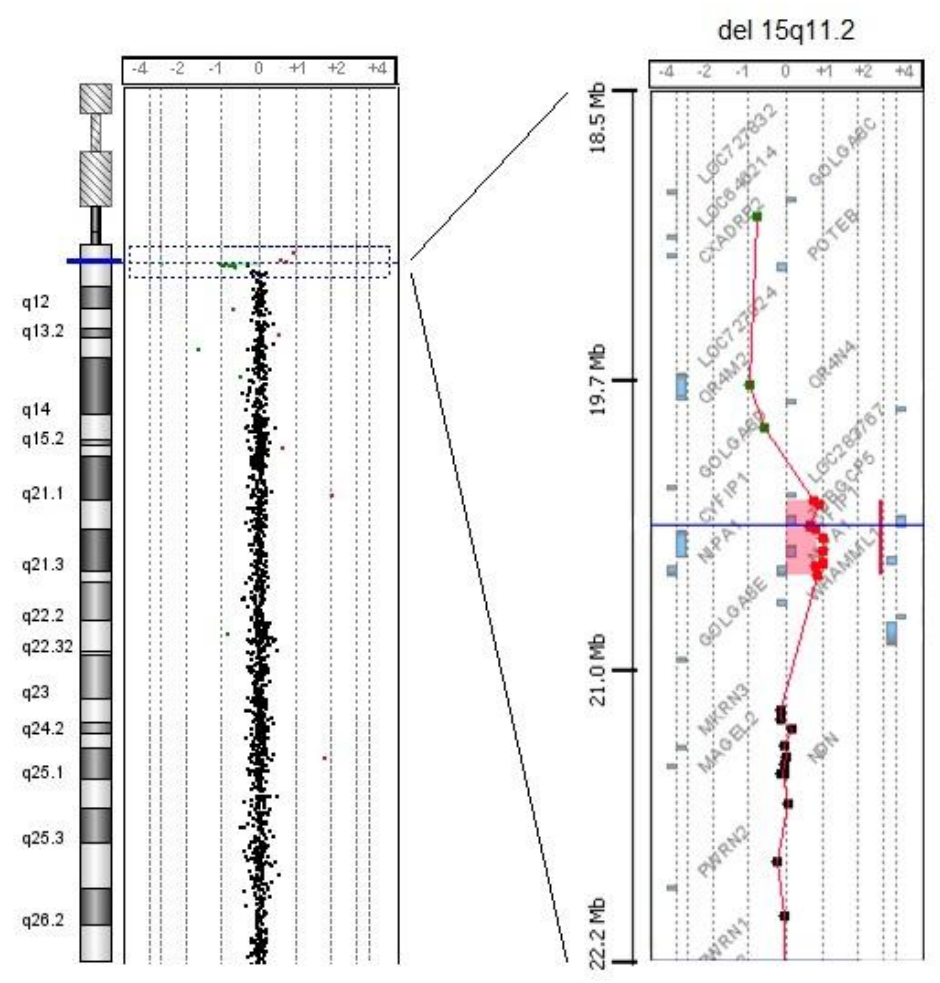

Figura IV.5 - Microdeleção de $320 \mathrm{~Kb}$ em 15q11.2, detectada no paciente AO (plataforma 44K, Agilent Technologies). A barra vermelha na imagem à direita indica o segmento deletado. 


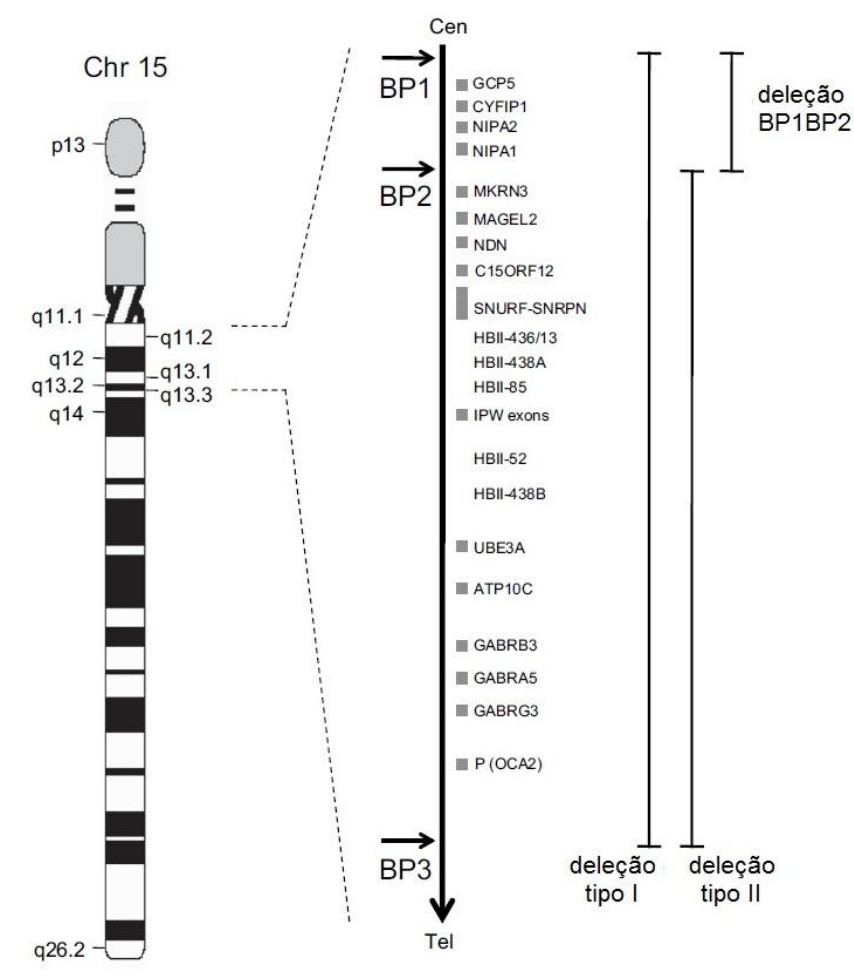

Figura IV.6 - Idiograma do cromossomo 15 e a ordem dos genes no segmento 15q11-q13. Três pontos de quebra comuns estão indicados (BP1, BP2 e BP3). Deleções recorrentes tipo I e II estão associadas a AS e PWS. Nosso paciente AO e outros (revisão em Von der Lippe e col., 2010) apresentam microdeleções semelhantes entre os pontos de quebra BP1 e BP2, segmento em que estão localizados os genes TUBGCP5, CYFIP1, NIPA2 e NIPA1 (modificada de Doornbos e col., 2009).

No paciente AO identificamos também uma microdeleção em 12p13.31 (64,3 Kb), segmento no qual estão mapeados os genes SLC2A14 e SLC2A3 [solute carrier family 2 (facilitated glucose transporter), member 14 e 3], cujas proteínas são membros de uma família de transportadores de glicose (Entrez Gene, NCBI). Várias alterações nesse segmento do cromossomo 12 estão documentadas no DGV em indivíduos normais da população, constituindo provavelmente um polimorfismo. Cerca de 50 microdeleções e 200 microduplicações incluem a variante que detectamos e existem ainda diversas variações menores ou abrangendo parte dela. No DECIPHER, encontramos um paciente com duplicação num segmento semelhante; esse desequilíbrio, no entanto, foi herdado de um genitor clinicamente normal e o paciente apresenta diversas alterações em outros cromossomos. 
Na paciente AY, a microdeleção, de aproximadamente 95,8 Kb em 16p13.11, abrange os genes PDXDC1 (pyridoxal-dependent decarboxylase domain containing 1) e NTAN1 (N-terminal asparagine amidase), ambos com função desconhecida (Figura IV.7). Duplicações e deleções restritas ao gene $P D X D C 1$ aparecem com frequência elevada (>10\%) em indivíduos clinicamente normais no DGV. No entanto, menos de $0,2 \%$ da população apresenta deleção do gene NTAN1.

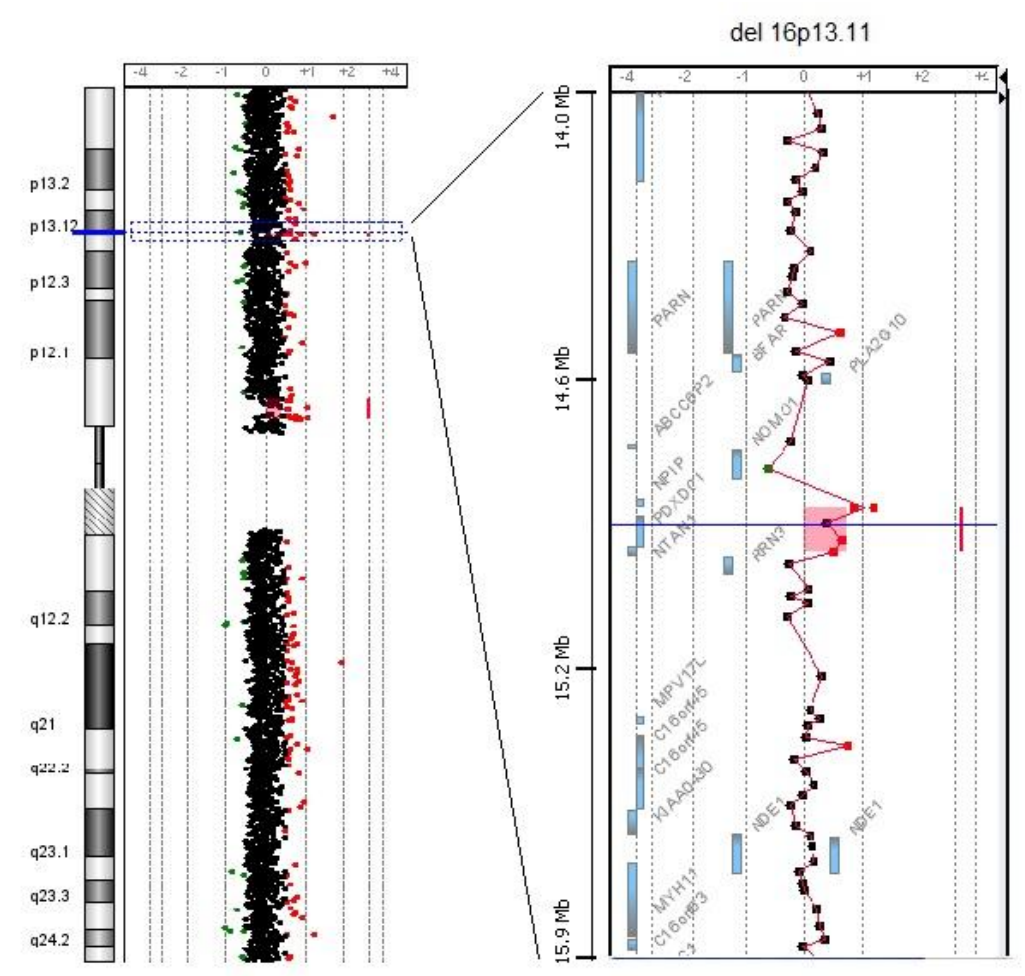

Figura IV.7 - Microdeleção de 95,8 Kb em 16p13.11, detectada na paciente AY, por a-CGH (plataforma 105K, Agilent Technologies). A barra vermelha na imagem à direita indica o segmento deletado.

Hannes e col. (2009) analisaram por a-CGH, utilizando duas plataformas de BAC (uma com 3200 clones e outra com 2000 clones), 1027 pacientes com deficiência mental ou anomalias congênitas múltiplas e detectaram cinco com deleções e outros cinco com duplicações recíprocas de 1,65 Mb em 16p13.11, abrangendo 15 genes. Além da deficiência mental, três dos pacientes com deleção apresentavam microcefalia e epilepsia e desses, dois tinham baixa estatura. Em alguns pacientes essas alterações foram herdadas de pais não afetados e nos outros eram de novo. Nesse estudo, os autores ainda avaliaram 2014 indivíduos normais da população, 
mas não encontraram deleções semelhantes, mostrando que esses desequilíbrios estavam significativamente associados aos quadros clínicos $(p=0.0048)$. As duplicações recíprocas foram observadas também de forma herdada ou de novo, mas estavam presentes com igual frequência em indivíduos normais, indicando que essa variante é compatível com o fenótipo normal ou pode estar associada de maneira complexa a fenótipo patológico. Antes, Ullmann e col., (2007), analisando 182 pacientes com autismo por a-CGH de alta resolução, descreveram três portadores de uma duplicação de 1,5 Mb em 16p13.11. A mesma duplicação foi identificada em vários parentes afetados de maneira variável e também em parentes clinicamente normais. Uma deleção do mesmo segmento cromossômico foi detectada em três pacientes com deficiência mental e anomalias congênitas, mas foi identificada também em indivíduos com inteligência normal em suas famílias. Esses rearranjos não foram detectados em uma amostra de 4600 indivíduos clinicamente normais. A interpretação desses achados foi que microduplicações e microdeleções de $1.5 \mathrm{Mb}$ em 16p13.11 predispõem fortemente, mas não são suficientes, para causar autismo ou deficiência mental. Assim, o fenótipo patológico dependeria de outros fatores. Nossa paciente AY possui uma microdeleção de apenas 95,8 Kb, abrangendo dois genes do segmento considerado crítico para predispor ao quadro clínico de deficiência mental ou autismo. Não pudemos determinar se essa alteração era ou não herdada, devido a problemas técnicos decorrentes da qualidade do DNA extraído do sangue periférico dos pais, que nos foi enviado pela Universidade de Brasília. Portanto, não pudemos associar de forma clara essa variante ao fenótipo da SRS.

Além da deleção em 16p13.11, essa paciente apresentou uma microduplicação em 17q11.1, com cerca de $145 \mathrm{~Kb}$, abrangendo a porção 3' dos genes LGALS9 (lectin, galactosidebinding, soluble, 9) e NOS2 (nitric oxide synthase 2, inducible); LGALS9 faz parte de uma família de proteínas que modulam interações célula-célula e célula-matriz; NOS2 codifica uma sintase de óxido nítrico, um mediador de vários processos biológicos (Entrez Gene, NCBI). No DGV, foram compiladas algumas microdeleções e microduplicações maiores que incluem aquela identificada na nossa paciente. Outras microduplicações de segmentos menores abrangem somente LGALS9 ou NOS2. No DECIPHER, não encontramos associação dessa variante cromossômica com fenótipos patológicos. Assim, é mais provável que esses dois genes não estejam relacionados com o fenótipo da nossa paciente. 
$\mathrm{Na}$ paciente $\mathrm{D}$, identificamos uma microdeleção com aproximadamente 94,3 $\mathrm{Kb}$ em 13q24 (Figura IV.8). A região deletada abrange pelo menos quatro dos 24 exons do gene RASA3, cujo produto proteico faz parte da família GAP1 de proteínas ativadoras de GTPase. A proteína estimula a atividade de GTPase da p21 RAS, o que permite o controle de proliferação e diferenciação celular (Entrez Gene, NCBI). Deleções maiores ( 160-190 Kb), abrangendo toda a extensão do gene RASA3 foi descrita apenas em dois indivíduos normais, num total de 515 investigados (DGV). No DECIPHER, não encontramos alteração semelhante. Investigamos a genitora clinicamente normal da paciente, mas não encontramos a microdeleção. Não foi possível realizar o teste no pai, que é falecido. Portanto, não sabemos se o desequilíbrio cromossômico foi herdado. A paciente é filha única e membros da família paterna não estavam disponíveis para exame. A pouca informação acerca da função do gene RASA3 e a presença da deleção em heterozigose com o alelo normal em pessoas normais não nos permitiu atribuir-lhe efeito clínico claro.

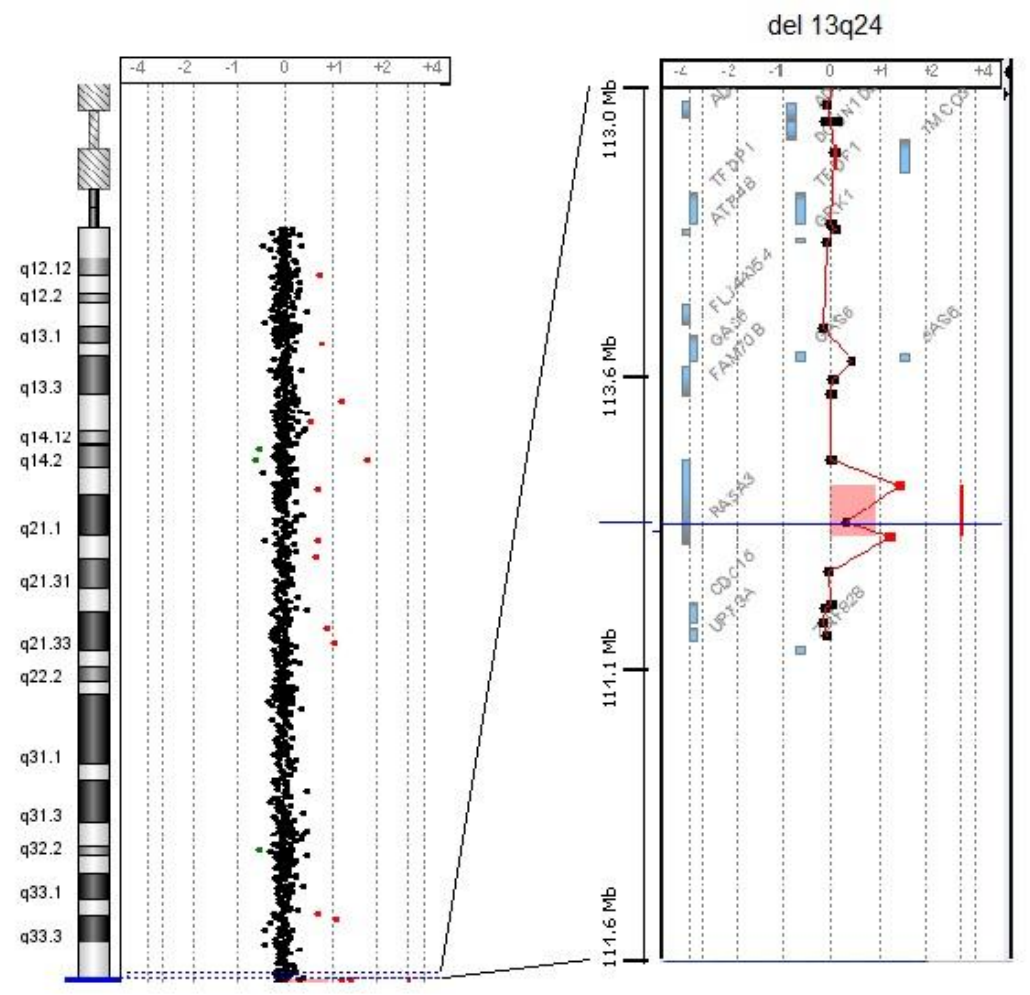

Figura IV.8 - Microdeleção de $94,3 \mathrm{~Kb}$ em 13q24, detectada na paciente D, por a-CGH (plataforma 44K, Agilent Technologies). A barra vermelha na imagem à direita indica o segmento deletado. 
Ainda na paciente D, detectamos uma microdeleção em 19p13.3 (52,7 Kb), que abrange parte dos genes SCAMP4 (secretory carrier membrane protein 4) e CSNK1G2 (casein kinase 1, gamma 2) e o gene C19orf34. Os dois primeiros são codificadores de proteínas, enquanto o último é um RNA não codificador, todos com função desconhecida (Entrez Gene, NCBI). No DGV, uma microdeleção semelhante foi descrita em indivíduo fenotipicamente normal; o banco de dados lista também 11 deleções e 13 duplicações de segmentos cromossômicos maiores e cerca de 20 alterações menores que estão incluídas na variante que detectamos. No DECIPHER, não encontramos associação dessa variante com fenótipos patológicos. A falta de informação sobre os genes localizados no segmento deletado em nossa paciente não nos permitiu atribuir-lhe efeito clínico.

No paciente $X$, detectamos uma microdeleção abrangendo cerca de $320 \mathrm{~Kb}$ em 2p23.3 (Figura IV.9). A região contém quatro genes com função conhecida (Entrez Gene, NCBI): FKBP1B (FK506 binding protein 1B, $12.6 \mathrm{kDa}$ ), SF3B14 (splicing factor 3B, $14 \mathrm{kDa}$ subunit), TP53I3 (tumor protein p53 inducible protein 3) e ITSN2 (intersectin 2). Nenhum outro indivíduo com microdeleção semelhante está documentado no DGV ou no DECIPHER. Entretanto, ao investigar se essa microdeleção era herdada, detectamos o desequilíbrio no pai do paciente, sem sinais clínicos de SRS. A proteína codificada pelo gene $F K B P 1 B$ faz parte de uma família de imunofilinas, que estão envolvidas em imunoregulação e processos celulares básicos, como dobramento e tráfico de proteínas. Existem indícios de seu papel fisiológico no acoplamento excitação-contração no músculo cardíaco. O gene $S F 3 B 14$ codifica uma subunidade do complexo de fatores de splicing 3b. O gene TP53I3 codifica uma proteína similar a oxidoredutases, que são enzimas que participam de respostas celulares a estresse oxidativo e irradiação. Esse gene é induzido pelo supressor de tumor p53 e acredita-se que esteja envolvido na morte celular mediada por p53. Contém motivos de ligação a p53, em sua região promotora e, na região downstream, em uma sequência de microssatélites pentanucleotídicos; ao interagir com esse segmento de microssatélites, p53 ativa a transcrição de TP53I3. A proteína codificada pelo gene ITSN2 atua na regulação da formação de vesículas revestidas por clatrina e pode participar da indução da endocitose de receptores de antígenos de células T. Os genes mapeados no segmento deletado não estão sujeitos a imprinting genômico. 
Considerando o fenótipo normal do pai da paciente, existe a possibilidade de penetrância incompleta. Outra possibilidade é que a microdeleção paterna tenha permitido a manifestação de mutação recessiva presente no cromossomo materno. Apesar de não haver deleção ou duplicação descrita nesse segmento em indivíduos normais da população, os genes mapeados no segmento deletado não têm relação direta com o crescimento, tornando difícil associar esse desequilíbrio cromossômico com o fenótipo do paciente $\mathrm{X}$.

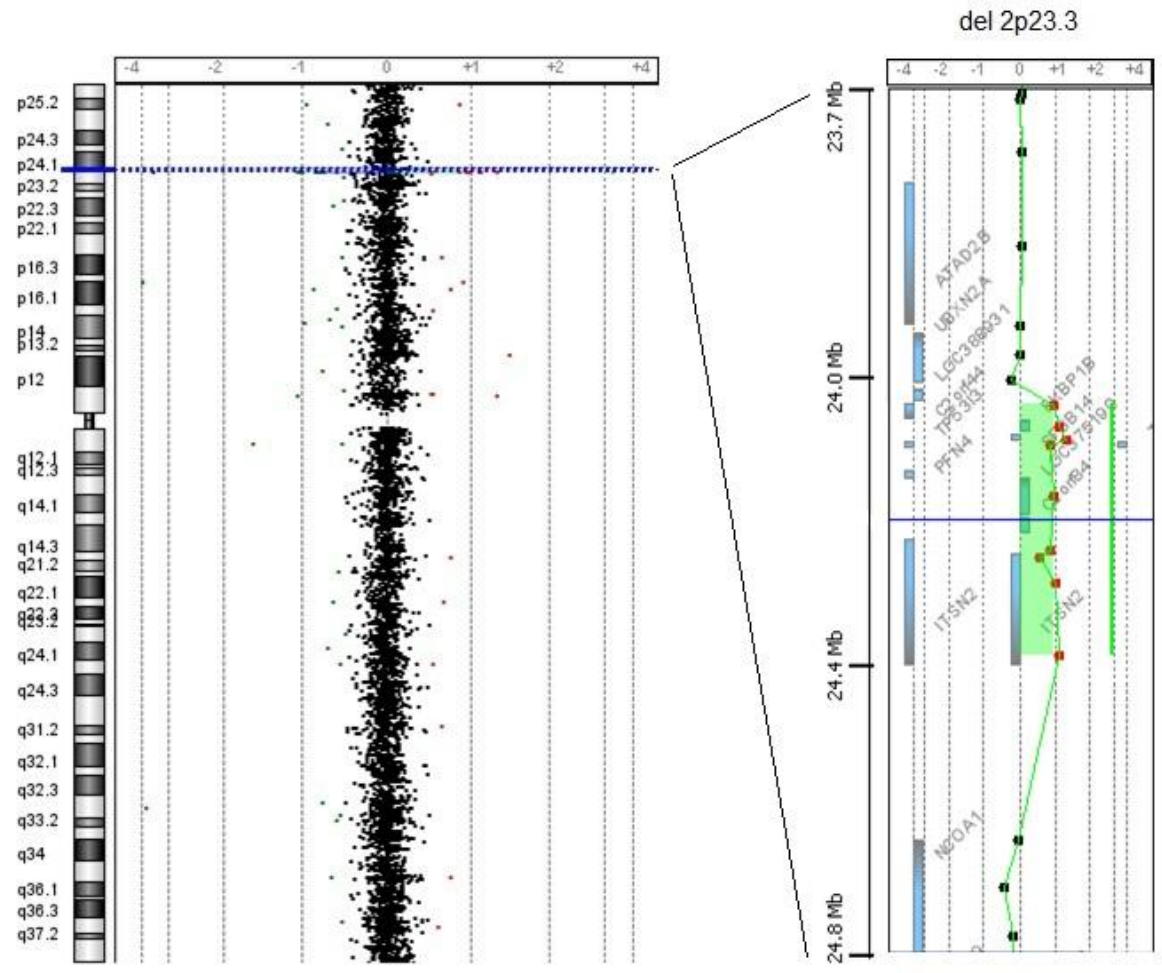

Figura IV.9 - Microdeleção com $\sim 320 \mathrm{~Kb}$ em 2p23.3, detectada no paciente X, por a-CGH (plataforma $44 \mathrm{~K}$. A barra verde na imagem à direita indica o segmento deletado.

Assim, a maioria das alterações cromossômicas que detectamos na pequena amostra de 19 pacientes com diagnóstico clínico da SRS, submetidos a análise por a-CGH, compreendeu variações polimórficas no número de cópias de DNA. Quatro microdeleções podem ter efeito patogênico (Tabela IV.3): em 13q34 (paciente D), em 2p23.3 (paciente X), em 15q11.2 (paciente AO) e em 16p13.11 (paciente AY). 
O paciente AF tem um irmão também com diagnóstico clínico de SRS. Nele não detectamos alteração em 11p15, matUPD(7) ou microrrearranjo cromossômico utilizando a plataforma 44K. Ele pode ser portador de microdeleção, não detectável pelas técnicas que utilizamos. A pesquisa dessas microdeleções por a-CGH será realizada, utilizando plataforma de maior resolução.

Outros estudos que utilizaram microarrays na busca de genes ou regiões cromossômicas associadas com a SRS, em que a causa genética era desconhecida, detectaram microduplicações e microdeleções, algumas potencialmente patogênicas. Bruce e col. (2010) utilizaram um microarray de SNP da Affymetrix, com 250.000 oligonucleotídeos, para investigar 12 pacientes com SRS nos quais a matUPD(7) e alterações epigenéticas em 11p15 foram afastadas, detectando três desequilíbrios cromossômicos não comuns na população. Spengler e col. (2010) estudaram 20 pacientes com SRS e causa genética desconhecida, utilizando microarray de SNP da Affymetrix, com 500.000 oligonucleotídeos e detectaram uma microdeleção incomum. Lin e col. (2010) utilizaram um microarray de SNP da Illumina, com 220.000 oligonucleotídeos, na investigação de 34 pacientes com SRS, sendo 21 com causa genética desconhecida, e cinco desses apresentaram deleções não comuns abrangendo entre 1,3 e 10,7 Mb.

Microdeleções de 2,6 e 4,4 Mb em 15q26.3, incluindo o gene IGF1R foram identificadas nos trabalhos de Bruce e col. (2010) e de Lin e col. (2010), respectivamente. Deleções mais extensas no segmento 15q26.1-qter haviam sido descritas anteriormente em pacientes considerados como tendo fenótipo SRS-like e, sempre que incluíam o gene $I G F 1 R$, os portadores apresentavam grave retardo de crescimento intrauterino e pós-natal (revisões em Hitchins e col., 2001a; Ester e col., 2009). Muitos desses pacientes apresentavam algumas características atípicas da SRS, como a microcefalia. Diversas mutações de ponto na região codificadora do gene $I G F 1 R$ foram associadas com fenótipo de retardo de crescimento intrauterino e pós-natal em nove pacientes (revisões em Ester e col., 2009; Choi e col., 2010). Entretanto deleções em 15q não foram detectadas em 38 pacientes com fenótipo de SRS (Rogan e col., 1996; Abu-Amero e col., 1997) nem mutações de ponto no gene IGFIR estavam presentes em 33 desses pacientes (AbuAmero e col., 1997). Visto que o produto do gene IGF1R modula diretamente os efeitos de IGF2 sobre o crescimento, esse gene ainda é considerado candidato para o fenótipo SRS ou SRS-like (Louvi e col., 1997). O grau de atraso no desenvolvimento e a ocorrência de dismorfismos 
clínicos podem estar relacionados à deleção de outros genes do segmento 15q26.1-qter, uma vez que são raros entre os pacientes com mutações de ponto no gene IGFIR (Walenkamp e col., 2008; Ester e col., 2009).

Outras microdeleções potencialmente patogênicas incluíam os genes $I G F 2 B P 3$ em 7p15 e GPC5 em 13q31.3 (Lin e col., 2010), o MAPK1 em 22q11.2 (Bruce e col., 2010) e o HMGA2 em 12q14 (Spengler e col., 2010), considerados candidatos, possivelmente influenciando o crescimento.

O gene IGF2BP3 foi considerado um excelente candidato para a SRS, por estar localizado no cromossomo 7 e pela participação de seu produto proteico na regulação do mRNA de IGF2. Estudos de expressão em humanos e camundongos mostraram que esse gene não está sujeito a imprinting genômico, mas é expresso principalmente durante o período fetal (Monk e col., 2002b). Apesar de seu papel na supressão do crescimento e na diferenciação celular, a investigação de mutações na sequência codificadora do gene IGF2BP3 em 25 pacientes com SRS não revelou alterações (Monk e col., 2002b). Novos estudos são necessários para uma conclusão sobre a participação desse gene no fenótipo da SRS.

Não há muita informação disponível acerca do gene GPC5. Foi sugerido que seu produto protéico pode participar do controle da divisão e do crescimento celular (Veugelers e col., 2001). Entretanto, numa revisão de 12 pacientes portadores de deleções com tamanhos variados em 13q, que incluíam ou não o gene $G P C 5$, não foi encontrada relação entre deleção de $G P C 5$ e o fenótipo de retardo de crescimento (Quélin e col., 2009).

Deleções em 22q11.2 foram descritas em associação com fenótipos clínicos variados, incluindo as síndromes de DiGeorge (DGS, MIM 188400) e velocardiofacial (VCFS, MIM 192430). Algumas microdeleções recorrentes, entretanto, caracterizaram uma nova síndrome, denominada síndrome de deleção distal em 22q11.2 (DECIPHER), com fenótipo distinto da DGS e da VCFS. Seis pacientes não aparentados foram recentemente descritos, portadores dessa microdeleção, que inclui o gene MAPK1 (Ben-Shachar e col., 2008). Bruce e col. (2010) descreveram uma paciente com fenótipo SRS, portadora de microdeleção distal em 22q11.2, que compartilhava várias características clínicas com outros pacientes que apresentavam deleção nesse segmento, como o retardo de crescimento intrauterino e pós-natal, clinodactilia e braquidactilia. No entanto, a maioria dessas características foram descritas isoladamente em 
pacientes com deleção distal de 22q11.2 e fenótipo não compatível com SRS-like. A proteína codificada pelo gene $M A P K 1$ é membro de uma família de quinases, que participam de grande variedade de processos celulares, como proliferação e diferenciação, e faz parte de uma via de sinalização que é ativada pela via IGF (Bruce e col., 2010). Diante disso, é possível que a haploinsuficiência de $M A P K 1$ esteja associada ao retardo de crescimento presente na paciente descrita por Bruce e col. (2010) e em outros (Ben-Shachar e col., 2008). No entanto, não há outras evidências da participação desse gene no fenótipo da SRS.

O gene HMGA2 codifica uma proteína que possui estrutura clássica de fator de transcrição. Em camundongos, sua expressão é elevada durante o desenvolvimento fetal. $H M G A 2$ participa da regulação da expressão do gene $I G F 2 B P 2$, cuja proteína faz parte de uma família de fatores que se ligam ao mRNA de IGF2 (Brants e col., 2004). Camundongos portadores de deleções do gene HMGA2 em homozigose apresentam retardo de crescimento grave, enquanto camundongos heterozigotos possuem cerca de $80 \%$ do peso dos animais selvagens (Zhou e col., 1995). Em humanos, foi postulado que o gene HMGA2 pode ser importante para o crescimento, ao serem detectadas deleções recorrentes em 12q14 que incluíam esse gene, em três pacientes com retardo de crescimento (Menten e col., 2007). Spengler e col. (2010) sequenciaram a região codificadora do gene $H M G A 2$ em um portador da deleção e em 19 outros pacientes com diagnóstico clínico da SRS, mas não encontraram mutações patogênicas. A redução do crescimento no paciente pode estar associada à haploinsuficiência do gene HMGA2. Mais evidências são necessárias para relacionar esse gene com a etiologia da SRS.

Em nosso estudo, utilizamos plataformas de oligonucleotídeos com resoluções diferentes, 44K (11 pacientes), 60K (5 pacientes) e 105K (3 pacientes), mas as três possuem sondas cobrindo todos os genes sugeridos como candidatos para a SRS nos estudos descritos acima. Dentre as CNV com possível efeito patogênico, três foram detectadas utilizando a plataforma $44 \mathrm{~K}$ e a microdeleção identificada na paciente AY, com a plataforma $105 \mathrm{~K}$, teria sido detectada também utilizando a $44 \mathrm{~K}$.

Algumas das alterações cromossômicas detectadas nesses estudos, incluindo as nossas, podem estar relacionadas ao fenótipo da SRS por mecanismos mais complexos de manifestação, como penetrância incompleta, expressividade variável, imprinting genômico e perda de heterozigose, levando a hemizigose de alelo recessivo patogênico. 
Por exemplo, ambos os pacientes AO e X herdaram uma microdeleção de um genitor normal; mesmo que os genes localizados nos segmentos deletados estejam associados ao fenótipo, a haploinsuficiência desses genes não é suficiente para causar a SRS. Uma possibilidade para explicar a penetrância incompleta nesses casos seria a necessidade de outro fator que, quando presente em conjunto com a microdeleção, geraria um quadro clínico alterado. Esse fator adicional poderia ser outra $\mathrm{CNV}$, uma mutação em determinado gene, ou um evento ambiental que influenciaria o fenótipo. Girirajan e col. (2010) demonstraram esse modelo (twohit model) ao estudar pacientes com deficiência mental e atraso no desenvolvimento portadores de deleção no segmento 16p12.1; quando os pacientes apresentavam um segundo desequilíbrio cromossômico, o fenótipo resultante era mais grave.

A hemizigose de alelo recessivo patogênico, presente no segmento materno de 2 p23.3 do paciente $X$, seria outra possibilidade para explicar a manifestação da SRS na criança, mas não de seu pai. Um exemplo desse tipo de combinação foi descrito no estudo de Lesnik Oberstein e col. (2006), que identificaram uma microdeleção de aproximadamente 1,5 Mb, em 13q12.3-q13.1, em dois irmãos afetados pela síndrome de Peters Plus (MIM 261540); a mesma deleção estava presente na mãe dos pacientes. Uma mutação herdada do pai foi detectada no gene B3GALTL (beta 1,3-galactosyltransferase-like), mapeado no segmento deletado. Mutações em homozigose nesse gene foram detectadas em outros pacientes com a doença, indicando a relação causal.

Apesar de a busca de desequilíbrios cromossômicos submicroscópicos não terem apontado genes definitivamente relacionados de maneira causal com a SRS (Bruce e col., 2010; Spengler e col., 2010; Lin e col., 2010; este estudo), estima-se que CNV potencialmente patogênicas estejam presentes em pelo menos 1\% dos afetados (Eggermann, 2010a). O número de pacientes estudados é ainda pequeno e os microrrearranjos potencialmente patogênicos encontrados indicam que a investigação em maior número de pacientes com fenótipo SRS, se faz necessária. 


\section{IV.4 Busca de mutações no gene $C D K A L 1$}

Em estudo anterior no laboratório (LGH - IB-USP), Fonseca (2005) identificou uma translocação aparentemente equilibrada entre os cromossomos 5 e 6 em uma paciente com quadro clínico de SRS (Figura I.14, item I.4). O mapeamento dos pontos de quebra foi realizado por FISH (Fluorescence In Situ Hybridization), utilizando segmentos clonados em BAC. No cromossomo 5, o ponto de quebra foi mapeado num segmento de $93 \mathrm{~Kb}$, não contendo genes. Já o ponto de quebra do cromossomo 6 estava contido no gene CDKAL1, interrompendo-o. Esse gene foi, assim, considerado candidato para a síndrome. Nessa paciente, afastamos alterações em 11 15 e matUPD(7). A análise por a-CGH com a plataforma Agilent 44K não revelou perda ou ganho de segmentos cromossômicos. Assim, consideramos a possibilidade de mutação em heterozigose no gene $C D K A L 1$ como causa do fenótipo da SRS. Ao todo, 30 pacientes tiveram a sequência das regiões codificadoras, incluindo os segmentos de junção intron/exon, do gene $C D K A L 1$ analisada por sequenciamento direto. Os pacientes que apresentavam matUPD(7) ou alterações (epi)genéticas em 11p15 foram excluídos da investigação, mas em seis, que tiveram o gene sequenciado, a análise de 11 p15 não foi realizada por motivo técnico e neles a hipometilação de ICR1 não pode ser excluída (Tabela IV.4).

Não foi encontrada alteração patogênica no gene CDKAL1 nos pacientes investigados (Tabela IV.5). Os SNP detectados foram confirmados no banco de dados do UCSC (University of California, Santa Cruz; http://genome.ucsc.edu/). Esse resultado indica que mutações de ponto na região codificadora do gene $C D K A L 1$ não é causa comum da SRS. Existe a possibilidade de deleções extensas não detectáveis pelo sequenciamento e de mutações em regiões não sequenciadas do gene, como a promotora. Em 18 dos 30 pacientes que tiveram o gene CDKAL1 sequenciado, investigamos a presença de microdeleções e microduplicações por a-CGH e não encontramos alteração que incluísse esse gene (todas as plataformas de array utilizadas possuíam sondas no gene). Assim, considerando o pequeno tamanho amostral, não podemos excluir definitivamente a possibilidade de que alterações no gene CDKAL1 possam contribuir para a etiologia da síndrome de Silver-Russell.

As Tabelas IV.4 e IV.5 resumem os resultados do estudo genético da SRS, que realizamos. 
Tabela IV.4 - Resumo da estratégia adotada na investigação dos pacientes com diagnóstico de SRS: pesquisa de alterações em 11p15, matUPD(7), CNV e mutações no gene CDKAL1.

\begin{tabular}{|c|c|c|c|c|c|c|c|c|}
\hline & \multicolumn{2}{|l|}{ Alterações em 11p15 } & \multicolumn{2}{|c|}{ matUPD(7) } & \multicolumn{2}{|c|}{ CNV } & \multicolumn{2}{|c|}{$C D K A L 1$} \\
\hline \multirow{2}{*}{$\begin{array}{c}\text { Pacientes } \\
\text { testados por } \\
\text { MS-MLPA }\end{array}$} & \multicolumn{2}{|l|}{$n=49$} & \multicolumn{2}{|c|}{$\mathrm{n}=27 *$} & \multicolumn{2}{|c|}{$n=26$} & \multicolumn{2}{|c|}{$n=26$} \\
\hline & $\begin{array}{l}\text { Hipometilação ICR1 } \\
\text { Hipometilação ICR1 e ICR2 } \\
\text { Duplicação ICR2 (mat) }\end{array}$ & $\begin{array}{c}20 \\
1 \\
1\end{array}$ & matUPD(7) & 1 & Analisados & 19 & Analisados & 24 \\
\hline Pacientes não & $\mathbf{n}=15$ & & $\mathbf{n}=\mathbf{1}$ & & & & $\mathbf{n}=$ & \\
\hline $\begin{array}{c}\text { testados por } \\
\text { MS-MLPA }\end{array}$ & & & matUPD(7) & 2 & & & Analisados & 6 \\
\hline
\end{tabular}

*Outros 11 pacientes foram inicialmente estudados quanto a matUPD(7) e posteriormente revelaram alterações em $11 \mathrm{p} 15$.

Tabela IV.5 - Resumo das análises de metilação e número de cópias de segmentos em 11p15 (MSMLPA), UPD(7) (genotipagem de microssatélites), microrrearranjos cromossômicos (a-CGH) e mutação em CDKNIC (sequenciamento direto), nos pacientes com SRS.

\begin{tabular}{|c|c|c|c|c|c|}
\hline Paciente & $\begin{array}{l}\text { Número de cópias } \\
\text { de segmentos de } \\
\text { DNA em 11p15 }\end{array}$ & $\begin{array}{l}\text { Padrão de metilação } \\
\text { em 11p15 }\end{array}$ & $\operatorname{UPD}(7)$ & a-CGH & CDKAL1 \\
\hline $\mathbf{A}^{1}$ & & & Biparental & & \\
\hline $\mathbf{B}^{4}$ & Normal & Hipometilação de ICR1 & Biparental & & \\
\hline $\mathbf{C}^{3}$ & Normal & Normal & Biparental & Sem alteração & $\begin{array}{l}\mathrm{t}(5 ; 6), C D K A L 1 \\
\text { interrompido }\end{array}$ \\
\hline$D^{4}$ & Normal & Normal & Biparental & $\begin{array}{l}\text { Del 13q34 } \\
\text { Del 19 p13.3 }\end{array}$ & Sem alteração \\
\hline $\mathbf{E}^{2}$ & Normal & Normal & Biparental & & \\
\hline $\mathbf{F}^{1,4}$ & & & Biparental & & \\
\hline $\mathbf{G}^{1}$ & & & Biparental & & Sem alteração \\
\hline $\mathbf{H}$ & Normal & Hipometilação de ICR1 & Biparental & & \\
\hline $\mathbf{I}^{1}$ & & & Biparental & & \\
\hline $\mathbf{J}$ & Normal & Normal & Biparental & Dup 14q11.1-11.2 & Sem alteração \\
\hline $\mathbf{K}$ & Normal & Hipometilação de ICR1 & Biparental & & \\
\hline $\mathbf{L}$ & Normal & Hipometilação de ICR1 & Biparental & & \\
\hline $\mathbf{M}^{1}$ & & & Biparental & & Sem alteração \\
\hline $\mathbf{N}^{1}$ & & & Biparental & & \\
\hline $\mathbf{O}^{1}$ & & & Biparental & & Sem alteração \\
\hline
\end{tabular}


Tabela IV.5 - continuação

\begin{tabular}{|c|c|c|c|c|c|}
\hline Paciente & $\begin{array}{l}\text { Número de cópias } \\
\text { de segmentos de } \\
\text { DNA em 11p15 }\end{array}$ & $\begin{array}{l}\text { Padrão de metilação } \\
\text { em 11p15 }\end{array}$ & UPD7 & a-CGH & CDKAL1 \\
\hline $\mathbf{P}$ & & & $\operatorname{matUPD}(7)$ & & \\
\hline $\mathbf{Q}^{1}$ & & & Biparental & & \\
\hline $\mathbf{R}^{1}$ & & & Biparental & & Sem alteração \\
\hline $\mathbf{S}$ & Normal & Normal & Biparental & $\begin{array}{l}\text { Del 1q31.3 } \\
\text { Del 10q11.22 }\end{array}$ & \\
\hline $\mathbf{T}^{2,4}$ & Normal & Normal & Biparental & & Sem alteração \\
\hline$U^{2,4}$ & Normal & Normal & Biparental & & Sem alteração \\
\hline $\mathbf{V}^{1}$ & & & Biparental & & Sem alteração \\
\hline $\mathbf{W}^{1}$ & & & Biparental & & Sem alteração \\
\hline $\mathbf{X}$ & Normal & Normal & Biparental & Del 2p23.3 (pat) & Sem alteração \\
\hline $\mathbf{Y}$ & $\begin{array}{l}\text { Duplicação do } \\
\text { segmento controlado } \\
\text { por ICR2 }\end{array}$ & ICR1 normal & Biparental & & \\
\hline $\mathbf{Z}$ & Normal & Hipometilação de ICR1 & & & \\
\hline $\mathbf{A A}$ & Normal & Normal & Biparental & Sem alteração & Sem alteração \\
\hline $\mathbf{A B}$ & Normal & Hipometilação de ICR1 & Biparental & & \\
\hline $\mathbf{A C}$ & Normal & Normal & Biparental & Dup 5q13.2 & Sem alteração \\
\hline AD & Normal & Hipometilação de ICR1 & Biparental & & \\
\hline $\mathbf{A E}$ & Normal & Normal & Biparental & Sem alteração & Sem alteração \\
\hline $\mathbf{A F}$ & Normal & Normal & Biparental & Sem alteração & Sem alteração \\
\hline $\mathbf{A G}$ & Normal & Normal & Biparental & Sem alteração & Sem alteração \\
\hline $\mathbf{A H}$ & Normal & Hipometilação de ICR1 & & & \\
\hline AI & Normal & Hipometilação de ICR1 & & & \\
\hline AJ & Normal & Normal & Biparental & Del 15q11.2 & Sem alteração \\
\hline $\mathbf{A K}$ & Normal & Normal & $\operatorname{matUPD(7)}$ & & \\
\hline $\mathbf{A L}$ & Normal & Hipometilação de ICR1 & & & \\
\hline $\mathbf{A M}$ & Normal & $\begin{array}{l}\text { Hipometilação de ICR1 } \\
\text { e ICR2 }\end{array}$ & & & \\
\hline $\mathbf{A N}$ & Normal & Hipometilação de ICR1 & & & \\
\hline
\end{tabular}

${ }^{1}$ Qualidade da amostra de DNA recebida não permitiu análise por MS-MLPA; ${ }^{2}$ qualidade da amostra de DNA recebida não permitiu a realização do a-CGH; ${ }^{3}$ alteração cromossômica detectada anteriormente (Fonseca, 2005); ${ }^{4}$ matUPD(7) analisada anteriormente a este trabalho. 
Tabela IV.5 - continuação

\begin{tabular}{|c|c|c|c|c|c|}
\hline Paciente & $\begin{array}{l}\text { Número de cópias } \\
\text { de segmentos de } \\
\text { DNA em } 11 \text { p15 }\end{array}$ & $\begin{array}{l}\text { Padrão de metilação } \\
\text { em 11p15 }\end{array}$ & UPD7 & a-CGH & CDKAL1 \\
\hline AO & Normal & Normal & Biparental & $\begin{array}{l}\text { Del 12p13.31 } \\
\text { Del 15q11.2 (mat) }\end{array}$ & Sem alteração \\
\hline $\mathbf{A} \mathbf{P}^{4}$ & & & $\operatorname{matUPD}(7)$ & & \\
\hline $\mathbf{A} \mathbf{Q}^{4}$ & Normal & Hipometilação de ICR1 & Biparental & & \\
\hline $\mathbf{A} \mathbf{R}^{4}$ & Normal & Hipometilação de ICR1 & Biparental & & \\
\hline $\mathbf{A} \mathbf{S}^{4}$ & Normal & Hipometilação de ICR1 & Biparental & & \\
\hline $\mathbf{A T}^{2,4}$ & Normal & Normal & Biparental & & Sem alteração \\
\hline $\mathbf{A} \mathbf{U}^{2,4}$ & Normal & Normal & Biparental & & Sem alteração \\
\hline$A V^{1,4}$ & & & Biparental & & \\
\hline$A W^{4}$ & Normal & Hipometilação de ICR1 & Biparental & & \\
\hline$A X^{1,4}$ & & & Biparental & & \\
\hline AY & Normal & Normal & Biparental & $\begin{array}{l}\text { Del 16p13.11 } \\
\text { Dup 17q11.1 }\end{array}$ & Sem alteração \\
\hline$A Z^{2,4}$ & Normal & Normal & Biparental & & Sem alteração \\
\hline $\mathrm{BA}^{2,4}$ & Normal & Normal & Biparental & & Sem alteração \\
\hline BB & Normal & Hipometilação de ICR1 & & & \\
\hline BC & Normal & Normal & Biparental & Sem alteração & Sem alteração \\
\hline BD & Normal & Normal & Biparental & $\begin{array}{l}\text { Del 1p36.11 } \\
\text { Del 8p11.23 } \\
\text { Dup Xq28 }\end{array}$ & Sem alteração \\
\hline BE & Normal & Normal & Biparental & Dup 2q37 & Sem alteração \\
\hline BF & Normal & Normal & Biparental & Sem alteração & Sem alteração \\
\hline BG & Normal & Hipometilação de ICR1 & & & \\
\hline BH & Normal & Hipometilação de ICR1 & & & \\
\hline BI & Normal & Hipometilação de ICR1 & & & \\
\hline BJ & Normal & Hipometilação de ICR1 & & & \\
\hline BK & Normal & Normal & Biparental & Del 15q11.2 & Sem alteração \\
\hline BL & Normal & Normal & Biparental & Sem alteração & Sem alteração \\
\hline BM & Normal & Normal & Biparental & Del 8p11.23 & Sem alteração \\
\hline
\end{tabular}

${ }^{1}$ Qualidade da amostra de DNA recebida não permitiu análise por MS-MLPA; ${ }^{2}$ qualidade da amostra de DNA recebida não permitiu a realização do a-CGH; ${ }^{3}$ alteração cromossômica detectada anteriormente (Fonseca, 2005); ${ }^{4}$ matUPD(7) analisada anteriormente a este trabalho. 


\section{SUMÁRIO E CONCLUSÕES}




\section{SUMÁRIO E CONCLUSÕES}

A SRS foi descrita na década de 50 e caracteriza-se principalmente por grave retardo de crescimento intrauterino e pós-natal, face típica, pequena e triangular, com frontal amplo e micrognatia, macrocrania relativa, assimetria corporal e clinodactilia de quintos dedos. A considerável heterogeneidade clínica dificulta estabelecer critérios precisos para o diagnóstico clínico da SRS.

A SRS é geneticamente heterogênea, ocorrendo em geral de forma esporádica. Alterações em 11p15 são as principais causas da síndrome. A hipometilação do centro de imprinting telomérico (ICR1) em 11p15 ocorre em pelo menos 40\% dos afetados e duplicações cromossômicas de origem materna incluindo o centro de imprinting centromérico (ICR2) estão presentes em 1-2\% dos casos. A dissomia uniparental materna do cromossomo 7 (matUPD7) é responsável por 5-10\% dos casos. Apesar de alguns pacientes apresentarem alterações cromossômicas, excetuando aquelas dos cromossomos 7 e 11, nenhuma outra foi recorrente. Mais recentemente microdeleções e microduplicações cromossômicas foram investigadas, em número ainda reduzido de pacientes, algumas delas se mostrando com possível efeito patogênico. Com a identificação da hipometilação de ICR1 em 11p15, matUPD(7) e desequilíbrios (sub)microscópicos, a confirmação molecular para o diagnóstico clínico da SRS tornou-se possível em $\sim 50 \%$ dos pacientes, o que deixa metade dos casos sem causa genética determinada.

O objetivo deste estudo foi buscar mecanismos genéticos que expliquem os casos da SRS não relacionados a alterações de metilação em 11p15 ou a matUPD(7). Para isso buscamos genes ou regiões cromossômicas relacionadas à síndrome, investigando os pacientes quanto a alterações cromossômicas submicroscópicas. Avaliamos também a contribuição de mutações no gene CDKAL1 (cyclin-dependent kinase 5 regulatory subunit associated protein 1-like 1) para a SRS; esse gene foi considerado candidato por ter sido interrompido por um dos pontos de quebra de translocação t( $5 ; 6)$, detectada numa paciente com SRS, em estudo anterior do laboratório.

A amostra foi constituída por 64 pacientes brasileiros não aparentados, com suspeita clínica da síndrome de Silver-Russell. O diagnóstico clínico baseou-se na presença obrigatória de grave retardo de crescimento intrauterino e pós-natal, face típica e pelo menos mais um sinal clínico da SRS. A investigação incluiu, primeiramente, a busca de alterações no cromossomo 11 
(MS-MLPA) e de matUPD(7) (genotipagem de microssatélites) para afastar as causas mais comuns da SRS. A investigação de microdeleções e microduplicações genômicas foi realizada por hibridação genômica comparativa baseada em array (a-CGH) e a busca de mutações no gene candidato $C D K A L 1$, por sequenciamento direto.

Entre os 49 pacientes analisados quanto ao padrão de metilação e número de cópias de DNA em 11p15, detectamos hipometilação de ICR1 em 21 (43\%), frequência que está de acordo com a literatura. Em um desses pacientes, ambos os centros, ICR1 e ICR2, estavam hipometilados (2\%), alteração complexa que já foi relatada em $4 \%$ dos pacientes com SRS que apresentavam hipometilação de ICR1. A hipometilação de ICR2 é responsável por cerca da metade dos casos da síndrome de Beckwith-Wiedman e a perda de metilação em ambas as ICR foi descrita também nesses pacientes. A distribuição do mosaicismo dos defeitos epigenéticos entre os diferentes tecidos poderia explicar a dominância de um fenótipo ou de outro.

A frequência de alteração da metilação em 11p15 pode estar subestimada, pois a análise, a exemplo da quase totalidade dos estudos da SRS, limitou-se ao sangue periférico e as alterações de metilação em 11p15 provavelmente ocorrem após a fertilização, o que resulta em mosaicismo, podendo a alteração estar restrita a determinados tecidos.

A análise de 11p15 revelou, em um dos pacientes (2\%), uma microduplicação de origem materna que incluía o domínio ICR2, mas não ICR1. Essa microduplicação segrega em uma família com cinco crianças afetadas pela SRS e a manifestação da síndrome depende da transmissão via materna. Cinco crianças com fenótipo da SRS, dois meninos e três meninas, herdaram a microduplicação de suas mães clinicamente normais; o desequilíbrio estava presente também em dois tios maternos fenotipicamente normais, e sete parentes clinicamente normais das crianças não apresentaram a duplicação. Esses achados permitiram inferir que o avô dos afetados, já falecido, era o portador da microduplicação e que, quando ele a transmitia, sua prole não apresentava SRS. A microduplicação tem aproximadamente 1,6 Mb e abrange todos os genes sujeitos a imprinting do domínio ICR2. Outra microduplicação de origem materna restrita ao domínio ICR2 e associada com SRS foi descrita anteriormente. Entre os genes duplicados nos dois casos, CDKN1C aparece como candidato para o fenótipo da SRS, devido a seu efeito negativo sobre o crescimento celular e expressão elevada na placenta. Esse novo caso familial vem confirmar que a duplicação restrita ao domínio ICR2, de herança materna, está causalmente 
associada com a SRS; mostra também que nenhuma alteração fenotípica aparente está presente, quando a duplicação é herdada via paterna.

Entre os 64 pacientes da amostra, três $(4,7 \%)$ apresentaram matUPD(7), resultado que está de acordo com a literatura. Não podemos, contudo, afastar a possibilidade de que determinadas UPD segmentares não tenham sido detectadas, apesar de consideradas eventos raros.

A investigação de microrrearranjos cromossômicos por a-CGH foi realizada em 19 pacientes, que previamente tiveram afastadas alterações em 11p15 e matUPD(7). A maioria dos pacientes não apresentou alterações $(n=7)$ ou possuía apenas CNV frequentes em indivíduos normais da população e consideradas polimorfismos $(n=8)$. Dessa forma, não podemos atribuir efeito desses desequilíbrios cromossômicos na patologia da SRS e a presença delas não foi investigada nos genitores dos pacientes. Quatro pacientes apresentaram alterações potencialmente patogênicas. Em nenhum dos casos foi possível estabelecer relação direta com o fenótipo da SRS, porque não foi possível investigar ambos os genitores ou a alteração estava presente em um genitor clinicamente normal ou já tinha sido relatada em indivíduo normal da população, não havendo, entretanto, indicação de ser polimórfica: (1) Microdeleção de 320 Kb em 15q11.2, abrangendo os genes TUBGCP5, CYFIP1, NIPA2 e NIPA1, foi herdada via materna; essa microdeleção, com frequência menor que $1 \%$ entre indivíduos normais, foi detectada num grupo de pacientes com atraso no desenvolvimento global, distúrbios de comportamento e dismorfismos diversos, levando à sugestão de haver uma síndrome relacionada com microdeleção em 15q11.2, estando alguns de seus sinais presentes em nosso paciente. Os genes deletados não estão sujeitos a imprinting genômico e a presença da microdeleção na maioria dos genitores clinicamente normais ou levemente afetados seria explicada por penetrância incompleta e expressividade variável. (2) Microdeleção em 16p13.11, de 95,8 Kb, abrangendo os genes PDXDC1 e NTAN1, ambos com função desconhecida; a deleção de PDXDC1 aparece com frequência populacional elevada (>10\%) e a deleção de NTAN1 tem frequência estimada em menos de $0,2 \%$ entre os indivíduos normais; não foi possível determinar se a alteração foi herdada. (3) Microdeleção de $~ 94,3 \mathrm{~Kb}$ em 13q24; deleções incluindo esse segmento foram descritas em dois indivíduos normais. Abrange o gene $R A S A 3$, que codifica uma proteína que estimula a atividade de GTPase da p21 RAS, atuando assim no controle da 
proliferação e da diferenciação celular. O pai do paciente era falecido e a microdeleção não estava presente em sua mãe. (4) Microdeleção de $320 \mathrm{~Kb}$ em 2p23.3, abrangendo quatro genes com função conhecida, FKBP1B, SF3B14, TP53I3 e ITSN2, nenhum deles sujeito a imprinting genômico. Essa microdeleção não foi relatada antes, mas estava presente no pai do paciente, com fenótipo aparentemente normal, o que pode resultar de penetrância incompleta. Outra possibilidade é que a microdeleção paterna tenha permitido a manifestação de mutação recessiva presente no cromossomo materno. Entretanto, os genes incluídos na deleção não têm relação direta com o crescimento.

Três estudos recentes que utilizaram microarrays na busca de genes ou regiões cromossômicas associadas com a SRS, em que a causa genética era desconhecida, detectaram microduplicações e microdeleções, algumas potenciamente patogênicas. Ao todo foram estudados 53 pacientes. O achado mais interessante foi o de uma microdeleção em 15q26.3, incluindo o gene IGFIR, identificada dois pacientes. Outras microdeleções potencialmente patogênicas incluíam os genes $I G F 2 B P 3$ em 7p15, GPC5 em 13q31.3, o MAPK1 em 22q11.2 e o HMGA2 em 12q14, considerados candidatos, possivelmente influenciando o crescimento.

Esse conjunto de resultados indica que a investigação de microrrearanjos deve estender-se a um número maior de pacientes com SRS, na busca regiões cromossômicas e genes que possam estar causalmente associados com a síndrome.

Em 30 pacientes com SRS, buscamos mutações no gene CDKAL1, por sequenciamento direto das regiões codificadoras. Nenhuma alteração patogênica foi detectada. Esse resultado indica que mutações de ponto na região codificadora do gene CDKAL1 não é causa comum da SRS. Existe a possibilidade de deleções extensas não detectáveis pelo sequenciamento e de mutações em regiões não sequenciadas do gene, como a região promotora. Somente em 18 dos 30 pacientes, investigamos a presença de microdeleções e microduplicações por a-CGH e não encontramos alteração que incluísse esse gene. Assim, considerando o pequeno tamanho amostral, não podemos excluir definitivamente a possibilidade de que alterações no gene $C D K A L 1$ possam contribuir para a etiologia da SRS.

Neste estudo, 43\% dos pacientes investigados por MS-MLPA apresentaram hipometilação de ICR1 em 11p15. A frequência de matUPD(7) entre os 64 pacientes foi de 
4,7\%. Esses resultados, concordantes com o de outros estudos semelhantes, apontam para a seleção adequada dos pacientes com SRS, do ponto de vista clínico.

Entre os 51 pacientes com diagnóstico clínico de SRS, submetidos à investigação de alterações em 11p15 e de matUPD(7), ou nos quais um desses testes não foi realizado porque o outro se revelou positivo, $25(\sim 50 \%)$ tiveram a causa genética do quadro clínico determinada, resultado de acordo com a literatura. A busca dos mecanismos genéticos subjacentes aos casos não diagnosticados, deve incluir investigação detalhada de 11 p15 e do cromossomo 7, com possíveis alterações não detectáveis pelas técnicas utilizadas na maioria dos estudos. Deve abranger também a análise global de microrrearranjos e de alterações epigenéticas. 


\section{ABSTRACT}




\section{ABSTRACT}

Silver Russell syndrome (SRS) is characterized by severe intrauterine and postnatal growth retardation in association with a typical small triangular face and other variable features. Most cases are sporadic. Genetic and epigenetic disturbances on imprinted regions at chromosomes 7 and 11 are detected in about 50\% of the patients. Most frequently, SRS is caused by altered gene expression on chromosome $11 \mathrm{p} 15$ due to hypomethylation of the telomeric imprinting center (ICR1) that is present in at least $40 \%$ of the patients. Maternally inherited duplications encompassing the centromic imprinting center (ICR2) domains at 11p15 are present in about $1-2 \%$ of cases. Maternal uniparental disomy of chromosome 7 (mUPD7) is identified in $5-10 \%$ of patients. More recently, chromosomal microdeletions and microduplications were detected in a small group of SRS patients, some of them with possible pathogenic effect. This leaves approximately half of the SRS cases without a genetic cause determined.

Our cohort consisted of 64 unrelated Brazilian patients with clinical diagnosis of SRS. DNA copy number changes and the methylation pattern on chromosome 11 p15 were investigated in 49 patients by MS-MLPA, and 21 (43\%) presented with hypomethylation of ICR1. In one patient (2\%), both centers (ICR1 and ICR2) were hypomethylated, a complex alteration that has been reported in $\sim 4 \%$ of SRS patients that shows hypomethylation of ICR1. In a further patient ( $2 \%$ ), we detected a $\sim 1.6 \mathrm{Mb}$ microduplication encompassing the whole ICR2 domain, but not the ICR1. This microduplication was shown to segregate in a three-generation family, and was associated with SRS whenever maternally transmitted: there were four instances of paternal transmissions of the microduplication from a single male uniformly resulting in normal offspring, and five maternal transmissions, via two clinically normal sisters, with all the children exhibiting SRS. A maternally inherited microduplication also restricted to the ICR2 domain and associated with SRS in a boy was described previously. Among the duplicated genes in both cases, CDKNIC is a likely candidate for the SRS phenotype, because it encodes a cyclin-dependent kinase inhibitor that negatively regulates cell proliferation and growth, and plays a crucial role in human fetal development. This new case brings confirmatory evidence that microduplications restricted to the ICR2 domain result in SRS when maternally transmitted. It also shows that no apparent phenotypic change is present when ICR2 duplication is paternally inherited.

By genotyping chromosome 7 microsatellites, we identified three patients $(4.7 \%)$ with $\operatorname{mUPD}(7)$, in the cohort of 64 patients. 
The frequencies of hypomethylation of ICR1 (43\%) and mUPD(7) (4.7\%) among our patients are in accordance with the literature, and point to a proper selection of patients with SRS, from the clinical point of view.

The investigation of submicroscopic chromosomal imbalances by a-CGH was performed in 19 patients in whom (epi)genetic mutations at 11p15 and mUPD(7) had been excluded. Most patients showed no changes $(\mathrm{n}=7)$ or had only $\mathrm{CNV}$ considered to be polymorphic $(\mathrm{n}=8)$. Four potentially pathogenic microdeletions were detected, on chomosomes 2p23.3 ( 320 Kb), 13q24 $(\sim 94.3 \mathrm{~Kb}), 15 \mathrm{q} 11.2(\sim 320 \mathrm{~Kb})$ and 16p13.11 ( 95.8 Kb). In neither case we could establish a direct relationship between the imbalance and the phenotype, because it was not possible to investigate both parents or the change was present in a clinically normal parent or it had been reported in normal individuals, without, however, indication of being polymorphic. Incomplete penetrance or unmasking of a pathogenic recessive allele on the homologous chromosome are two possible explanations to the pathogenic effect of a microdeletion inherited from a clinically normal parent.

Three recent studies that used microarrays to identify genes or chromosomal regions associated with SRS, wherein the genetic cause was unknown, detected microdeletions and microduplications, some of them potentially pathogenic: a microdeletion at $15 \mathrm{q} 26.3$, including the IGFIR gene, was identified in two patients; other microdeletions included the IGF2BP3 gene at 7p15, GPC5 gene at 13q31.3, MAPK1 gene at 22q11.2 and HMGA2 gene at 12q14, which were considered candidates, possibly influencing growth. This set of results, including ours, indicates that the investigation of submicroscopic chromosomal imbalances should be extended to a larger cohort of SRS patients, in the search for chromosomal regions and genes that may be causally associated with the syndrome.

In 30 SRS patients, we searched for point mutations in the CDKAL1 gene by direct sequencing of coding regions. This gene was considered a candidate for SRS, after being disrupted in one of our SRS patients with a $\mathrm{t}(5 ; 6)$. No pathogenic mutation was detected and, therefore, point mutations in the coding region of CDKAL1 do not appear to be a common cause of SRS. In 18 of the 30 patients, we investigated the presence of microdeletions and microduplications by a-CGH and found no changes encompassing CDKAL1 gene. Considering the small cohort size, we cannot definitely exclude the possibility that changes in CDKALI gene may contribute to the etiology of SRS. 


\section{REFERÊNCIAS BIBLIOGRÁFICAS}




\section{REFERÊNCIAS BIBLIOGRÁFICAS}

Abu-Amero S, Price S, Wakeling E, Stanier P, Trembath R, Preece MA, Moore GE. Lack of hemizygosity for the insulin-like growth factor I receptor gene in a quantitative study of 33 Silver-Russell syndrome probands and their families. Eur J Hum Genet. 5:235-41, 1997.

Abu-Amero S, Wakeling EL, Preece M, Whittaker J, Stanier P, Moore GE - Epigenetic signatures of Silver-Russell syndrome. J Med Genet. 47:150-4, 2010.

Azzi S, Rossignol S, Steunou V, Sas T, Thibaud N, Danton F, Le Jule M, Heinrichs C, Cabrol S, Gicquel C, Le Bouc Y, Netchine I. - Multilocus methylation analysis in a large cohort of 11p15-related foetal growth disorders (Russell Silver and Beckwith Wiedemann syndromes) reveals simultaneous loss of methylation at paternal and maternal imprinted loci. Hum Mol Genet. 18:4724-33, 2009.

Bartholdi D, Krajewska-Walasek M, Ounap K, Gaspar H, Chrzanowska KH, Ilyana H, Kayserili H, Lurie IW, Schinzel A, Baumer A. - Epigenetic mutations of the imprinted IGF2-H19 domain in Silver-Russell syndrome (SRS): results from a large cohort of patients with SRS and SRS-like phenotypes. J Med Genet. 46:192-197, 2009.

Beckwith JB - Extreme cytomegaly of the adrenal fetal cortex, omphalocele, hyperplasia of kidneys and pancreas, and Leydig-cell hyperplasia: Another syndrome? Presented at 11th Annual Meeting of Western Society for Pediatric Research, Los Angeles, November 11, 12, 1963.

Begemann M, Spengler S, Kanber D, Haake A, Baudis M, Leisten I, Binder G, Markus S, Rupprecht T, Segerer H, Fricke-Otto S, Mühlenberg R, Siebert R, Buiting K, Eggermann $\mathrm{T}$ - Silver-Russell patients showing a broad range of ICR1 and ICR2 hypomethylation in different tissues. Clin Genet. Jul 22, 2010 (Epub ahead of print).

Ben-Shachar S, Ou Z, Shaw CA, Belmont JW, Patel MS, Hummel M, Amato S, Tartaglia N, Berg J, Sutton VR, Lalani SR, Chinault AC, Cheung SW, Lupski JR, Patel A - 22q11.2 distal deletion: a recurrent genomic disorder distinct from DiGeorge syndrome and velocardiofacial syndrome. Am J Hum Genet. 82:214-21, 2008.

Bernard LE, Peñaherrera MS, Van Allen MI, Wang MS, Yong SL, Gareis F, Langlois S, Robinson WP - Clinical and molecular findings in two patients with russell-silver syndrome and UPD7: comparison with non-UPD7 cases. Am J Med Genet. 87:230-6, 1999.

Biliya S, Bulla LA Jr - Genomic imprinting: the influence of differential methylation in the two sexes. Exp Biol Med (Maywood). 235:139-47, 2010. 
Binder G, Seidel AK, Weber K, Haase M, Wollmann HA, Ranke MB, Eggermann T - IGF-II serum levels are normal in children with Silver-Russell syndrome who frequently carry epimutations at the IGF2 locus. J Clin Endocrinol Metab. 91:4709-12, 2006.

Binder G, Seidel AK, Martin DD, Schweizer R, Schwarze CP, Wollmann HA, Eggermann T, Ranke MB - The endocrine phenotype in silver-russell syndrome is defined by the underlying epigenetic alteration. J Clin Endocrinol Metab. 93:1402-7, 2008.

Blagitko N, Schulz U, Schinzel AA, Ropers HH, Kalscheuer VM - gamma2-COP, a novel imprinted gene on chromosome 7q32, defines a new imprinting cluster in the human genome. Hum Mol Genet. 8:2387-96, 1999.

Bliek J, Maas SM, Ruijter JM, Hennekam RC, Alders M, Westerveld A, Mannens MM Increased tumour risk for BWS patients correlates with aberrant H19 and not KCNQ1OT1 methylation: occurrence of KCNQ1OT1 hypomethylation in familial cases of BWS. Hum Mol Genet. 10:467-76, 2001.

Bliek J, Terhal P, van den Bogaard MJ, Maas S, Hamel B, Salieb-Beugelaar G, Simon M, Letteboer T, van der Smagt J, Kroes H, Mannens M - Hypomethylation of the H19 gene causes not only Silver-Russell syndrome (SRS) but also isolated asymmetry or an SRS-like phenotype. Am J Hum Genet. 78:604-14, 2006.

Bliek J, Snijder S, Maas SM, Polstra A, van der Lip K, Alders M, Knegt AC, Mannens MMAM Phenotypic discordance upon paternal or maternal transmission of duplications of the 11p15 imprinted regions. Eur J Med Genet. 52:404-8, 2009.

Bonaldi A, Mazzeu JF, Costa SS, Honjo RS, Bertola DR, Albano LMJ, Furquim IM, Kim CA, Vianna-Morgante AM - Microduplication of the ICR2 Domain at Chromosome 11p15 and Familial Silver-Russell Syndrome. Am J Med Genet. A, 2011 (aceito para publicação).

Brants JR, Ayoubi TA, Chada K, Marchal K, Van de Ven WJ, Petit MM - Differential regulation of the insulin-like growth factor II mRNA-binding protein genes by architectural transcription factor HMGA2. FEBS Lett. 569:277-83, 2004.

Brown KW, Villar AJ, Bickmore W, Clayton-Smith J, Catchpoole D, Maher ER, Reik W Imprinting mutation in the Beckwith-Wiedemann syndrome leads to biallelic IGF2 expression through an H19-independent pathway. Hum Mol Genet. 5:2027-32, 1996.

Bruce S, Hannula-Jouppi K, Peltonen J, Kere J, Lipsanen-Nyman M - Clinically distinct epigenetic subgroups in Silver-Russell syndrome: the degree of H19 hypomethylation associates with phenotype severity and genital and skeletal anomalies. J Clin Endocrinol Metab. 94:579-87, 2009. 
Bruce S, Hannula-Jouppi K, Puoskari M, Fransson I, Simola KO, Lipsanen-Nyman M, Kere J. Submicroscopic genomic alterations in Silver-Russell syndrome and Silver-Russell-like patients. J Med Genet. 47:816-22, 2010.

Bullman H, Lever M, Robinson DO, Mackay DJ, Holder SE, Wakeling EL - Mosaic maternal uniparental disomy of chromosome 11 in a patient with Silver-Russell syndrome. J Med Genet. 45:396-9, 2008.

Cattanach BM, Kirk M. - Differential activity of maternally and paternally derived chromosome regions in mice. Nature 315:496-8, 1985.

Choi JH, Kang M, Kim GH, Hong M, Jin HY, Lee BH, Park JY, Lee SM, Seo EJ, Yoo HW Clinical and functional characteristics of a novel heterozygous mutation of the IGF1R gene and IGF1R haploinsufficiency due to terminal 15q26.2->qter deletion in patients with intrauterine growth retardation and postnatal catch-up growth failure. J Clin Endocrinol Metab. 96:E130-4, 2011.

Courtens W, Vermeulen S, Wuyts W, Messiaen L, Wauters J, Nuytinck L, Peeters N, Storm K, Speleman F, Nöthen MM - An interstitial deletion of chromosome 7 at band q21: a case report and review. Am J Med Genet A. 134A:12-23, 2005.

DeChiara TM, Efstratiadis A, Robertson EJ - A growth-deficiency phenotype in heterozygous mice carrying an insulin-like growth factor II gene disrupted by targeting. Nature 345:7880, 1990.

DeChiara TM, Robertson EJ, Efstratiadis A - Parental imprinting of the mouse insulin-like growth factor II gene. Cell 64:849-59, 1991.

Delaval K, Wagschal A, Feil R - Epigenetic deregulation of imprinting in congenital diseases of aberrant growth. Bioessays 28:453-9, 2006.

Diaz-Meyer N, Day CD, Khatod K, Maher ER, Cooper W, Reik W, Junien C, Graham G, Algar E, Der Kaloustian VM, Higgins MJ - Silencing of CDKN1C (p57KIP2) is associated with hypomethylation at KvDMR11 in Beckwith-Wiedemann syndrome. J Med Genet. 40:797801, 2003.

Doornbos M, Sikkema-Raddatz B, Ruijvenkamp CA, Dijkhuizen T, Bijlsma EK, Gijsbers AC, Hilhorst-Hofstee Y, Hordijk R, Verbruggen KT, Kerstjens-Frederikse WS, van Essen T, Kok K, van Silfhout AT, Breuning M, van Ravenswaaij-Arts CM - Nine patients with a microdeletion 15q11.2 between breakpoints 1 and 2 of the Prader-Willi critical region, possibly associated with behavioural disturbances. Eur J Med Genet. 52:108-15, 2009.

Edelmann L, Hirschhorn K - Clinical utility of array CGH for the detection of chromosomal imbalances associated with mental retardation and multiple congenital anomalies. Ann N Y Acad Sci. 1151:157-66, 2009. 
Eggermann T - Silver-Russell and Beckwith-Wiedemann syndromes: opposite (epi)mutations in 11 15 result in opposite clinical pictures. Horm Res. 71 suppl 2:30-5, $2009 \mathrm{~b}$.

Eggermann T - Russell-Silver syndrome. Am J Med Genet C Semin Med Genet. 154C:355-64, 2010a.

Eggermann T, Wollmann HA, Kuner R, Eggermann K, Enders H, Kaiser P, Ranke MB Molecular studies in 37 Silver-Russell syndrome patients: frequency and etiology of uniparental disomy. Hum Genet. 100:415-9, 1997.

Eggermann T, Eggermann K, Mergenthaler S, Kuner R, Kaiser P, Ranke MB, Wollmann HA Paternally inherited deletion of CSH1 in a patient with Silver-Russell syndrome. J Med Genet. 35:784-6, 1998.

Eggermann K, Wollmann HA, Tomiuk J, Ranke MB, Kaiser P, Eggermann T - Screening for mutations in the promoter and the coding region of the IGFBP1 and IGFBP3 genes in SilverRussell syndrome patients. Hum Hered. 49:123-8, 1999.

Eggermann T, Meyer E, Obermann C, Heil I, Schüler H, Ranke MB, Eggermann K, Wollmann HA - Is maternal duplication of 11 p15 associated with Silver-Russell syndrome? J Med Genet. 42:e26, 2005.

Eggermann $\quad$ T, Schönherr $\quad \mathrm{N}$, Meyer $\quad$ E, Obermann $\quad$ C, Mavany $\quad$ M, Eggermann $\quad$ K, Ranke MB, Wollmann HA - Epigenetic mutations in 11p15 in Silver-Russell syndrome are restricted to the telomeric imprinting domain. J Med Genet. 43:615-6, 2006.

Eggermann T, Eggermann K, Schönherr N - Growth retardation versus overgrowth: SilverRussell syndrome is genetically opposite to Beckwith-Wiedemann syndrome. Trends Genet. 24:195-204, 2008a.

Eggermann T, Meyer E, Caglayan AO, Dundar M, Schönherr N - ICR1 epimutations in 11p15 are restricted to patients with Silver-Russell syndrome features. J Pediatr Endocrinol Metab. 21:59-62, 2008b.

Eggermann T, Schönherr N, Eggermann K, Buiting K, Ranke MB, Wollmann HA, Binder G Use of multiplex ligation-dependent probe amplification increases the detection rate for 11 p15 epigenetic alterations in Silver-Russell syndrome. Clin Genet. 73:79-84, 2008c.

Eggermann T, Schönherr N, Jäger S, Spaich C, Ranke MB, Wollmann HA, Binder G Segmental maternal UPD(7q) in Silver-Russell syndrome. Clin Genet. 74:486-9, 2008d.

Eggermann T, Gonzalez D, Spengler S, Arslan-Kirchner M, Binder G, Schönherr N - Broad clinical spectrum in Silver-Russell syndrome and consequences for genetic testing in growth retardation. Pediatrics. 123:e929-31, 2009a. 
Eggermann T, Spengler S, Bachmann N, Baudis M, Mau-Holzmann UA, Singer S, Rossier E Chromosome 11p15 duplication in Silver-Russell syndrome due to a maternally inherited translocation t(11;15). Am J Med Genet A. 152A:1484-7, 2010 b.

Eggermann T, Begemann M, Binder G, Spengler S - Silver-Russell syndrome: genetic basis and molecular genetic testing. Orphanet J Rare Dis. 5:19, 2010c.

Ester WA, van Duyvenvoorde HA, de Wit CC, Broekman AJ, Ruivenkamp CA, Govaerts LC, Wit JM, Hokken-Koelega AC, Losekoot M - Two short children born small for gestational age with insulin-like growth factor 1 receptor haploinsufficiency illustrate the heterogeneity of its phenotype. J Clin Endocrinol Metab. 94:4717-27, 2009.

Fares F, David M, Lerner A, Diukman R, Lerer I, Abeliovich D, Rivlin J - Paternal isodisomy of chromosome 7 with cystic fibrosis and overgrowth. Am J Med Genet A. 140:1785-8, 2006.

Fisher AM, Thomas NS, Cockwell A, Stecko O, Kerr B, Temple IK, Clayton P - Duplications of chromosome $11 \mathrm{p} 15$ of maternal origin result in a phenotype that includes growth retardation. Hum Genet. 111:290-6, 2002.

Fitzpatrick GV, Soloway PD, Higgins MJ - Regional loss of imprinting and growth deficiency in mice with a targeted deletion of KvDMR11. Nat Genet. 32:426-31, 2002.

Fonseca S (2005): Alterações cromossômicas estruturais no mapeamento de regiões candidatas para quadros sindrômicos. Tese de doutorado (Dep. de Genética e Biologia Evolutiva Instituto de Biociências - USP): pp38-61.

Gicquel C, Rossignol S, Cabrol S, Houang M, Steunou V, Barbu V, Danton F, Thibaud N, Le Merrer M, Burglen L, Bertrand AM, Netchine I, Le Bouc Y. - Epimutation of the telomeric imprinting center region on chromosome 11 p15 in Silver-Russell syndrome. Nat Genet. 37:1003-7, 2005.

Girirajan S, Rosenfeld JA, Cooper GM, Antonacci F, Siswara P, Itsara A, Vives L, Walsh T, McCarthy SE, Baker C, Mefford HC, Kidd JM, Browning SR, Browning BL, Dickel DE,Levy DL, Ballif BC, Platky K, Farber DM, Gowans GC, Wetherbee JJ, Asamoah A, Weaver DD, Mark PR, Dickerson J, Garg BP, Ellingwood SA, Smith R, Banks VC, Smith W,McDonald MT, Hoo JJ, French BN, Hudson C, Johnson JP, Ozmore JR, Moeschler JB, Surti U, Escobar LF, El-Khechen D, Gorski JL, Kussmann J, Salbert B, Lacassie Y, Biser A, McDonald-McGinn DM, Zackai EH, Deardorff MA, Shaikh TH, Haan E, Friend KL, Fichera M, Romano C, Gécz J, DeLisi LE, Sebat J, King MC, Shaffer LG, Eichler EE - A recurrent 16p12.1 microdeletion supports a two-hit model for severe developmental delay. Nat Genet. 42:203-9, 2010.

Hall TA - BioEdit: a user-friendly biological sequence alignment editor and analysis program for Windows 95/98/NT. Nucl Acids Symp Ser. 41:95-8, 1999. 
Hannes FD, Sharp AJ, Mefford HC, de Ravel T, Ruivenkamp CA, Breuning MH, Fryns JP, Devriendt K, Van Buggenhout G, Vogels A, Stewart H, Hennekam RC, Cooper GM,Regan R, Knight SJ, Eichler EE, Vermeesch JR. - Recurrent reciprocal deletions and duplications of 16p13.11: the deletion is a risk factor for MR/MCA while the duplication may be a rare benign variant. J Med Genet. 46:223-32, 2009.

Hannula K, Lipsanen-Nyman M, Kontiokari T, Kere J - A narrow segment of maternal uniparental disomy of chromosome 7q31-qter in Silver-Russell syndrome delimits a candidate gene region. Am J Hum Genet. 68:247-53, 2001.

Hatada I, Ohashi H, Fukushima Y, Kaneko Y, Inoue M, Komoto Y, Okada A, Ohishi S, Nabetani A, Morisaki H, Nakayama M, Niikawa N, Mukai T - An imprinted gene p57KIP2 is mutated in Beckwith-Wiedemann syndrome. Nat Genet. 14:171-3, 1996.

Henckel A, Nakabayashi K, Sanz LA, Feil R, Hata K, Arnaud P - Histone methylation is mechanistically linked to DNA methylation at imprinting control regions in mammals. Hum Mol Genet. 18:3375-83, 2009.

Henry I, Bonaiti-Pellié C, Chehensse V, Beldjord C, Schwartz C, Utermann G, Junien C Uniparental paternal disomy in a genetic cancer-predisposing syndrome. Nature 351:665-7, 1991.

Hitchins MP, Stanier P, Preece MA, Moore GE - Silver-Russell syndrome: a dissection of the genetic aetiology and candidate chromosomal regions. J Med Genet. 38:810-9, 2001a.

Hitchins MP, Monk D, Bell GM, Ali Z, Preece MA, Stanier P, Moore GE - Maternal repression of the human GRB10 gene in the developing central nervous system; evaluation of the role for GRB10 in Silver-Russell syndrome. Eur J Hum Genet. 9:82-90, 2001 b.

Höglund P, Holmberg C, de la Chapelle A, Kere J - Paternal isodisomy for chromosome 7 is compatible with normal growth and development in a patient with congenital chloride diarrhea. Am J Hum Genet. 55:747-52, 1994.

Horike S, Mitsuya K, Meguro M, Kotobuki N, Kashiwagi A, Notsu T, Schulz TC, Shirayoshi Y, Oshimura M - Targeted disruption of the human LIT1 locus defines a putative imprinting control element playing an essential role in Beckwith-Wiedemann syndrome. Hum Mol Genet. 9:2075-83, 2000.

Horike S, Ferreira JC, Meguro-Horike M, Choufani S, Smith AC, Shuman C, Meschino W, Chitayat D, Zackai E, Scherer SW, Weksberg R - Screening of DNA methylation at the H19 promoter or the distal region of its ICR1 ensures efficient detection of chromosome 11 15 epimutations in Russell-Silver syndrome. Am J Med Genet A. 149A:2415-23, 2009.

Joyce CA, Sharp A, Walker JM, Bullman H, Temple IK - Duplication of 7p12.1-p13, including GRB10 and IGFBP1, in a mother and daughter with features of Silver-Russell syndrome. Hum Genet. 105:273-280, 1999. 
Kotzot D. Maternal uniparental disomy 7 and Silver-Russell syndrome - clinical update and comparison with other subgroups. Eur J Med Genet. 51:444-51, 2008.

Kotzot D, Schmitt S, Bernasconi F, Robinson WP, Lurie LW, Ilyina H, Méhes K, Hamel BCJ, Otten BJ, Hengersberg M, Werder E, Schoenle E, Schinzel A - Uniparental disomy 7 in Silver-Russell syndrome and primordial growth retardation. Hum Mol Genet. 4:583-587, 1995.

Kotzot D, Balmer D, Baumer A, Chrzanowska K, Hamel BC, Ilyina H, Krajewska-Walasek M, Lurie IW, Otten BJ, Schoenle E, Tariverdian G, Schinzel A - Maternal uniparental disomy 7 - review and further delineation of the phenotype. Eur J Pediatr. 159:247-256, 2000.

Krepischi-Santos AC, Vianna-Morgante AM, Jehee FS, Passos-Bueno MR, Knijnenburg J, Szuhai K, Sloos W, Mazzeu JF, Kok F, Cheroki C, Otto PA, Mingroni-Netto RC, Varela M, Koiffmann C, Kim CA, Bertola DR, Pearson PL, Rosenberg C - Whole-genome array$\mathrm{CGH}$ screening in undiagnosed syndromic patients: old syndromes revisited and new alterations. Cytogenet Genome Res. 115:254-61, 2006.

Kurukuti S, Tiwari VK, Tavoosidana G, Pugacheva E, Murrell A, Zhao Z, Lobanenkov V, Reik W, Ohlsson R - CTCF binding at the H19 imprinting control region mediates maternally inherited higher-order chromatin conformation to restrict enhancer access to Igf2. Proc Natl Acad Sci U S A. 103:10684-9, 2006.

Lam WWK, Hatada I, Ohishi S, Mukai T, Joyce JA, Cole TRP, Donnai D, Reik W, Schofield PN, Maher ER - Analysis of germline CDKN1C (p57-KIP2) mutations in familial and sporadic Beckwith-Wiedemann syndrome (BWS) provides a novel genotype-phenotype correlation. J Med Genet. 36:518-23, 1999.

Le Caignec C, Isidor B, de Pontbriand U, David V, Audrezet MP, Ferec C, David A - Third case of paternal isodisomy for chromosome 7 with cystic fibrosis: a new patient presenting with normal growth. Am J Med Genet A. 143A:2696-9, 2007.

Leach NT, Chudoba I, Stewart TV, Holmes LB, Weremowicz S - Maternally inherited duplication of chromosome 7, dup(7)(p11.2p12), associated with mild cognitive deficit without features of Silver-Russell syndrome. Am J Med Genet A. 143A:1489-93, 2007.

Leighton PA, Ingram RS, Eggenschwiler J, Efstratiadis A, Tilghman SM - Disruption of imprinting caused by deletion of the H19 gene region in mice. Nature 375:34-9, 1995.

Lesnik Oberstein SA, Kriek M, White SJ, Kalf ME, Szuhai K, den Dunnen JT, Breuning MH, Hennekam RC - Peters Plus syndrome is caused by mutations in B3GALTL, a putative glycosyltransferase. Am J Hum Genet. 79:562-6, 2006.

Li E, Beard C, Jaenisch R - Role for DNA methylation in genomic imprinting. Nature 366:3625, 1993. 
Liehr T - Cytogenetic contribution to uniparental disomy (UPD). Mol Cytogenet. 3:8, 2010.

Lin SY, Lee CN, Hung CC, Tsai WY, Lin SP, Li NC, Hsieh WS, Tung YC, Niu DM, Hsu WM, Chen LY, Fang MY, Tu MP, Kuo PW, Lin CY, Su YN, Ho HN - Epigenetic profiling of the H19 differentially methylated region and comprehensive whole genome array-based analysis in Silver-Russell syndrome. Am J Med Genet A. 152A: 2521-8, 2010.

Louvi A, Accili D, Efstratiadis A - Growth-promoting interaction of IGF-II with the insulin receptor during mouse embryonic development. Dev Biol. 189:33-48, 1997.

Mackay DJ, Temple IK. Transient neonatal diabetes mellitus type 1. Am J Med Genet C Semin Med Genet. 154C:335-42, 2010.

Malecová B, Morris KV - Transcriptional gene silencing through epigenetic changes mediated by non-coding RNAs. Curr Opin Mol Ther. 12:214-22, 2010.

Matsuoka S, Edwards MC, Bai C, Parker S, Zhang P, Baldini A, Harper JW, Elledge SJ p57KIP2, a structurally distinct member of the p21CIP1 Cdk inhibitor family, is a candidate tumor suppressor gene. Genes Dev. 9:650-62, 1995.

McGrath J, Solter D - Completion of mouse embryogenesis requires both the maternal and paternal genomes. Cell 37:179-83, 1984.

Menten B, Buysse K, Zahir F, Hellemans J, Hamilton SJ, Costa T, Fagerstrom C, Anadiotis G, Kingsbury D, McGillivray BC, Marra MA, Friedman JM, Speleman F, Mortier G Osteopoikilosis, short stature and mental retardation as key features of a new microdeletion syndrome on 12q14. J Med Genet. 44:264-8, 2007.

Mergenthaler S, Eggermann K, Tomiuk J, Ranke MB, Wollmann HA, Eggermann T - Exclusion of a disease relevant role of PAX4 in the aetiology of Silver-Russell syndrome: screening for mutations and determination of imprinted status. J Med Genet. 37:E44, 2000.

Monk D, Wakeling EL, Proud V, Hitchins M, Abu-Amero SN, Stanier P, Preece MA, Moore GE - Duplication of 7p11.2-p13, including GRB10, in Silver-Russell syndrome. Am J Hum Genet. 66:36-46, 2000.

Monk D, Bentley L, Hitchins M, Myler RA, Clayton-Smith J, Ismail S, Price SM, Preece MA, Stanier P, Moore GE - Chromosome 7p disruptions in Silver Russell syndrome: delineating an imprinted candidate gene region. Hum Genet. 111:376-87, 2002a.

Monk D, Bentley L, Beechey C, Hitchins M, Peters J, Preece MA, Stanier P, Moore GE Characterisation of the growth regulating gene IMP3, a candidate for Silver-Russell syndrome. J Med Genet. 39:575-81, 2002 b.

Moore T, Haig D - Genomic imprinting in mammalian development: a parental tug-of-war. Trends Genet. 7:45-9, 1991. 
Moore T, Reik W - Genetic conflict in early development: parental imprinting in normal and abnormal growth. Rev Reprod. 1:73-7, 1996.

Murthy SK, Nygren AO, El Shakankiry HM, Schouten JP, Al Khayat AI, Ridha A, Al Ali MT Detection of a novel familial deletion of four genes between BP1 and BP2 of the PraderWilli/Angelman syndrome critical region by oligo-array $\mathrm{CGH}$ in a child with neurological disorder and speech impairment. Cytogenet Genome Res. 116:135-40, 2007.

Nakabayashi K, Fernandez BA, Teshima I, Shuman C, Proud VK, Curry CJ, Chitayat D, Grebe T, Ming J, Oshimura M, Meguro M, Mitsuya K, Deb-Rinker P, Herbrick JA, Weksberg R, Scherer SW - Molecular genetic studies of human chromosome 7 in Russell-Silver syndrome. Genomics. 79:186-96, 2002.

Netchine I, Rossignol S, Dufourg MN, Azzi S, Rousseau A, Perin L, Houang M, Steunou V, Esteva B, Thibaud N, Raux Demay MC, Danton F, Petriczko E, Bertrand AM, Heinrichs C, Carel JC, Loeuille GA, Pinto G, Jacquemont ML, Gicquel C, Cabrol S, Le Bouc Y - 11p15 ICR1 loss of methylation is a common and specific cause of typical Russell-Silver Syndrome: clinical scoring system and epigenetic-phenotypic correlations. J Clin Endocrinol Metab. 92:3148-54, 2007.

Norman AM, Read AP, Clayton-Smith J, Andrews T, Donnai D - Recurrent WiedemannBeckwith syndrome with inversion of chromosome (11)(p11.2p15.5). Am J Med Genet. 42:638-41, 1992.

Nygren AO, Ameziane N, Duarte HM, Vijzelaar RN, Waisfisz Q, Hess CJ, Schouten JP, Errami A - Methylation-specific MLPA (MS-MLPA): simultaneous detection of CpG methylation and copy number changes of up to 40 sequences. Nucleic Acids Res. 33:e128, 2005.

Obermann C, Meyer E, Prager S, Tomiuk J, Wollmann HA, Eggermann T - Searching for genomic variants in IGF2 and CDKN1C in Silver-Russell syndrome patients. Mol Genet Metab. 82:246-50, 2004.

Pan Y, McCaskill CD, Thompson KH, Hicks J, Casey B, Shaffer LG, Craigen WJ - Paternal isodisomy of chromosome 7 associated with complete situs inversus and immotile cilia. Am J Hum Genet. 62:1551-5, 1998.

Pauler FM, Koerner MV, Barlow DP - Silencing by imprinted noncoding RNAs: is transcription the answer? Trends Genet. 23:284-92, 2007.

Peñaherrera MS, Weindler S, Van Allen MI, Yong SL, Metzger DL, McGillivray B, Boerkoel C, Langlois S, Robinson WP - Methylation profiling in individuals with Russell-Silver syndrome. Am J Med Genet A. 152A:347-55, 2010. 
Prawitt D, Enklaar T, Gärtner-Rupprecht B, Spangenberg C, Oswald M, Lausch E, Schmidtke P, Reutzel D, Fees S, Lucito R, Korzon M, Brozek I, Limon J, Housman DE, Pelletier $\mathrm{J}$, Zabel B - Microdeletion of target sites for insulator protein CTCF in a chromosome 11p15 imprinting center in Beckwith-Wiedemann syndrome and Wilms' tumor. Proc Natl Acad Sci USA. 102:4085-90, 2005.

Preece MA, Price SM, Davies V, Clough L, Stanier P, Trembath RC, Moore GE - Maternal uniparental disomy 7 in Silver-Russell syndrome. J Med Genet. 34:6-9, 1997.

Preece MA, Abu-Amero SN, Ali Z, Abu-Amero KK, Wakeling EL, Stanier P, Moore GE - An analysis of the distribution of hetero- and isodisomic regions of chromosome 7 in five mUPD7 Silver-Russell syndrome probands. J Med Genet. 36:457-60, 1999.

Price SM, Stanhope R, Garrett C, Preece MA, Trembath RC - The spectrum of Silver-Russell syndrome: a clinical and molecular genetic study and new diagnostic criteria. J Med Genet. 36:837-42, 1999.

Quélin C, Bendavid C, Dubourg C, de la Rochebrochard C, Lucas J, Henry C, Jaillard S, Loget P, Loeuillet L, Lacombe D, Rival JM, David V, Odent S, Pasquier L - Twelve new patients with $13 \mathrm{q}$ deletion syndrome: genotype-phenotype analyses in progress. Eur J Med Genet. 52:41-6, 2009.

Redon R, Ishikawa S, Fitch KR, Feuk L, Perry GH, Andrews TD, Fiegler H, Shapero MH, Carson AR, Chen W, Cho EK, Dallaire S, Freeman JL, González JR, Gratacòs M, Huang J, Kalaitzopoulos D, Komura D, MacDonald JR, Marshall $\quad$ CR, Mei R, Montgomery L, Nishimura K, Okamura K, Shen F, Somerville MJ, Tchinda J, Valsesia A, Woodwark C, Yang F, Zhang J, Zerjal T, Zhang J, Armengol L, Conrad DF, Estivill X, Tyler-Smith C, Carter NP, Aburatani H, Lee C, Jones KW, Scherer SW, Hurles ME Global variation in copy number in the human genome. Nature 444:444-54, 2006.

Reik W, Brown KW, Schneid H, Le Bouc Y, Bickmore W, Maher ER - Imprinting mutations in the Beckwith-Wiedemann syndrome suggested by an altered imprinting pattern in the IGF2H19 domain. Hum Molec Genet. 4:2379-85, 1995.

Reik W, Walter J - Genomic imprinting: parental influence on the genome. Nat Rev Genet. 2:21-32, 2001.

Riesewijk AM, Blagitko N, Schinzel AA, Hu L, Schulz U, Hamel BC, Ropers HH, Kalscheuer VM - Evidence against a major role of PEG1/MEST in Silver-Russell syndrome. Eur J Hum Genet. 6:114-20, 1998.

Robinson WP - Mechanisms leading to uniparental disomy and their clinical consequences. Bioessays. 22:452-9, 2000. 
Rogan PK, Seip JR, Driscoll DJ, Papenhausen PR, Johnson VP, Raskin S, Woodward AL, Butler MG. Distinct $15 \mathrm{q}$ genotypes in Russell-Silver and ring 15 syndromes. Am J Med Genet. 62:10-15, 1996.

Rossignol S, Steunou V, Chalas C, Kerjean A, Rigolet M, Viegas-Pequignot, Jouannet P, Le Bouc Y, Gicquel C - The epigenetic imprinting defect of patients with Beckwith-Wiedemann syndrome born after assisted reproductive technology is not restricted to the $11 \mathrm{p} 15$ region. $\mathbf{J}$ Med Genet. 43:902-7, 2006.

Russell A - A syndrome of intra-uterine dwarfism recognizable at birth with cranio-facial dysostosis, disproportionately short arms, and other anomalies (5 examples). Proceedings of the Royal Society of Medicine 47:1040-4, 1954.

Russo S, Bedeschi MF, Cogliati F, Natacci F, Gianotti A, Parini R, Selicorni A, Larizza L Maternal chromosome 7 hetero/isodisomy in Silver-Russell syndrome and PEG1 biallelic expression. Clin Dysmorphol. 9:157-62, 2000.

Schönherr N, Meyer E, Eggermann K, Ranke MB, Wollmann HA, Eggermann T (Epi)mutations in 11p15 significantly contribute to Silver-Russell syndrome: but are they generally involved in growth retardation? Eur J Med Genet. 49:414-18, 2006.

Schönherr N, Meyer E, Roos A, Schmidt A, Wollmann HA, Eggermann T - The centromeric 11 p15 imprinting centre is also involved in Silver-Russell syndrome. J Med Genet. 44:5963, 2007.

Shinawi M, Cheung SW - The array CGH and its clinical applications. Drug Discov Today. 13:760-70, 2008.

Silver HK, KiyasuW, George J, Deamer WC - Syndrome of congenital hemihypertrophy, shortness of stature, and elevated urinary gonadotropins. Pediatrics. 12:368-76, 1953.

South ST, Whitby H, Maxwell T, Aston E, Brothman AR, Carey JC - Co-occurrence of 4p16.3 deletions with both paternal and maternal duplications of 11p15: modification of the WolfHirschhorn syndrome phenotype by genetic alterations predicted to result in either a Beckwith-Wiedemann or Russell-Silver phenotype. Am J Med Genet Part A. 146A:26917, 2008.

Sparago A, Cerrato F, Vernucci M, Ferrero GB, Silengo MC, Riccio A - Microdeletions in the human H19 DMR result in loss of IGF2 imprinting and Beckwith-Wiedemann syndrome. Nat Genet. 36:958-60, 2004.

Spence JF, Perciaccante RG, Greig GM, Huntington FW, Ledbetter DH, Hjtmaneik JF, Pollack MS, O’Brien WE, Beaudet AL - Uniparental disomy as a mechanism for human genetic disease. Hum Genet. 42:217-226, 1988. 
Spengler S, Schönherr N, Binder G, Wollmann H, Fricke-Otto S, Mühlenberg R, Denecke B, Baudis M, Eggermann T - Submicroscopic chromosomal imbalances in idiopathic SilverRussell syndrome (SRS): the SRS phenotype overlaps with the 12q14 microdeletion syndrome. J Med Genet. 47:356-60, 2010.

Spotila LD, Sereda L, Prockop DJ - Partial isodisomy for maternal chromosome 7 and short stature in an individual with a mutation at the COL1A2 locus. Am J Hum Genet. 51:1396$1405,1992$.

Stancáková A, Pihlajamäki J, Kuusisto J, Stefan N, Fritsche A, Häring H, Andreozzi F, Succurro E, Sesti G, Boesgaard TW, Hansen T, Pedersen O, Jansson PA, Hammarstedt A,Smith U, Laakso M; EUGENE2 Consortium - SNP rs7754840 of CDKAL1 is associated with impaired insulin secretion in non-diabetic offspring of Type 2 diabetic subjects (the EUGENE2 study) and in a large sample of men with normal glucose tolerance. J Clin Endocrinol Metab. 93:1924-30, 2008.

Sun FL, Dean WL, Kelsey G, Allen ND, Reik W - Transactivation of Igf2 in a mouse model of Beckwith-Wiedemann syndrome. Nature 389:809-15, 1997.

Surani MA, Barton SC, Norris ML - Development of reconstituted mouse eggs suggests imprinting of the genome during gametogenesis. Nature 308:548-50, 1984.

Thorvaldsen JL, Duran KL, Bartolomei MS - Deletion of the H19 differentially methylated domain results in loss of imprinted expression of H19 and Igf2. Genes Dev. 12:3693-702, 1998.

Tommerup N, Brandt CA, Pedersen S, Bolund L, Kamper J - Sex dependent transmission of Beckwith-Wiedemann syndrome associated with a reciprocal translocation t(9;11)(p11.2;p15.5). J Med Genet. 30:958-61, 1993.

Turleau C, de Grouchy J, Chavin-Colin F, Martelli H, Voyer M, Charlas R - Trisomy 11p15 and Beckwith-Wiedemann syndrome. A report of two cases. Hum Genet. 67:219-21, 1984.

Turner CL, Mackay DM, Callaway JL, Docherty LE, Poole RL, Bullman H, Lever M, Castle BM, Kivuva EC, Turnpenny PD, Mehta SG, Mansour S, Wakeling EL, Mathew V, Madden J, Davies JH, Temple IK - Methylation analysis of 79 patients with growth restriction reveals novel patterns of methylation change at imprinted loci. Eur J Hum Genet. 18:648-55, 2010.

Ullmann R, Turner G, Kirchhoff M, Chen W, Tonge B, Rosenberg C, Field M, Vianna-Morgante AM, Christie L, Krepischi-Santos AC, Banna L, Brereton AV, Hill A, Bisgaard AM, Müller I, Hultschig C, Erdogan F, Wieczorek G, Ropers HH - Array CGH identifies reciprocal 16p13.1 duplications and deletions that predispose to autism and/or mental retardation. Hum Mutat. 28:674-82, 2007. 
van Dijk MA, Rodenburg RJ, Holthuizen P, Sussenbach JS - The liver-specific promoter of the human insulin-like growth factor II gene is activated by CCAAT/enhancer binding protein (C/EBP). Nucleic Acids Res. 20:3099-104, 1992.

Verona RI, Mann MR, Bartolomei MS - Genomic imprinting: intricacies of epigenetic regulation in clusters. Annu Rev Cell Dev Biol. 19:237-59, 2003.

Veugelers M, De Cat B, Delande N, Esselens C, Bonk I, Vermeesch J, Marynen P, Fryns JP, David G - A 4-Mb BAC/PAC contig and complete genomic structure of the GPC5/GPC6 gene cluster on chromosome 13q32. Matrix Biol. 20:375-85, 2001.

von der Lippe C, Rustad C, Heimdal K, Rødningen OK - 15q11.2 microdeletion - Seven new patients with delayed development and/or behavioural problems. Eur J Med Genet. Dec 25, 2010 (Epub ahead of print).

Voss R, Ben-Simon E, Avital A, Godfrey S, Zlotogora J, Dagan J, Tikochinski Y, Hillel J Isodisomy of chromosome 7 in a patient with cystic fibrosis: could uniparental disomy be common in humans? Am J Hum Genet. 45:373-380, 1989.

Waddinton C - The epigenotype. Endeavor 1:18-24, 1942. Apud Zuo e col., 2009.

Wakeling EL, Amero SA, Alders M, Bliek J, Forsythe E, Kumar S, Lim DH, MacDonald F, Mackay DJ, Maher ER, Moore GE, Poole RL, Price SM, Tangeraas T, Turner CL, Van Haelst MM, Willoughby C, Temple IK, Cobben JM - Epigenotype-phenotype correlations in Silver-Russell syndrome. J Med Genet. 47:760-8, 2010.

Walenkamp MJ, de Muinck Keizer-Schrama SM, de Mos M, Kalf ME, van Duyvenvoorde HA, Boot AM, Kant SG, White SJ, Losekoot M, Den Dunnen JT, Karperien M, Wit JM Successful long-term growth hormone therapy in a girl with haploinsufficiency of the insulin-like growth factor-I receptor due to a terminal 15q26.2->qter deletion detected by multiplex ligation probe amplification. J Clin Endocrinol Metab. 93:2421-5, 2008.

Waziri M, Patil SR, Hanson JW, Bartley JA - Abnormality of chromosome 11 in patients with features of Beckwith-Wiedemann syndrome. J Pediatr. 102:873-6, 1983.

Weksberg R, Shen DR, Fei YL, Song QL, Squire J - Disruption of insulin-like growth factor 2 imprinting in Beckwith-Wiedemann syndrome. Nat Genet. 5:143-50, 1993.

Weksberg R, Smith AC, Squire J, Sadowski P - Beckwith-Wiedemann syndrome demonstrates a role for epigenetic control of normal development. Hum Mol Genet. 12 Spec No 1:R61-8, 2003.

Weksberg R, Shuman C, Beckwith JB - Beckwith-Wiedemann syndrome. Eur J Hum Genet. 18:8-14, 2010.

Wiedemann HR - Complexe malformatif familial avec hernie ombilicale et macroglossia, un 'syndrome nouveau. J Genet Hum. 13:223-32, 1964. 
Yamazawa K, Kagami M, Nagai T, Kondoh T, Onigata K, Maeyama K, Hasegawa T, Hasegawa Y, Yamazaki T, Mizuno S, Miyoshi Y, Miyagawa S, Horikawa R, Matsuoka K, Ogata T Molecular and clinical findings and their correlations in Silver-Russell syndrome: implications for a positive role of IGF2 in growth determination and differential imprinting regulation of the IGF2-H19 domain in bodies and placentas. J Mol Med. 86:1171-81, 2008a.

Yamazawa K, Kagami M, Fukami M, Matsubara K, Ogata T - Monozygotic female twins discordant for Silver-Russell syndrome and hypomethylation of the H19-DMR. J Hum Genet. 53:950-5, 2008b.

Yoshihashi H, Maeyama K, Kosaki R, Ogata T, Tsukahara M, Goto Y, Hata J, Matsuo N, Smith RJ, Kosaki K - Imprinting of human GRB10 and its mutations in two patients with RussellSilver syndrome. Am J Hum Genet. 67:476-82, 2000.

Zeggini E, Weedon MN, Lindgren CM, Frayling TM, Elliott KS, Lango H, Timpson NJ, Perry JR, Rayner NW, Freathy RM, Barrett JC, Shields B, Morris AP, Ellard S, Groves CJ,Harries LW, Marchini JL, Owen KR, Knight B, Cardon LR, Walker M, Hitman GA, Morris AD, Doney AS; Wellcome Trust Case Control Consortium (WTCCC), McCarthy MI,Hattersley AT - Replication of genome-wide association signals in UK samples reveals risk loci for type 2 diabetes. Science. 316:1336-41, 2007.

Zhou X, Benson KF, Ashar HR, Chada K - Mutation responsible for the mouse pygmy phenotype in the developmentally regulated factor HMGI-C. Nature 376:771-4, 1995.

Zuo T, Tycko B, Liu TM, Lin HJ, Huang TH - Methods in DNA methylation profiling. Epigenomics. 1:331-345, 2009. 